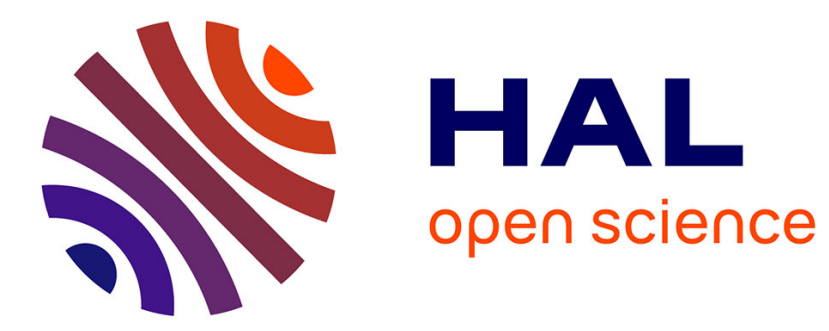

\title{
Le " grand bouleversement" (long trod là âât) : regards croisés sur la réforme agraire en République démocratique du Viêt Nam
}

Olivier Tessier

\section{- To cite this version: \\ Olivier Tessier. Le "grand bouleversement" (long trod là âât) : regards croisés sur la réforme agraire en République démocratique du Viêt Nam. Bulletin de l'Ecole française d'Extrême-Orient, 2008, 95-96, pp.73-134. 10.3406/befeo.2008.6105 . halshs-02555882}

\section{HAL Id: halshs-02555882 \\ https://shs.hal.science/halshs-02555882}

Submitted on 27 Apr 2020

HAL is a multi-disciplinary open access archive for the deposit and dissemination of scientific research documents, whether they are published or not. The documents may come from teaching and research institutions in France or abroad, or from public or private research centers.
L'archive ouverte pluridisciplinaire HAL, est destinée au dépôt et à la diffusion de documents scientifiques de niveau recherche, publiés ou non, émanant des établissements d'enseignement et de recherche français ou étrangers, des laboratoires publics ou privés. 
Le « grand bouleversement " (long trod là âât) : regards croisés sur la réforme agraire en République démocratique du Viêt Nam Olivier Tessier

\section{Citer ce document / Cite this document :}

Tessier Olivier. Le " grand bouleversement » (long trod là âât) : regards croisés sur la réforme agraire en République démocratique du Viêt Nam. In: Bulletin de l'Ecole française d'Extrême-Orient. Tome 95-96, 2008. pp. 73-134;

doi : https://doi.org/10.3406/befeo.2008.6105

https://www.persee.fr/doc/befeo_0336-1519_2008_num_95_1_6105

Fichier pdf généré le 08/02/2019 


\title{
Résumé
}

En République démocratique du Viêt Nam, l'application d'une réforme agraire radicale de 1953 à 1956 a permis, grâce à l'octroi d'un lopin de terre aux paysans les plus démunis, de revitaliser pour un temps l'agriculture du Nord du Viêt Nam. Cette réalité est indéniable, tout comme le sont les graves excès et dérives idéologiques, souvent violents, qui furent commis en son nom. La dimension politique de cette réforme, le poids de l'environnement politico-militaire national et international, notamment la prégnance d'un schéma idéologique importé de Chine, ont été principalement décrits et analysés sous une focale large visant à embrasser la globalité historique et événementielle. La démarche proposée dans cet article est quelque peu différente. Elle s'attache à poser un regard croisé sur la réforme agraire en jouant sur les échelles d'observation et en s'intéressant aux conséquences locales qu'ont eues les grandes options politiques des nouveaux maîtres de Hà Nôi dans un village de la province de Phu Tho, le village de Hay, sur la façon dont ces choix ont été vécus, perçus et reformulés par ceux « d'en bas », sur l'empreinte qu'ils ont laissé dans leur mémoire. Cet exercice de va-et-vient entre le cadre imposé par les autorités centrales et sa réalisation concrète sur le terrain montre qu'à l'échelle villageoise, la réforme a non seulement provoqué une redistribution des moyens de production mais a également, et peut-être surtout, transformé les espaces sociaux locaux en changeant radicalement la donne sociale, politique et religieuse. La reformulation autoritaire de l'espace villageois, l'exclusion de certains groupes de parenté, le remaniement complet de la trame du pouvoir local, la destruction des lieux de culte, sont parmi les illustrations les plus symptomatiques de la volonté de refonte de collectivités paysannes jugées arriérées et féodales afin de donner naissance à " l'Homme nouveau ».

\begin{abstract}
Through the granting of small plots of land to the poorest peasants, the implementation of land reform in the Democratic Republic of Vietnam from 1953 to 1956 revitalised the agricultural sector of northern Vietnam for a period of time. This is an undeniable reality, as indeed were the grave excesses and ideological abuses, which were often violent, committed in its name. The political dimension of this reform, the heavy presence of the national and international politico-military context and, notably, the influence of an ideological schema imported from China have mostly been studied and analysed in a broad perspective aiming to embrace its historical and factual entirety. This article differs to some extent in its approach. A mixed perspective is taken on the reform, operating at different levels of observation, to examine the local consequences of the great political decisions made by the new masters of Hanoi in a village in Phu Tho province - the village of Hay — and the ways these decisions were experienced, perceived and reformulated by those "at the grassroots". This exercise necessitates some toing and froing between the framework imposed by the central government and its actual implementation on the ground. It demonstrates that, at the village level, land reform not only caused a redistribution of the means of production but also, and perhaps above all, transformed local social spaces through a radical modification of the social, political and religious order. The authoritarian reformulation of village space, the exclusion of certain family groups, the destruction of places of worship are among the most symptomatic illustrations of the will to remake peasant collectivities, deemed backward and feudal, to give birth to the "New Man".
\end{abstract}

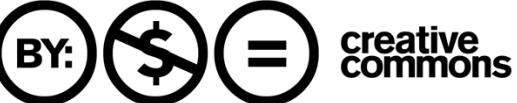




\title{
Le « grand bouleversement » (long trời lở đất) : regards croisés sur la réforme agraire en République démocratique du Việt Nam
}

\author{
Olivier TESSIER*
}

Le 2 septembre 1945, le président Hồ Chí Minh proclamait l'indépendance du Việt Nam, rebaptisé République démocratique du Việt Nam (RDVN), devant plusieurs centaines de milliers de personnes rassemblées sur la place Ba Đình à Hà Nội. Le 29 octobre 1956, à l'issue du X $\mathrm{X}^{\mathrm{e}}$ plénum ( 25 août-5 octobre) du Comité central du Parti des travailleurs du Việt Nam ', le général Võ Nguyên Giáp - le vainqueur de Điện Biên Phủ - s'adressait à la population de la capitale pour affirmer que, si la réforme agraire avait été dans ses grandes lignes une nouvelle victoire du peuple et du Parti, puisque «le régime de la propriété agraire féodale est à jamais aboli », les graves erreurs commises en ont néanmoins limité la portée. Ce discours lançait officiellement la campagne de rectification des erreurs. Deux dates extrêmes qui bornent une décennie cruciale et terrible pendant laquelle la naissance de la RDVN et la longue guerre de libération qui s'engage en 1946 ont fait basculer le pays dans l'ère contemporaine, selon la chronologie adoptée par l'historiographie officielle (Hữu Ngọc 1997).

Parallèlement à l'affrontement militaire, la réforme agraire, première étape sur la voie de la " grande agriculture socialiste », allait radicalement bouleverser le paysage social, économique et politique des campagnes nord-vietnamiennes. Le poids de l'environnement politico-militaire national et international, la multiplicité des événements qui se sont succédé et télescopés au cours de cette décennie, la diversité des enjeux qui ont amené les dirigeants de la RDVN à opter pour des orientations trop souvent en décalage avec la situation réelle de la paysannerie parce qu'inspirées d'un schéma idéologique « prêt-à-

* $\quad$ Maître de conférences à l'EFEO.

1. Le Parti des travailleurs du Việt Nam (Đảng Lao Động) fut le nouveau nom donné au Parti communiste indochinois $(\mathrm{PCI})$ à l'issue de son $\mathrm{II}^{\mathrm{e}}$ congrès (11-19 février 1951), congrès qui marqua également la dissolution officielle du Việt-minh au sein du nouveau Parti. Le Việt-minh (Việt Nam Độc Lập Đồng Minh Hội [Alliance pour l'indépendance du Việt Nam]) avait officiellement vu le jour au mois de mai 1941 , réunissant sous son aile les organisations anti-impérialistes (hội phản đế) créées par le PCI. Suivant les termes de Ngô Văn, il fut plus exactement « ressuscité » à cette occasion, sa création originelle remontant à 1936, et fut l'œuvre de Phan Bội Châu et de deux de ses compagnons (Ngô Văn 1995 : 296). Ce mouvement révolutionnaire adopta le drapeau rouge frappć cn son ccntrc d'une étoile jaune. Enfin, depuis le 29 mai 1946, le PCI et le Việt-minh étaient des composantes du Liên Việt (Union nationale du Việt Nam), structure fédérative créée par Hồ Chí Minh afin d'unifier toutes les forces nationales. Le Liên Việt fut à son tour remplacé par le Front de la Patrie (Mặt trận tổ quốc), le 10 septembre 1955 . 
penser » importé de Chine et d'URSS, ont été principalement décrits et analysés sous une focale large visant à embrasser la globalité historique et événementielle. Notre démarche est quelque peu différente. Elle s'attache à poser un regard croisé sur la réforme agraire en jouant sur les échelles d'observation et en s'intéressant aux conséquences locales qu'ont eues les grandes options politiques des nouveaux maîtres de Hà Nội, sur la façon dont ces choix ont été vécus, perçus et reformulés par ceux qui les ont subis, sur l'empreinte qu'ils ont laissée dans leur mémoire. Pour réaliser ce va-et-vient entre le cadre imposé par les autorités centrales et sa réalisation concrète sur le terrain, nous avons retenu l'exemple d'une commune de la province de Phú Thọ (voir carte 1) : Ninh Dân. Située au cœur de la Moyenne région (Trung $\mathrm{Du}$ ) à environ cent vingt kilomètres au nord-ouest de Hà Nội, la commune de Ninh Dân, composée de quatre villages ou thôn (thôn Đồng Xa, thôn Mánh, thôn Sen et thôn Hay), est caractéristique de cette région vallonnée, prise en étau entre le delta du fleuve Rouge et les massifs accidentés de la Haute région. Une série d'entretiens avec des villageois précipités dans la tourmente de la réforme agraire a été réalisée dans un des quatre villages qui composent la commune, le village de Hay, afin de tenter de reconstituer par bribes l'histoire sociale d'une expérience qui bouleversa durablement la paysannerie (voir carte 1).

\section{La politique agraire de 1945 à 1953 : entre volonté de réforme et pragmatisme imposé par la guerre de résistance}

Ce que l'on a coutume d'appeler la réforme agraire (1953-1956) est l'aboutissement d'un processus de restructuration de la propriété foncière engagé depuis la Révolution d'août 1945, processus que Trường Chinh, secrétaire général du Parti et président du Comité de la réforme agraire, définissait en 1953 comme s'articulant en trois étapes successives : $1^{\circ}$ confiscation des terres appartenant aux impérialistes et aux traîtres et répartition des terres communales, des terres en friche et de celles appartenant aux propriétaires absents afin « de diriger le fer de lance de la politique agraire sur les impérialistes et les féodaux ultraréactionnaires " ; $2^{\circ}$ réduction des fermages et des taux d'intérêt, et abolition des dettes " pour affaiblir la puissance économique des féodaux, faire un premier pas pour abattre leur autorité politique à la campagne et renforcer la paysannerie travailleuse $» ; 3^{\circ}$ réalisation de la réforme agraire proprement dite pour " abolir le droit d'appropriation des terres des féodaux, détruire leur puissance politique, réaliser le mot d'ordre "la terre à ceux qui la travaillent, la paysannerie totalement maître de la campagne "2" "

Le célèbre mot d'ordre « la terre à ceux qui la travaillent » s'inscrivait ainsi dans une stratégie révolutionnaire globale devant aboutir à l'avènement de la révolution marxisteléniniste selon un processus en deux temps : la révolution nationale et démocratique, tout d'abord, c'est-à-dire le renversement du régime colonial par un large front antiimpérialiste unissant toutes les forces patriotiques, y compris les forces bourgeoises, à laquelle devait succéder la révolution socialiste, impliquant l'abolition du système féodal et l'instauration d'un régime dirigé par la classe ouvrière dans le cadre d'une alliance " ouvriers - paysans ${ }^{3}$, pour conduire le pays vers le socialisme.

2. Pour la réalisation de la Réforme agraire, rapport présenté à la $1^{\text {re }}$ conférence nationale du Parti, 14-23 novembre 1953 (Trường Chinh $1994: 451$ ).

3. Dans le contexte vietnamien de l'époque, revendiquer le caractère démocratique et populaire d'un régime dirigé par la classe ouvrière et fondé sur l'alliance « ouvriers - paysans » était une figure de style 
Or, si la réforme agraire était inscrite dans le programme du PCI dès sa fondation ( 18 février 1930), et en des termes explicites comme «saisir toutes les terres de la clique des propriétaires fonciers étrangers, indigènes et de l'Église pour les restituer aux paysans moyens et pauvres » (cité par Hoàng Ước 1968 : 51), l'appel prononcé à cette occasion par le futur président Hồ Chí Minh se focalisa sur la réalisation de la première étape de la révolution. Dans son Appel à l'occasion de la fondation du Parti communiste indochinois lancé le 18 février 1930, il détermina ainsi comme cinquième tâche révolutionnaire la confiscation de « toutes les plantations et autres propriétés des impérialistes et des bourgeois vietnamiens réactionnaires pour les distribuer aux paysans pauvres » (Hồ Chí Minh 1994 : 38). Quelle était alors la situation dans les campagnes du Nord du Việt Nam?

\section{Une paysannerie exsangue}

Les études menées au début des années 1930 sur la tenure foncière dans le delta du fleuve Rouge montrent une structure de la propriété extrêmement morcelée : $60 \%$ des propriétaires du delta possédaient moins d'un $m \tilde{\hat{a} u}{ }^{4}$ de rizières $(0,36 \mathrm{ha}), 90 \%$ des exploitations comptaient moins de 5 mấu $(1,8 \mathrm{ha})$, alors que la moyenne et la grande propriété étaient peu développées (Dumont 1995 : 36).

Tableau $n^{\circ} 1$ : Structure de la tenure foncière du delta du fleuve Rouge (Source : P. Gourou 1940)

\begin{tabular}{|l|l|c|c|c|}
\cline { 2 - 5 } \multicolumn{1}{c|}{} & $\begin{array}{l}\text { Taille moyenne de } \\
\text { l'exploitation }\end{array}$ & $\begin{array}{l}\text { Pourcentage / nombre } \\
\text { total de propriétaires }\end{array}$ & $\begin{array}{l}\text { Pourcentage de la } \\
\text { superficie totale }\end{array}$ & $\begin{array}{l}\text { Superficie } \\
\text { concernée }\end{array}$ \\
\hline $\begin{array}{l}\text { Petits } \\
\text { propriétaires }\end{array}$ & 0 à 5 mẫu $(0$ à 1,8 ha) & $90 \%$ & $36,7 \%$ & 440000 ha \\
\hline $\begin{array}{l}\text { Propriétaires } \\
\text { moyens }\end{array}$ & $\begin{array}{l}5 \text { à } 10 \text { mấu }(1,8 \text { à } \\
3,6 \text { ha) }\end{array}$ & $\begin{array}{l}10 \% \text { (fusion des deux } \\
\text { catégories) }\end{array}$ & $26,7 \%$ & 320000 ha \\
\cline { 1 - 4 } $\begin{array}{l}\text { Grands } \\
\text { propriétaires }\end{array}$ & \begin{tabular}{l}
10 à 100 mâu $(3,6$ à \\
\cline { 1 - 4 }
\end{tabular} & & $16,7 \%$ & 200000 ha \\
\hline $\begin{array}{l}\text { Terres } \\
\text { communales }\end{array}$ & & & $20 \%$ & 240000 ha \\
\hline
\end{tabular}

La répartition de la propriété n'en était pas moins nettement inégalitaire, puisque $90 \%$ des propriétaires ne détenaient qu'un peu plus du tiers des surfaces disponibles, proportion qui, de surcroît, ne comptabilisait pas les métayers, fermiers et journaliers agricoles ne disposant d'aucune terre. D'autre part, $P$. Gourou constata à la même époque un glissement vers la grande propriété, c'est-à-dire une tendance à la concentration foncière

empruntée à l'appareil doctrinal soviétique, puisque la classe ouvrière était insignifiante au regard de l'écrasante masse de la paysannerie ( $90 \%$ de la population du pays). Pour Trịnh Văn Thảo, ce fait est constitutif de "l'originalité du communisme vietnamien » où, faute d'une classe ouvrière, s'opéra un mécanisme de transfert, « les paysans tenant la place des ouvriers », le Parti ouvrier et paysan se substituant au Parti ouvrier (1987: 177). L'article «Communistes et paysans au Vietnam » de P. Brocheux (1981) met en lumière les efforts dialectiques consentis par Nguyễn Ái Quốc (Hồ Chí Minh) dans les années 1920 pour intégrer la masse paysanne dans le mouvement prolétarien révolutionnaire sous la direction éclairée de la classe ouvrière. Pour que cette intégration soit efficiente, il était au préalable indispensable d'éveiller et d'éduquer politiquement la classe paysanne, puis de l'organiser.

4. Au Nord du Việt Nam, les unités de mesures des surfaces agraires sont les suivantes : 1 thrớc $=$ $24 \mathrm{~m}^{2} ; 1$ sào $=360 \mathrm{~m}^{2}=15$ thicóc $; 1$ mấu $=3600 \mathrm{~m}^{2}=10$ sào. 
entre les mains d'une minorité. Cette tendance concerna les terres privées mais également publiques, dans le cadre d'un mouvement de privatisation en sous-main de ces dernières par les notables locaux ${ }^{5}$. La raison en était, selon l'auteur, le développement incontrôlé de l'usure et de l'affermage pratiqués à des taux tellement prohibitifs qu'ils étranglaient la masse des petits propriétaires et contraignaient une part croissante d'entre eux à vendre leurs terres, quand bien même ils en restaient propriétaires sur le papier, dans le cadre d'un système de vente à réméré (Gourou 1940). Si l'on ne peut discuter ici des raisons objectives qui conduisirent $\mathrm{P}$. Gourou à ne retenir comme origine de ce mouvement que le recours accru à l'usure et à l'affermage, causalité endogène qui se trouvait ainsi affranchie du poids de l'environnement colonial, force est de constater que cette spirale de précarisation était une réalité. Pour la majorité des petits paysans souvent réduits à l'état de journaliers agricoles, une mauvaise récolte, l'augmentation de la pression fiscale, le moindre accident climatique d'importance - et ils étaient fréquents (inondation, sécheresse, typhon) -, prenait rapidement des proportions dramatiques. Autrement dit, dans le cadre de cette microfundia, l'imprévisible et l'accidentel étaient à même de rompre à tout moment un équilibre vivrier extrêmement fragile. Illustrations de cette précarité structurelle, les séries établies par P. Brocheux et D. Hémery (1995:259-260) à partir des Annuaires statistiques de l'Indochine (1913-1943) donnent une moyenne de 2 quintaux de paddy/habitant/an, soit 150 à $170 \mathrm{~kg}$ de riz blanc, ration insuffisante à l'entretien d'un adulte ${ }^{6}$. Surtout, ces séries mettent en évidence une dégradation tendancielle de la situation alimentaire depuis le début du siècle (cf. graphique p. 108). Cette dégradation résultait d'une conjonction de facteurs parmi lesquels on peut retenir, en première analyse, un fort accroissement de la population, conséquence d'une baisse importante du taux de mortalité. C'est la principale explication qui fut retenue à l'époque par les services techniques coloniaux pour expliquer le développement d'un prolétariat rural au Nord du pays, " où la densité alimentaire (nombre d'habitants par $\mathrm{km}^{2}$ de rizières) atteint le chiffre de 678 pour l'ensemble du Tonkin et de 800 à 1200 pour plusieurs provinces du delta » (Henry $1932: 8$ ).

La situation se détériora brutalement à la suite de la crise internationale de 1929 , dont les répercussions sur l'économie coloniale, et donc sur les peuples colonisés d'Indochine, se soldèrent par une dégradation alarmante des conditions matérielles de la paysannerie entraînant famines et mouvements de révolte. Les autorités du

5. En 1930, les terres relevant du régime public représentaient $20 \%$ du foncier agricole dans le delta du fleuve Rouge, moyenne qui masquait cependant une forte disparité entre les villages. Leur redistribution périodique (généralement tous les 3 ans) aux inscrits de la commune permettait une amélioration vitale de la situation économique des plus modestes d'entre eux. La privatisation en sous-main des terres publiques et semi-publiques par les notables locaux fut maintes fois citée par les auteurs de l'école " moderniste » de la première moitié du $x^{e}$ e siècle, incarnée par des figures emblématiques telles Phan Kế Bính et Nguyễn Van Huyên, comme l'exemple le plus symptomatique de la perversion du système villageois. Ces auteurs dépeignirent et dénoncèrent une société pervertie par ses propres institutions traditionnelles, où l'avidité, la corruption, le clientélisme, le népotisme, la course effrénée au prestige et à la reconnaissance sociale ont progressivement dénaturé la valeur originelle d'institutions à vocation communautaire et égalitariste pour en faire des instruments d'accaparement et de profit au service de quelques puissants locaux. Ce point de vue fut également adopté par certains observateurs étrangers de l'époque (Chassigneux, Delamarre, Rouilly, Gourou), qui, en fustigeant les abus et dérives dont ils étaient témoins, légitimaient du même coup la présence française et les réformes entreprises par les autorités du Protectorat, en occultant la part de responsabilité du système d'exploitation coloniale dans la dégradation de la situation de la paysannerie (Tessier \& Papin 2002).

6. On retient généralement comme apport moyen nécessaire à l'alimentation d'un adulte une ration annuelle de 300 à $350 \mathrm{~kg}$ d'équivalent paddy, soit 210 à $250 \mathrm{~kg}$ de riz/habitant/an. 
Protectorat amorcèrent alors un changement d'attitude vis-à-vis des campagnes en initiant une politique volontariste articulée autour de deux axes. Le premier visait un décongestionnement des provinces les plus densément peuplées du delta par l'organisation de mouvements de migration vers les zones sous-peuplées du Centre et du Sud du pays : les résultats furent largement en deçà des attentes initiales. Le second axe consistait en un ambitieux programme d'aménagement d'ensemble du delta du fleuve Rouge afin de le doter d'infrastructures hydrauliques permettant la généralisation de la double riziculture annuelle ${ }^{7}$ et une sécurisation relative des récoltes. Sur ce point, les efforts consentis furent considérables (Vesin 1992). Mais l'accroissement de la pression fiscale le fut tout autant. Entre 1920 et 1934, la charge fiscale pour une famille de cinq personnes passa, en équivalent paddy, de 323 kilos à plus d'une tonne (Brocheux \& Hémery 1995). De surcroît, la collecte de l'impôt ne semblait plus souffrir des mêmes dérogations et aménagements que par le passé ${ }^{8}$.

En résumé ${ }^{9}$, en faisant entrer l'Indochine dans la transition démographique sans pour autant mobiliser des moyens humains et financiers capables d'impulser un développement de la production agricole en rapport avec l'accroissement exponentiel de la population, le pouvoir colonial contribua à entraîner le Nord du pays dans une spirale de paupérisation et de crise alimentaire structurelle où une frange croissante de la paysannerie connaissait une sous-alimentation chronique. Inévitablement, des ruptures se produisaient dès qu'un des piliers participant au maintien de cet équilibre précaire venait à vaciller. La terrible famine de 1945 en fut la matérialisation la plus terrifiante. Entre l'automne 1944 et l'hiver 1945, 1,5 à 2 millions de paysans périrent, principalement dans le delta du fleuve Rouge. Pour tenter d'expliquer cette tragédie humaine qui décima plus du quart de la population du delta, les travaux de Nguyễn Thế Anh (1985) et l'ouvrage de Van Tao et Furuta Moto (1995) retiennent la convergence de deux facteurs essentiels. Le premier vient d'être évoqué : il s'agit de la dégradation constante du ratio grain/population, qui connut une aggravation brutale à la suite d'une série d'accidents climatiques qui s'échelonnèrent à partir de 1943. En second lieu, les reconversions en cultures industrielles exigées par l'appareil colonial français afin de faire face aux pénuries imposées par la guerre, combinées aux prélèvements croissants de riz effectués par l'armée d'occupation japonaise, furent deux catalyseurs de la crise et en expliquent l'ampleur.

Face au spectre permanent de la famine, la campagne du Việt-minh axée sur la lutte contre la faim, qui occupait déjà une place prépondérante dans la stratégie politique du PCI depuis sa fondation, permit à Hồ Chí Minh de prendre la tête d'un véritable mouvement populaire et, à la faveur des troubles qui suivirent la capitulation japonaise, de s'emparer du pouvoir en août 1945 (Nguyễn Thế Anh 1985).

7. En zone deltaïque, la mise en place de réseaux hydrauliques ne peut se faire qu'à grande échelle afin de permettre non seulement l'irrigation, mais aussi le drainage des eaux excédentaires lors de la mousson : cela nécessite d'importants moyens mécaniques d'élévation de l'eau combinés à de puissants canaux de drainage et d'irrigation.

8. Comme l'indique ce témoignage de R. Dumont : "J'ai été moralement obligé de quitter un pays auquel je m'attachais, après qu'en septembre 1931, un adjudant aviateur de l'armée coloniale m'a dit à Vinh "s'être déshonoré" en tirant sur ordre à la mitrailleuse, de son avion, sur une colonne de paysans désarmés. Dans cette province du Nghê An, celle d'Hô Chi Minh, ces paysans demandaient, à la suite de la sécheresse, une réduction d'impôts que l'empire d'Annam leur accordait en pareil cas. » (1995:xiii)

9. Pour une synthèse sur le sujet, voir Tessier \& Fontenelle 2000. 


\section{Recomposition de la tenure foncière et virage idéologique}

Le 13 novembre 1945, le ministère de l'Intérieur publia un décret ordonnant une réduction de $25 \%$ des rentes foncières (affermage), l'annulation des rentes secondaires et des impôts indirects ainsi que des créances contractées avant la révolution. Ce décret complétait une série de mesures prises au moment de la déclaration d'indépendance concernant, notamment, l'abolition de l'impôt personnel. Cependant, jusqu'en 1949, ces mesures furent suivies de peu d'effets. Elles n'affectèrent que $10 \%$ des terres auxquelles elles devaient s'appliquer : si la majorité des propriétés foncières des colons français avait été confisquée $(61,2 \%)$ ainsi que celle des « traîtres vietnamiens », seuls $31,7 \%$ du total des terres publiques et $10,4 \%$ des terres des «propriétaires terriens » (địa chü) avaient été redistribués, ces derniers s'opposant à une réduction significative des taux d'affermage (Hoàng U'ớc 1968 : 66-71). Il faut dire que malgré les gages donnés à une paysannerie exsangue encore sous le choc du traumatisme de la famine de 1945, les priorités des nouveaux maîtres de Hà Nội étaient ailleurs.

En effet, à l'issue de la conférence de Potsdam qui se tint le 12 juillet 1945, soit quelques semaines avant le déclenchement de l'insurrection d'août 1945, les Alliés confièrent la responsabilité du désarmement des troupes japonaises au nord du $16^{\mathrm{e}}$ parallèle ${ }^{10}$ à $1^{\text {'armée }}$ chinoise nationaliste (anticommuniste) du Yunnan, dirigée par le général Lu Han : entre septembre et octobre 1945, ce sont ainsi 180000 hommes de troupe qui pénétrèrent au Tonkin. Face au danger que représentait un retour en force des partis nationalistes noncommunistes sur le devant de la scène politique locale et nationale, le Việt-minh procéda entre 1945 et 1946 à la liquidation méthodique de tous les mouvements d'opposition anticolonialiste et à l'élimination physique des leaders à même de contester sa position dominante pour aboutir, au final, à la destruction de l'élite politique et intellectuelle non communiste ". Durant la même période, Hồ Chí Minh, investi à la tête du "Gouvernement d'union nationale et de résistance », et Jean Sainteny, commissaire de France au Tonkin, engagèrent de longues tractations qui aboutirent à la signature d'un accord le 6 mars 1946. Toutefois, la situation délétère née de positions diamétralement opposées entre Français et Vietnamiens quant à l'avenir du pays se dégrada rapidement pour atteindre un point de non-retour à la suite d'une série d'incidents et de provocations des deux bords en novembre et décembre 1946 à Hải Phòng, Lạng Sơn et Hà Nội. Le 19 décembre, Hồ Chí Minh lança un appel à la résistance nationale : la première guerre d'Indochine débutait, obligeant le Việt-minh à reprendre la clandestinité et à se replier dans la Haute région.

Selon l'historiographie officielle, le peu d'effet des mesures prises en 1945 en faveur de la paysannerie s'explique par le fait que les zones libres, c'est-à-dire placées sous le contrôle du Việt-minh, étaient peu nombreuses et parce que les paysans n'étaient pas encore prêts idéologiquement pour mener une réforme agraire. Mais dans ce contexte de forte instabilité et de lutte armée, une autre explication s'impose, plus pragmatique : pour être conduite avec succès, la guerre de résistance avait besoin d'une unité consensuelle la plus large possible, qui ne pouvait se fonder sur une division de la population en classes antagonistes. Concrètement, il s'agissait de ne pas effrayer la bourgeoisie, la notabilité

10. Au sud du $16^{\circ}$ parallèle, cette tâche fut confiée aux Britanniques, qui considéraient que l'administration légitime en Indochine était celle de la France.

11. Sur cette facette méconnue des premières années du régime, car éludée par l'historiographie officielle, on pourra se reporter au récent article de F. Guillemot (2004) qui décrit et analyse minutieusement la stratégie du Việt-minh combinant un jeu d'alliances complexes et versatiles et une répression extrêmement violente. 
foncière et les minorités confessionnelles ${ }^{12}$ que l'on souhaitait rallier à la lutte pour l'indépendance dans un front uni de toutes les forces patriotiques anti-impérialistes (Ngô Văn 1995). Les premiers pas du processus de la réforme agraire devaient donc permettre de neutraliser les " proprietaires fonciers » (địa chü) sans pour autant les pousser vers les rangs ennemis (Nguyễn Đức Truyên 1993 : 17).

À la fin des années 1940, l'évolution des rapports de force au Nord du Việt Nam et, plus globalement, sur l'échiquier international, fit pencher la balance en faveur du Việtminh, ce qui lui permit de réaffirmer sa ligne politique ${ }^{13}$. Le tournant majeur fut sans nul doute la victoire de Mao Zedong et l'avènement de la République populaire de Chine en $1949^{14}$. La loi sur la réforme agraire publiée le 29 juin 1950 et sa mise en œuvre sur l'ensemble du territoire pendant les deux années qui suivirent, sur la base des expériences acquises lors de la réforme agraire plus radicale menée à partir de 1947 dans les régions libérées du Nord et du Nord-Est (Chen Chi-Yi 1962), tracèrent la voie que devait suivre la RDVN ${ }^{15}$. Malgré des différences fondamentales évidentes entre les situations éco-

12. Ainsi, pendant les premières années de la guerre de résistance, c'est-à-dire jusqu'au durcissement idéologique de la ligne du Parti en 1950, le clergé catholique et les leaders du Việt-minh avaient mené une politique de conciliation dans le cadre d'une union nationale anticolonialiste. C'est d'ailleurs ce qu'illustre le traitement de faveur qui fut réservé à certaines personnalités du clergé ou de confession catholique, en comparaison de la répression sanglante qui s'abattit sur les mouvements anticolonialistes non communistes (1945-1947). Au-delà du sentiment nationaliste qui le motiva, l'engagement de la minorité catholique au sein de l'appareil du Việt-minh visait à mettre un terme à l'accusation de « traîtres à la patrie » qui stigmatisait cette minorité, accusée d'avoir adhéré à une religion étrangère perçue comme dangereuse par le pouvoir confucéen puis de s'être rendue coupable de la perte d'indépendance du pays. Ironie de l'histoire, ce rapprochement fut involontairement favorisé par une hiérarchic catholique majoritairement française qui niait la réalité de l'engagement nationaliste de la communauté catholique et pour qui seule l'autorité française pouvait garantir leur apostolat (Trần Thị Liên 2004).

13. D'une part, les zones libres sous le contrôle du Việt-minh ne cessaient de s'étendre au fur et à mesure que le pouvoir français en zone rurale déclinait et était contesté pour se voir progressivement circonscrit aux seuls centres urbains; d'autre part, le soutien des pays frères, l'URSS et la Chine en tête, s'affirmait chaque jour un peu plus (le 18 janvier 1950, la nouvelle Chine communiste reconnaissait la RDVN, suivie douze jours plus tard par l'URSS).

14. La prégnance des modèles soviétique et maoïste ne laissait guère d'alternative aux autorités de Hà Nội, comme le rappelle l'historien et député Dương Trung Quốc : la réforme agraire fut imposée par les deux grands pays du bloc comme une manifestation d'allégeance des dirigeants et du peuple de la RDVN à l'Internationale socialiste, dans la mesure où sa réalisation effective conditionnait l'octroi de l'aide massive dont le pays avait cruellement besoin (Dương Trung Quốc 2007 : 7).

15. Nous évoquerons principalement dans cet article l'influence envahissante de l'expérience chinoise dans la mesure où c'est le modèle qui fut directement appliqué par les milliers de conseillers chinois qui noyautèrent les équipes et brigades chargées de la mise en œuvre de la réforme agraire dans les villages de la RDVN. Il n'en reste pas moins vrai que le « modèle du modèle » fut la révolution agraire soviétique déclenchée en 1929. Révolution, car « l'action de l'État fut un véritable assaut contre la paysannerie, un exploit de "génie social" qui, par son ampleur, son audace et sa violence, reléguait dans l'ombre "la transformation par en haut" de Stolypine » (Lewin 1982 : 77). En effet, la distribution de la population en cinq classes - source d'inspiration évidente des réformes agraires chinoise puis vietnamienne - qui fonda et légitima la « dékoulakisation », synonyme de la mort de plusieurs millions de paysans, avait pour objet la collectivisation des moyens de production et la création de la grande agriculture socialiste kolkhozienne, et non une redistribution équitable du foncier. Cette dernière avait été pour partie réalisée par les paysans eux-mêmes au lendemain de la guerre civile dans le cadre d'une transformation progressive des structures économiques et foncières impulsée par la NEP (Nouvelle politique économique) décidée par Lénine. En comparaison du totalitarisme absolu et aveugle qui s'abattit sur les campagnes à la fin des années 1920, la NEP avait des « allures de "contrat social" [et] devait bientôt apparaître comme un âge d'or de liberté et de pluralisme » (Lewin $1982: 77$ ). 
nomiques, sociales et politiques des campagnes chinoises et vietnamiennes, les autorités de Hà Nội importèrent en bloc le modèle chinois pour l'appliquer sans grand discernement.

À partir de 1949, sous la houlette de Trường Chinh, le Parti des travailleurs durcit ses positions et décida de lancer la grande réforme agraire (la $3^{\mathrm{e}}$ étape du processus), même s'il fallut encore attendre deux ans pour qu'elle soit mise en œuvre dans les campagnes. Une nouvelle série de décrets et de résolutions insista sur l'obligation absolue ${ }^{16} \mathrm{~d}^{1}$ appliquer la réduction des taux d'intérêt ainsi que la baisse stricte des fermages et stipula que les propriétés de l'Église et les terres abandonnées et en friche devaient être redistribuées aux paysans pauvres. En 1951, une réorganisation complète du système fiscal favorable aux plus modestes vint compléter cet arsenal législatif. Il s'agissait d'établir une assiette d'impôt graduelle suivant les classes considérées : les paysans pauvres ne devaient plus être taxés qu'à hauteur de 6 à $10 \%$ de leur récolte, les paysans moyens de 15 à $20 \%$, la pression fiscale étant déplacée sur les paysans riches et les dị chủ qui devaient s'acquitter d'une quote-part de 35 à $50 \%$, voire, dans certains cas, de $65 \%$ (Houtard \& Lemercinier $1984: 10-11$ ). À la fin de l'année 1952, $90 \%$ des concessions détenues par des colons français et par des «traîtres vietnamiens » ainsi que $77 \%$ des terres publiques et semipubliques avaient d'ores et déjà été confisquées ou réquisitionnées puis redistribuées. Quant aux « propriétaires terriens » (địa chủ), ils ne détenaient plus, officiellement, que $43,5 \%$ des terres qu'ils possédaient avant la Révolution d'août 1945. Inévitablement, cette recomposition de la tenure foncière s'accompagna d'une transformation structurelle des classes rurales ${ }^{17}$.

Après quelques années de mise en œuvre, la politique du Parti avait donc porté ses fruits, puisque 480000 ha avaient déjà été distribués en 1953, c'est-à-dire à la veille de la réforme agraire proprement dite, soit $59 \%$ des 810000 ha qui changèrent de main entre 1945 et 1957 et qui furent attribués à 2,1 millions de paysans (Vickerman 1986 : $60-63)^{18}$. Or ce succès s'avéra être à double tranchant au regard des caractéristiques de la situation foncière nord-vietnamienne, qui n'avait rien de latifundiaire. Cette restructuration de la propriété foncière avait en effet considérablement réduit la quantité des terres

16. Signe de cette intransigeance croissante pour la mise en œuvre de la politique agraire dans les zones libérées, une série de textes précise la nature des structures administratives en charge de son application au niveau provincial. La résolution $n^{\circ} 174$ du 11/08/1949 ordonne la création dans chaque province d'une commission spéciale ad hoc chargée de la redistribution des terres confisquées aux traîtres viet-

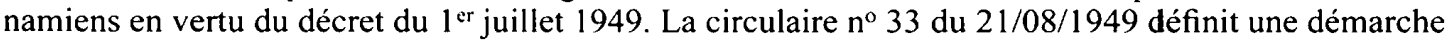
identique pour les terres confisquées aux Français. Le décret présidentiel no 89 en date du 22/05/1950, amendé le 21 décembre 1949, entérine la création d'une nouvelle catégorie de corps auxiliaires locaux, les Comités provinciaux, chargés de superviser et de contrôler l'application effective des mesures visant la réduction des rentes foncières, l'annulation des rentes secondaires et des impôts indirects ainsi que celle des créances contractées avant la révolution (Ginsburgs $1962: 199-200$ ).

17. Une enquête du Comité de la réforme agraire menée en 1953 dans 93 communes et 31 villages de 16 provinces du Nord (Việt Bắc) releva que le nombre de propriétaires terriens avait été réduit d'un tiers par rapport à 1945 et que la superficie possédée par les paysans moyens et pauvres représentait $80 \%$ du total des terres, c'est-à-dire qu'elle avait presque doublé. La proportion des salariés agricoles avait enregistré une baisse significative de 21 à $14 \%$, mais le nombre de paysans pauvres avait dans le même temps augmenté de 35 à $44 \%$ (Lê Thành Khôi $1978: 54$ ).

18. Terres publiques et semi-publiques : 289300 ha redistribués entre 1945 et 1953 pour un total de 3757000 ha (1945-1956); propriétaires terriens et «traîtres »: 156600 ha pour un total de 380300 ha; concessions françaises : 26800 ha pour un total de 30000 ha; terres de l'Église : 3200 ha pour un total de 24000 ha (Vickerman $1986: 61$ ). Citant un rapport du Comité central de rectification des erreurs (1956), Đặng Phong (2005: 91) avance des proportions similaires : sur les 510710 ha confisqués aux propriétaires fonciers féodaux, aux traîtres et aux colons dans 3035 communes du Việt Bắc, 63,7\% avaient été redistribués aux paysans en 1953. 
susceptibles d'être redistribuées, tout en ne répondant que partiellement aux attentes de la paysannerie. De surcroît, l'État avait jusqu'alors exercé son droit de préhension sur des catégories de terres dont le statut ne souffrait guère de contestation pour quiconque aspirait à la naissance d'une société plus équitable sans pour autant qu'elle soit obligatoirement d'obédience marxiste-léniniste. En effet, qu'il s'agisse du foncier confisqué aux colons français, aux «traîtres vietnamiens ", ou de la réquisition des terres publiques et semi-publiques qui représentaient $60 \%$ des terres redistribuées, leur nouvelle affectation avait fait l'objet d'un large consensus. Le plus dur restait donc à faire.

Dans ces conditions, comment légitimer la poursuite de la réforme agraire qui devait entrer dans sa phase ultime et décisive? La seule option possible était de l'inscrire plus que jamais dans le registre politique et dogmatique, en s'attaquant aux ennemis du prolétariat (l'alliance virtuelle ouvriers-paysans). Pour ce faire, outre une autocritique virulente de l'insertion jugée insuffisante du Parti au niveau local dont Trường Chinh se fit le chantre et l'intercesseur, l'opprobre se focalisa sur les « exploiteurs-réactionnaires » coupables de manœuvres de dissimulation et de falsification qui leur avaient permis de conserver la mainmise sur la paysannerie tout en donnant des gages fallacieux d'allégeance au gouvernement et à la résistance. Concrètement, ils auraient procédé depuis 1949 à une réallocation en trompe-l'œil de leur patrimoine foncier : dispersion des terres au sein des réseaux de parenté et de clientèle, simulacres de « dons » aux paysans sans terre (métayers ou fermiers) en contrepartie de travail gratuit, remise des rizières les moins fertiles à la résistance, aliénation et ventes camouflées favorisées par la chute du marché foncier à la suite de la réforme fiscale de 1951, etc. (Pagniez 1955 : 48-50). Trường Chinh fit de cette suspicion obsessionnelle de la dissimulation et de la conscience révolutionnaire feinte, suspicion qu'il projeta sur le Parti lui-même - car il le pensait noyauté et miné par les ennemis de l'intérieur (la classe des exploiteurs, les patriotes de circonstance, etc.) -, une des justifications essentielles à la conduite de l'étape ultime de la réforme agraire. La rhétorique doctrinale était donc des plus orthodoxes : l'exploitation de la paysannerie et l'accaparement des moyens de production par une poignée de nantis à la solde des impérialistes avaient certes notablement diminué grâce à la justesse de la politique conduite par le Parti, mais renaîtraient irrémédiablement si des conditions favorables aux exploiteurs étaient à nouveau réunies ${ }^{19}$. La deuxième étape de la révolution socialiste, c'est-à-dire le renversement de l'ordre « féodal » ancien et l'instauration d'un régime prolétarien, ne pouvait, par essence, faire l'objet de compromis et passait donc par la lutte des classes et par l'éradication irréversible de la classe des exploiteurs ${ }^{20}$. Et si le

19. Cette nécessité absolue se fondait sur une crainte énoncée en 1937 par Võ Nguyên Giáp et Trừơng Chinh dans le texte Vấn Đề Dân Cày [La Question paysanne], publié à Hà Nội en 1937 puis réédité en 1959. Partant du principe que « le problème de la terre et le problème paysan sont les fondements du problème indochinois » (cité par Brocheux 1981 : 255), les deux auteurs affirment que la paysannerie possède un potentiel révolutionnaire, mais aussi la possibilité de verser du côté de la réaction, en s'appuyant pour cela sur l'exemple de l'Allemagne nazie où les paysans soutenaient le régime d'Hitler (Brocheux 1981:255).

20. Une fois encore, la voie avait été tracée quelques années auparavant par le grand frère chinois. Dans un discours du 3 novembre 1950, le Premier ministre Tchou en Laï avait écrit que « la loi est un instrument aux mains d'une classe pour l'oppression d'une autre classe », ce que M. Teng Tsé Haï, viceprésident du Comité militaire et administratif, avait traduit en décembre de la mème année en des termes on ne peut plus explicites : "La réforme agraire - confiscation de la propriété féodaliste et redistribution des terres - est la phase la plus féroce de la lutte antiféodale. Ce serait une grande erreur que de séparer la réforme agraire des autres aspects de la lutte et de ne voir en elle qu'une simple redistribution des terres. [...] » (cité par Brenier $1954: 200$ ) 
volant de terres non encore redistribuées était ténu ( $41 \%$ du total), cela n'était en fin de compte qu'un problème annexe inféodé à l'objectif final : l'avènement de la révolution marxiste-léniniste. La réforme se devait d'être à son service et, à ce titre, pouvait faire l'objet d'aménagements avec les réalités de la situation dans les campagnes ${ }^{21}$.

\section{Sur le terrain, les prémices du bouleversement à venir}

Quel fut l'impact de ces deux premières étapes de la réforme au niveau local? Les rares monographies villageoises disponibles occultent la phase de réduction des fermages ou l'évoquent brièvement sans aborder sa réalisation concrète. Dans la commune de Ninh Dân, les villageois interrogés sur la question font généralement un amalgame entre cette période et la dernière étape de la réforme agraire qui, elle, reste gravée dans toutes les mémoires. Et pourtant, les actions menées furent bien réelles. En mai 1950, un Conseil d'attribution provisoire des rizières (Hội Đồng Tạm Cấp Ruộng Đất) fut institué et procéda à une réallocation des rizières publiques, il est vrai peu nombreuses ( 20 mẫu sur un total de $600 \mathrm{mâ} u$ ), et des terres appartenant à la mission catholique (30 mẫu de rizières). Une centaine de familles, soit approximativement un tiers des 310 foyers que comptait la commune en 1954, bénéficia ainsi de l'attribution de trois à cinq sào de rizières. Autre aspect, une caisse d'entraide et de soutien aux paysans pauvres et sans terre fut créée et permit de constituer un fonds solidaire de 24 tonnes de paddy. Chaque foyer pauvre put ainsi emprunter entre 20 et $50 \mathrm{~kg}$ de paddy par saison à un taux d'intérêt extrêmement bas fixé à $1 \%$. La caisse fonctionna jusqu'à la collectivisation (1959). Cette forme primitive de coopérative de crédit revêtait une double importance : d'un point de vue idéologique, elle démontrait tout le bénéfice que l'on pouvait tirer de l'investissement collectif et, par là même, la justesse de la politique du Parti dans sa quête d'une mutualisation des moyens de production; en pratique, elle permit d'alléger le fardeau des plus pauvres en s'imposant comme une alternative crédible à l'usure. Quant à la refonte du système fiscal, elle est brièvement évoquée dans l'histoire de la cellule du Parti communiste de la commune ${ }^{22}$ :

En mai 1951, le gouvernement a édicté la politique des impôts agricoles. La réalisation de cette politique était une lutte de classes. Certains propriétaires qui étaient opposés à cette politique ont été condamnés, comme par exemple M. Hiện qui a été condamné à neuf ans de prison. [...] Le service des impôts de la commune a demandé aux habitants de déclarer leurs surfaces réelles, leurs vrais rendements. Ainsi, pendant 4 années (1951-1954), la commune de Ninh Dân a collecté 60 tonnes de paddy d'impôts pour les 600 mấu de rizières [...]; 700000 đồng d'impôts pour les 700 mấu de thé. (Ninh Dân $1996: 35$ )

L'allusion aux « surfaces réelles » et aux «vrais rendements » fait implicitement référence à la pratique généralisée de la dissimulation des inscrits et des rizières orches-

21. Conscient que le volume de terres disponibles ne suffirait pas à satisfaire les attentes de la paysannerie, le gouvernement de Hồ Chí Minh définit dans le décret « sur la politique agraire » de mai 1953 un ordre de priorité des bénéficiaires de la redistribution inspiré par l'état de guerre du moment et par les enjeux idéologiques de la réforme fondée sur la lutte des classes : les anciens combattants, les familles des soldats tombés au champ d'honncur, les membres des forces de résistance, ctc., « recevront les meilleures rizières, celles qui ont une valeur supérieure aux autres » (cité par Fall 1960: 272).

22. Lịch Sü Đäng Bộ xã Ninh Dân [Histoire de la cellule du Parti communiste de la commune de Ninh Dân], rédigé en 1996 par M. An, habitant du village de Hay. Il s'agit d'un manuscrit non publié et donc d'une version non expurgée. 
trée par les notables et les villageois. En regard de cette pratique caractéristique de «l'ancienne société féodale », l'application du nouveau régime d'imposition se devait d'être stricte et transparente, puisqu'elle symbolisait les premiers pas de l'instauration d'un nouveau rapport à l'État, rapport dans lequel le pouvoir était détenu et exercé par le peuple maître. Léser l'État, c'était donc léser le peuple dans son ensemble et trahir la cause révolutionnaire. Aussi, les sanctions à l'encontre des fraudeurs devaient-elles être sévères et exemplaires, à l'instar de la lourde peine d'emprisonnement infligée au propriétaire terrien récalcitrant donné en exemple. Cette sévérité illustre le basculement de la politique consensuelle d'alliance de classes, de mise jusqu'en 1949, vers l'intransigeance dogmatique qui s'imposa au début des années 1950. La rupture apparaît encore plus évidente lorsqu'on compare la liste nominative des ressortissants de la commune qui participèrent financièrement aux principaux mouvements de soutien à l'effort de guerre 23 et leur classification lors de la réforme agraire.

Tableau $\mathrm{n}^{\circ} 2$ : Participation matérielle à l'effort de guerre (Source : Histoire du Parti de la commune de Ninh Dân, 1996)

\begin{tabular}{|c|c|c|c|c|c|}
\hline $\begin{array}{l}\text { Classement } \\
\text { (personnes citées) }\end{array}$ & $\begin{array}{l}\text { "Semaine } \\
\text { de l'or » } \\
1945^{*}\end{array}$ & $\begin{array}{l}\text { «Soutenir } \\
\text { les } \\
\text { soldats » } \\
1947-1950\end{array}$ & $\begin{array}{l}\text { Soutien à } \\
\text { l'association } \\
\text { « hôi nuôi quân» } \\
1948\end{array}$ & $\begin{array}{l}\text { « Héberger } \\
\text { des } \\
\text { soldats » } \\
1949\end{array}$ & $\begin{array}{l}\text { Emprunts } \\
\text { publics pour la } \\
\text { résistance** }\end{array}$ \\
\hline $\begin{array}{l}\text { - địa chủ (propriétaire terrien) } \\
\text { - phú nông (propriétaire riche) } \\
\text { - Indéterminé }\end{array}$ & 4 & $\begin{array}{l}4+\text { le } \\
\text { prêtre de la } \\
\text { paroisse }\end{array}$ & $\begin{array}{l}8 \\
3 \\
2\end{array}$ & $\begin{array}{c}10 \\
1\end{array}$ & $\begin{array}{l}13 \\
3 \\
4\end{array}$ \\
\hline total personnes citées & 4 & 5 & 13 & 11 & 20 \\
\hline
\end{tabular}

* Ce mouvement de contribution citoyenne, lancé le 16 septembre 1945, visait à soutenir le nouveau gouvernement de la RDVN qui devait faire face à une sérieuse pénurie financière. D'autres appels aux donations populaires furent lancés la même année («Fonds de l'Indépendance ", «Fonds pour la défense nationale ») afin de participer à la mise en place des structures administratives et de renforcer les forces armées populaires. En effet, lors de la prise du pouvoir, le PCI avait commis l'erreur de ne pas prendre le contrôle de la Banque de l'Indochine laissée aux mains de l'administration française, et cela même après le coup de force japonais du 9 mars. Cette banque continuait ainsi à contrôler les flux financiers et l'émission de la monnaie, la piastre indochinoise (Stowe 2004 : 61-62). Une autre facette de la guerre de résistance, monétaire celle-là, commençait.

** L'auteur de l'histoire du Parti a pris soin de préciser que seules les familles aisées pouvaient souscrire aux emprunts publics pour la résistance et aux emprunts d'État. Les trois vagues de souscription ont permis de collecter 88,8 tonnes de paddy et 2 tonnes de thé, contributions qui ont été remises aux services logistiques de l'APV pour la campagne Lý Thường Kiệt (Nghia Lộ).

23. Il s'agissait de campagnes de contribution et de soutien à la résistance, associées à des slogans cherchant à galvaniser l'effort de guerre et l'esprit de sacrifice. Les emprunts publics pour la résistance et les contributions pour la défénse nationale furent stimulés par un Comité de propagande communale comprenant des représentants du Parti et du Liên Việt. Parallèlement à l'organisation de collectes, des associations du Liên Việt, au premier rang desquelles l'Association de soutien aux militaires (hội nuối quân), œuvraient au profit de la résistance. Entre autres missions, cette association organisait la prise en charge des soldats de l'Armée populaire du Việt Nam (APV) par la population. 
Les données synthétisées dans ce tableau montrent une situation apparemment paradoxale, puisque les donateurs ont été pour la plupart classés quelques années plus tard "propriétaires terriens » (dịa chủ), c'est-à-dire exploiteurs du peuple. Prosaïquement, on peut estimer que cette corrélation entre la personnalité des principaux donneurs et leur classement lors de la réforme agraire est la conséquence logique de leur aisance économique. Certes, il y a sûrement une part de vérité dans cette assertion de bon sens, mais cet investissement dans la résistance ne fut pas homogène, loin s'en faut. Sur les vingt-huit địa chủ identifiés en 1954 (cf. infra), seuls onze ont contribué matériellement à l'effort de guerre, et parmi eux, six ont participé à quatre mouvements, ce qui rend peu probable l'hypothèse d'une participation obligatoire, même si des pressions furent sûrement exercées par les cadres locaux du Parti. Et cela n'a pas plaidé en leur faveur lors du « jugement populaire ", puisque sur les quatre propriétaires déclarés " địa chủ cường hào » (propriétaires terriens notables tyranniques) qui furent condamnés à mort ou à de lourdes peines d'emprisonnement, trois faisaient partie du groupe des onze propriétaires qui avaient apporté leur soutien financier à la résistance. Patriotisme de circonstance, stratagème visant à faire oublier leur passé « d'exploiteur » comme l'affirmait Trường Chinh, ou bien nationalisme sincère mais non teinté de communisme parce qu'inconciliable avec les convictions ou les privilèges de ces nantis? Il est évidemment impossible de trancher, les choix de chacun étant, pour partie tout au moins, la résultante de leur situation singulière : l'intérêt ici est de souligner que la société villageoise était autrement plus complexe que ce que le jugement manichéen du pouvoir central voulait laisser croire.

Le cas de M. Hiện, cité plus haut en exemple, est symptomatique de cette ambiguïté de l'engagement, dont le durcissement de la ligne politique fut en partie la cause. Cet homme fut non seulement emprisonné pour neuf années en 1951, mais il fut à nouveau condamné à douze ans de prison en 1954 en tant que " propriétaire terrien notable tyrannique " : officiellement, il mourut en prison en 1956, ce que récuse son petit-fils, qui affirme qu'il aurait été fusillé. Et pourtant, M. Hiện fut l'habitant de la commune de Ninh Dân qui apporta, entre 1945 et 1951, le plus important concours matériel à la lutte pour l'indépendance. Lorsqu'en 1949, des représentants provinciaux de l'Association de soutien aux militaires " hội nuôi quân " vinrent faire de la propagande dans la commune, " une cérémonie de présentation s'est tenue chez M. Hiện pendant deux jours en présence de $M$. Vương Ngọc Hoàn, chef du service militaire de la province » (Ninh Dân 1996 : 23-24). À la suite de quoi, M. Hiện hébergea une section des troupes de l'APV, les autres propriétaires se limitant à prendre en charge une escouade ou un simple soldat. Il fit également don de sept bœufs à l'Association de soutien aux militaires, versa de l'argent, du paddy et des vêtements à cette même association.

\section{De la réforme agraire à la rectification (1953-1956)}

\section{Principes et finalités : une lutte de classes}

Le cadre général de la réforme fut fixé par le président Hồ Chí Minh dans son rapport présenté le $1^{\text {er }}$ décembre 1953 à la III session de l'Assemblée nationale : "Pendant la résistance, le gouvernement a ordonné la réduction des taux de fermage, le remboursement des trop-perçus, l'attribution aux paysans des rizières appartenant aux colonialistes et aux traîtres et l'affectation provisoire des rizières communales en zone libre. [...] Le problème central reste toujours sans solution : les masses paysannes n'ont pas ou pas assez de rizières. Nos paysans, qui représentent près de $90 \%$ de la population, ne possèdent que $3 / 10^{\mathrm{e}}$ des terres environ, peinent toute l'année et mènent une vie de misère. 
Les terriens féodaux n'atteignent pas $5 \%$ de la population, mais avec les colonialistes, ils s'approprient environ $70 \%$ des rizières pour mener une vie oisive et dorée. Cette situation est d'une injustice criante. [...] La réforme agraire donnera la terre à ceux qui la travaillent et libérera les forces productrices à la campagne des entraves imposées par la classe des propriétaires terriens; il faut partager la terre [...]» (1994: 167).

Il n'est pas utile d'insister outre mesure sur le caractère fallacieux des proportions chiffrées avancées dans ce discours, proportions qui fondent l'argumentaire légitimant le déclenchement de la phase décisive de la réforme agraire, d'autres auteurs l'ont fait par le passé (Vickerman 1986, Woodside 190, etc.). La situation dépeinte pourrait à la rigueur correspondre à celle de la structure de la propriété foncière du Việt Bắc telle que décrite par Võ Nguyên Giáp et Trừơng Chinh en 1937 dans La Question paysanne, si tant est que les $20 \%$ de terres publiques et semi-publiques aient été intégralement accaparés par les « propriétaires terriens féodaux et les colonialistes ", ce qui ne fut aucunement le cas. En définitive, cet exercice de rhétorique idéologique revint à nier les résultats obtenus depuis 1945 par la mise en œuvre de la politique agraire du Parti, ce qui n'est pas le moindre des paradoxes.

La loi sur la réforme agraire fut adoptée à l'unanimité par les députés trois jours plus tard, le 4 décembre 1953, selon des critères de priorité qui reflétaient l'état de guerre sous lequel les statuts avaient été arrêtés (Fall 1960 : 272). Dans ce contexte, au-delà du souci affiché de justice sociale et de stimulation du redressement économique, la volonté du Parti était de provoquer une rupture politique et sociale radicale et de précipiter l'issue du conflit, comme en témoignent les objectifs assignés à la réforme :

- supprimer le régime féodal d'accaparement et d'exploitation et distribuer la terre à ceux qui la travaillent afin de provoquer un accroissement de la production dans les campagnes;

- provoquer un nouvel élan de la mobilisation de la paysannerie $(90 \%$ de la population) pour la guerre de résistance afin d'en précipiter l'inéluctable dénouement, après sept longues années de combats ${ }^{24}$;

- améliorer le niveau culturel des masses, car « qui a mangé pense à la sagesse " (Hồ Chí Minh 1994 : 170);

- poser les bases de la collectivisation des moyens de production et lutter contre les ennemis de l'intérieur ralliés au «gouvernement fantoche de Bảo Đại », qui était en train de lancer sa propre réforme agraire au Sud (Pagniez $1955: 45$ );

- réformer l'organisation locale du Parti en s'appuyant sur la réforme pour asseoir son ancrage au sein de structures villageoises réputées hermétiques. "Après la Révolution, dans de nombreuses régions, les propriétaires fonciers se sont emparés de la direction de diverses organisations rurales. [...] Dans d'autres régions, ils s'infiltrent dans diverses organisations communales : cellule du Parti, organe administratif, Union paysanne, Front national [Liên Việt : Union nationale du Việt Nam] et s'en servent pour opprimer et exploiter les paysans, saboter la résistance et les politiques du gouvernement. [...] C'est pourquoi il faut réorganiser les cellules du Parti dans les campagnes, combattre la

24. Dans ses mémoires consacrés à la bataille de Điện Biên Phủ, le général Võ Nguyên Giáp évoque brièvement le sort de la paysannerie et ses attentes vis-à-vis du nouveau pouvoir révolutionnaire : « Nous n'étions pas encore assez forts pour réaliser un objectif majeur de la révolution, donner la terre à ceux qui la cultivent. Le 4 décembre 1953, sur proposition du Parti, l'Assemblée nationale de la RDVN avait adopté une loi agraire. L'importance de l'événement avait insufflé une nouvelle énergie aux résistants, surtout aux cadres et aux combattants qui étaient issus pour la plupart de la classe paysanne. Un peuple tout entier partait en guerre avec ardeur. » $(2005: 88)$ 
tendance à sous-estimer leur édification pendant la réforme agraire ${ }^{25} »$. Pour concilier ces objectifs politiques, sociaux et économiques tout en menant à son terme la guerre d'indépendance, le Parti réaffirma qu'il suivait une « ligne de classe » en se livrant pour cela à un exercice d'autocritique (chỉnh huấn) ${ }^{26}$ visant à mettre en lumière les errances qui avaient jusqu'alors caractérisé l'application de la politique agraire : " notre erreur principale jusqu'à présent a été de ne pas comprendre que la réalisation de la politique agraire du Parti et du Gouvernement est une lutte de classes âpre et ardue et que pour entreprendre la réforme agraire, il faut déclencher résolument la mobilisation des masses, il faut suivre une ligne de masse 27 ».

Afin de rectifier le déviationnisme autoritaire, bureaucratique et "droitiste », la ligne générale définie par Hồ Chí Minh tint en une formule lapidaire : «s'appuyer sans réserve sur les paysans pauvres et les paysans sans terre, s'unir étroitement aux paysans moyens, s'entendre avec les paysans riches, supprimer par étapes et avec discrimination le régime d'exploitation féodale, développer la production, pousser la résistance ${ }^{28} \gg$. Si la réforme devait être une étape décisive sur la voie du socialisme ${ }^{29}$, le président n'en appela pas moins à agir avec discernement et pragmatisme afin, sur le plan politique, de ne pas se couper des classes moyennes et, sur le plan économique, de ne pas détruire l'outil de production (de Hartingh 2003). Cinq classes furent déterminées à partir d'un critère principal, la possession des facteurs de production et donc de moyens de subsistances : terres, bétail (notamment les animaux de trait) et instruments aratoires, recours à de la main-d'œuvre salariée, affermage des terres. Voici en résumé comment ces cinq classes ${ }^{30}$ furent définies à l'époque (Hoàng Ước $1968: 147-161)^{31}$ :

$1^{\circ}$ Les « cố nông » (littéralement " paysans prolétaires », terme souvent traduit par " paysans sans terre ») n'ont ni terre ni instrument, et ont systématiquement recours au salariat pour survivre.

25. Op. cit., Trường Chinh $1994:$ 457-458.

26. Chinh huấn, terme que G. Boudarel traduit par « réforme-instruction » ou « refonte-instruction », méthode chinoise (Cheng Fen) mise au point par Mao Zedong en 1942 et qui fut « entièrement importée de Yan'an (Yenan) jusqu'à son dernier écrou et son mode d'emploi » en 1950 au Việt Nam (1983:47).

27. En parfait accord avec la dialectique maoïste, le déclenchement d'un mouvement populaire devait être le moteur de la réforme agraire et le garant de son équité politique, sociale et économique. $A$ posteriori, Trường Chinh justifia ce choix en arguant du fait qu'il n'existait que deux voies possibles pour réaliser une réforme agraire, quel que soit le pays concerné : une voie pacifique où s'opère un simple transfert du foncier au profit des paysans pauvres et sans terre, mais sans que soit éliminée la classe des exploiteurs; une voie fondée sur la mobilisation et la conscientisation des masses, par nature violente puisqu'inscrite dans le cadre plus général de la révolution prolétarienne et de l'éradication des classes impérialistes et féodales. Seule la seconde voie est à même d'aboutir à l'avènement d'une société socialiste (Trường Chinh 1956:11).

28. Rapport présenté à la III' session de l'Assemblée nationale, $1^{\text {er }}$ décembre 1953 (Hồ Chí Minh $1994: 167)$.

29. Comme l'expliqua le propagandiste Nguyễn Khắc Viện : « Le développement agricole n’a pas été conçu comme une politique indépendante, mais a été intégré à une stratégie révolutionnaire générale qui doit résoudre par un même processus les problèmes de la guerre de libération nationale et ceux de l'édification d'une économie et d'une société nouvelle. [...] La réforme agraire comportant l'abolition de la propriété féodale a libéré les paysans d'un régime millénaire [...] » (1974: 505-506).

30. Cette division en cinq classes est la copie conforme de celle déterminée par Mao Zedong pour les campagnes chinoises (Chen Chi-Yi 1962:219).

31. Les critères et modalités de classification ne figurent pas explicitement dans la loi sur la réforme agraire, parce qu'ils avaient été auparavant précisés par décret (n²39 B/TTg du 5 mars 1953). 
$2^{\circ}$ Les « bà̀n nông » (paysans pauvres) manquent de terre et d'instruments aratoires. Contraints d'affermer leurs terres, ils sont exploités par des taux d'affermage et d'intérêt excessifs et comme main-d'œuvre.

$3^{\circ}$ Les «trung nông » (paysans moyens) ont suffisamment de terres, de bétail, d'instruments aratoires. Ils sont autosuffisants et ne se louent ni n'exploitent les autres.

$4^{\circ}$ Les "phú nông » (paysans riches) ont des terres et suffisamment d'instruments aratoires, qu'ils exploitent pour partie eux-mêmes, mais une source importante de leurs revenus repose également sur la location de main-d'œuvre ou sur l'affermage de leurs terres.

$5^{\circ}$ Les « địa chu » (propriétaires terriens) ont accaparé beaucoup de terres et ne participent généralement pas aux travaux agricoles, dernière caractéristique qui doit permettre de les différencier de la classe des paysans riches. Leurs principaux revenus proviennent de l'usure et de l'exploitation du peuple par l'affermage ou la location de main-d'œuvre. Cette classe est subdivisée en trois sous-catégories en fonction de l'engagement politique et du comportement vis-à-vis du peuple : a) les traîtres, réactionnaires, notables tyranniques; b) les propriétaires ordinaires; c) les propriétaires résistants, parmi lesquels se trouve un petit nombre de personnalités démocrates.

Cette détermination de l'appartenance de classe représentait la clé de voûte de la réforme, puisqu'elle déterminait ceux à qui on allait prendre la terre et dans quelles conditions. Signe du climat de suspicion permanent qu'entretenait le Parti vis-à-vis des propriétaires « dissimulateurs », il fut décidé que la catégorisation de la paysannerie se baserait rétroactivement sur l'état de la propriété détenue en 1949, c'est-à-dire avant que les propriétaires n'aient pu manœuvrer pour échapper à la justice prolétarienne.

Quant au droit de préhension que l'État se réservait sur les terres et biens, il ne dépendait pas directement de la superficie possédée, mais de l'appartenance sociopolitique des propriétaires. Trois régimes furent ainsi déterminés : $1^{\circ}$ la confiscation sans indemnisation, définie comme une forme de sanction à l'égard des contre-révolutionnaires et de ceux qui avaient commis des crimes contre la résistance ou le peuple ${ }^{32} ; 2^{\circ}$ la réquisition sans indemnisation était un droit de saisie qui s'appliquait aux terres publiques, semi-publiques abandonnées ou en friche, aux terres dédiées au culte des ancêtres (hương hỏa : la part du feu et de l'encens) propriétés lignagères et familiales, aux terres du clergé et des pagodes, sachant toutefois qu'une partie pouvait être théoriquement laissée à la personne physique ou morale propriétaire (lignage, église, pagode ${ }^{33}$ ) afin que les activités cultuelles puissent perdurer; $3^{\circ}$ le rachat administratif (vente obligatoire au prix fixé par l'État) était une mesure de faveur envers les propriétaires résistants et les propriétaires n'ayant pas violé la loi, les propriétaires normaux. Mais quel que soit le mode de préhension, il importait de laisser aux propriétaires une partie de leurs biens pour qu'ils puissent subsister grâce à leur propre travail, pour éviter qu'ils ne tombent dans la déchéance et, en même temps, pour qu'ils aient la possibilité de se rééduquer par le travail. Dans ce dispositif, la classe

32. Si la loi prévoyait que certains paysans riches aient pu se rendre coupables des tels actes, auquel cas ils étaient considérés comme des agents de la classe des propriétaires et voyaient à ce titre tout ou partie de leurs terres confisquées, nulle part il n'est fait mention de l'éventualité qu'un paysan moyen ou pauvre puisse être un traître ou un réactionnaire. L'intégrité du dogme, le matérialisme historique, étaient ainsi respectés.

33. «La question des terres appartenant aux églises, pagodes ou autres temples religieux, etc. sera réglée, en vue du partage aux paysans. [...] Les terres et les biens acquis légitimement seront rachetés; les autres catégories de terres appartenant aux communautés religieuses seront réquisitionnées; les terres appartenant aux prêtres, bonzes et autres dignitaires religieux seront jugées en fonction de l'appartenance sociale de leur propriétaire », op. cit., Trường Chinh $1994: 478$. 
des " paysans moyens " jouait le rôle de pivot, leurs terres et autres biens devant être intégralement préservés.

Le principe de la redistribution était donc on ne peut plus simple, tout au moins dans son énoncé : les terres saisies ou rachetées par l'État devaient être partagées entre ceux qui en manquaient ${ }^{34}$, avec un seuil maximum de 0,5 ha par bouche à nourrir, afin de libérer les forces productives de la paysannerie. À ce titre, l'article 34 de la loi (chapitre IV) est essentiel, car il octroie officiellement un droit de propriété plein et entier sur les terres reçues par les bénéficiaires de la redistribution sans qu'ils aient à s'acquitter d'un quelconque dédommagement au profit de leur ancien propriétaire ou de l'autorité publique.

Cette restructuration de la propriété foncière n'était bien évidemment pas uniquement motivée par des considérations de justice sociale, mais visait également une refonte de l'institution villageoise, par le biais de l'abolition des deux formes de propriété collective, les terres publiques et les terres dédiées au culte des ancêtres (huong-hoả), propriété des lignages. Il s'agissait de saper deux fondements essentiels de la cohésion sociale et de la hiérarchisation du pouvoir au village, l'institution lignagère et la répartition périodique des terres publiques représentant les deux pôles moteurs du cycle d'intégration / exclusion dans la société rurale prérévolutionnaire.

\section{Déroulement : de la cohésion à la division}

La réalisation effective de la réforme agraire fut précédée d'une phase préliminaire de formation idéologique des exécutants (cadres politiques) sous la supervision de conseillers chinois ${ }^{35}$. «Sur le plan organisationnel, le travail de préparation comporte la mise en ordre des organisations et la formation des cadres en vue de la réforme agraire. Durant les campagnes de rectification idéologique (chinh huấn) au sein du Parti et de l'Armée, comme lors de la mobilisation des masses pour la réduction de la rente foncière accomplie cette année, nous avons déjà fait ce travail et nous somme en train de le continuer ${ }^{36}$. " Ainsi formés, les cadres politiques organisés en « équipes de réforme agraire » étaient envoyés dans les villages afin de mener la première phase de la réforme, dont l'objectif était d'aboutir à une réduction radicale des rentes foncières, des taux de fermage et des intérêts usuraires, la seconde phase, la classification et la redistribution des terres, ne devant débuter dans une localité donnée qu'une fois réunies les conditions fixées par le Parti et le Comité provincial de la réforme agraire.

Le mouvement fut déclenché au mois d'avril 1953 (décret n 149/SL de Mobilisation des masses pour réaliser la réduction des fermages du 12/04/1953 - résolution $\mathrm{n}^{\circ} 253$ du 20/04/1953 pour l'exécution du décret $\mathrm{n}^{\circ} 149 / \mathrm{SL}$ ), soit sept mois avant le vote de la loi par l'Assemblée nationale $(04 / 12 / 1953)^{37}$ et au moment même où se livrait l'ultime

34. L'article 25 définit les catégories de bénéficiaires par ordre de priorité : $1^{\circ}$ les paysans pauvres, paysans prolétaires, paysans moyens manquant de terres $; 2^{\circ}$ les autres travailleurs ruraux; $3^{\circ}$ les soldats engagés dans la résistance, les familles d'invalides ou des morts au champ d'honneur, les familles de cadres et de fonctionnaires; $4^{\circ}$ les chômeurs et réfugiés dans le pays.

35. «La réforme agraire fut mise en place après que des centaines de conseillers chinois nous eurent présenté l'expérience de leur propre pays. Je me souviens encore des huit séminaires auxquels durent participer tous les cadres. [...] Ils comprenaient de nombreuses séances de discussions de groupe et des débats au cours desquels nous devions apprendre à "développer notre esprit de classe" " (Bùi Tín $1999: 48)$.

36. Op. cit., Trường Chinh $1994: 505$.

37. Cette réalité incontestable rend équivoque et donc discutable l'analyse proposée par B. de Hartingh qui confère une importance de fond aux débats qui eurent lieu à l'Assemblée nationale lors 
bataille de Điện Biên Phủ, et il se poursuivit jusqu'à l'automne 1956. Il se décomposa en huit vagues de réduction des fermages (đợt giảm tô) et en six vagues de réforme agraire (đợt cái cách ruộng đất) ${ }^{38}$. Pratiquement, dès décembre 1953, les deux phases se chevauchèrent pour se confondre lors des $7^{\mathrm{e}}$ et $8^{\mathrm{e}}$ vagues de réduction des fermages et des $4^{\mathrm{e}}$ et $5^{\mathrm{e}}$ vagues de la réforme agraire (Hoàng Ước $\left.1968: 107\right)$.

La première phase devait permettre à l'équipe de réforme agraire d'identifier les propriétaires fonciers traîtres et/ou tyranniques et de « mobiliser les masses » pour qu'elles mènent elles-mêmes la lutte contre les propriétaires fonciers. D'un point de vue sémantique, on doit comprendre la «mobilisation des masses » comme un processus composé de trois étapes successives, copie conforme de celui mené en Chine entre 1950 et 1952 : a) la création d'un courant psychologique dirigé contre les propriétaires terriens ; b) le classement de la population selon les catégories prédéfinies (cf. supra); c) l'expropriation totale et la condamnation des propriétaires terriens dans le cadre de procès populaires conduits sous l'autorité des tribunaux spéciaux de la réforme agraire (ou tribunaux populaires), créés à cet effet en avril 1953 (Fall 1960 : 283). Pour cela, l'Assemblée des représentants des paysans et le Comité exécutif de l'Association des paysans furent désignés comme les organes légaux chargés de l'exécution de la politique agraire du Parti et du gouvernement à l'échelon communal en collaboration avec le Comité administratif et de résistance de la commune, l'Union des femmes et l'Union des jeunes. Concrètement, chacun des cadres de l'équipe de réforme agraire devait s'installer dans un foyer paysan déshérité (pauvre ou sans terre) et prenait le pouls de la situation en pratiquant les « trois avec » (ba cìng) : « travailler avec, dormir avec, manger avec ». Selon le mot d'ordre «bắt rễ, xâu chuô̂i », « en prenant racines » (bắt rễ), le mouvement de « conscientisation » et de diffusion de la politique du Parti et du gouvernement devait se propager par réaction en chaîne (xâu chuối) à l'ensemble des paysans prolétaires, pauvres et moyens. Le but n'était donc pas que les cadres de la réforme partageassent la vie de toutes les familles d'une commune donnée, mais qu'à partir de quelques foyers initiaux, la prise de conscience de classe se diffusât spontanément, se répandît en tache d'huile.

Une équipe arriva dans la commune de Ninh Dân au début du mois de septembre 1953, dans le cadre de la seconde vague de réduction des fermages, lancée en août, et qui se déroula pendant trois mois dans 163 communes des zones libérées (provinces de Phú Thọ et de Thái Nguyên, notamment) :

En 1953, notre Parti a mené une politique de « réduction des rentes foncières et des taux d'intérêt » (giảm tô, giảm tức). Le groupe envoyé dans la commune comprenait M. Khóa (chef), M. Tuyên (sous-chef), M. Vân, M. Bổng, M. Tât

de l'adoption de la loi sur la réforme agraire (2003:50-55), tout en admettant in fine que « ce que les dirigeants recherchaient par l'organisation de la session, c'était uniquement un habillage légal, donc à priori plus contraignant, à des mesures préalablement fixées » $(2003: 55)$. En réalité, la situation ne souffrait aucune ambiguïté : si des avis divergents ont effectivement été émis par certains députés, les jeux étaient faits depuis longtemps. Pour preuve, la décision finale avait été officiellement entérinée le 14 novembre 1953 lors du V $V^{e}$ congrès du Comité exécutif central et du Congrès national du Parti, soit trois semaines avant que la loi ne soit soumise à l'Assemblée (Nguyễn Quang Duy 2007).

38. La vague expérimentale fut menée dans 6 communes entre le 25/12/1953 et le 30/03/1954 : la vague $n^{\prime \prime} 1$ dans 53 communes (25/5/1954-20/09/1954); la vague $n^{\circ} 2$ dans 210 communes (23/10/1954$15 / 01 / 1955)$; la vague $n^{\circ} 3$ dans 466 communes $(18 / 2 / 1955-20 / 06 / 1955)$; la vague $n^{\circ} 4$ dans 859 communes $(27 / 06 / 1955-31 / 12 / 1955)$; la vague $\mathrm{n}^{\circ} 5$ dans 1720 communes $(25 / 12 / 1955-30 / 07 / 1956)$; soit un total de 3314 communes ( 3653 communes après que certaines eurent été divisées) appartenant à 22 provinces (Hoàng Ước $1968: 107-108$ ). 
et d'autres personnes (M. Vân est un artiste peintre, M. Bổng est écrivain). Ils habitaient chez M. Chú Cờ à xóm Chuối [village de Đồng Xa]. Dans le même temps, M. Việt est arrivé dans la commune pour diriger la campagne de réduction des rentes foncières avec des conseillers chinois tels que $M$. Hoàng Tỏa, qui habitait chez M. Khánh [village de Mánh].

Le groupe et la cellule du Parti ont déclenché la lutte. Les résultats obtenus : diminution de $20 \%$ de la rente foncière sur 200 mâu, soit $200 \times 160 \mathrm{~kg}=32$ tonnes de paddy. Pendant cette période, M. Đính ${ }^{39}$ a été exclu du Parti pour corruption, et $\mathrm{M}$. Gấm a été révoqué de son poste de président de la commune pour avoir participé à un repas avec les " exploiteurs ». Le groupe a également déclaré l'abolition des contrats d'anciennes dettes. Pour les nouvelles dettes, les taux d'intérêt furent baissés de 25 à $30 \%$. Le mouvement " giảm tô, giảm túc » a donc permis d'améliorer la position sociale des paysans tout en diminuant la puissance et le pouvoir des propriétaires terriens. » (Ninh Dân 1996 : 36)

Se dessinent, dans ce court récit, quelques signes avant-coureurs des tendances et dérives qui allaient caractériser la réalisation de la seconde phase. En premier lieu, les équipes, qui devinrent par la suite des brigades dirigées par le Comité communal de la réforme agraire, étaient pour le moins hétéroclites, composées de cadres improvisés et hâtivement formés qui n'étaient pas toujours au fait des réalités du monde rural (l'un est artiste-peintre, l'autre écrivain). Ensuite, au contraire de la large alliance de classes prônée à des fins pragmatiques par le président Hồ Chí Minh, l'application mécanique de principes idéologiques et classificatoires sommaires ainsi que la purge des organisations locales et des cellules du Parti étaient déjà de mise en $1953^{40}$. Enfin, dès les premières vagues de cette phase préparatoire, la présence d'un encadrement de conseillers chinois était un fait avéré au niveau communal, soit l'échelon de base auquel fut conduite la réforme, ce qui participa sans nul doute à déformer un peu plus la perception que les cadres pouvaient avoir des réalités de villages qui leur étaient totalement étrangers, à radicaliser leur approche dogmatique du terrain pour tenter de pallier cette méconnaissance. Sur ce dernier aspect, notons que lors de la mise en œuvre de la réforme agraire dans leur propre pays, les cadres chinois avaient déjà dû composer avec la situation réelle dans les campagnes, la structure de la propriété foncière ne présentant pas de caractéristiques latifundiaires comparables à celles qui prévalaient en Russie ou dans certains pays européens (Brenier 1951). Autrement dit, ces cadres arrivaient au Việt Nam avec une solide expérience de " réaménagement " des réalités de terrain et, pour tout dire, de falsification ${ }^{41}$.

39. Afin de nous conformer au principe d'identification des propos, les noms des villageois de la commune de Ninh Dân et des ressortissants des communes alentour ont été volontairement tronqués et réduits au seul prénom des personnes citées.

40. La violence qui avait caractérisé la consolidation de son pouvoir par le Việt-minh au lendemain de la révolution n'avait en fait jamais cessé et les éliminations physiques de membres du Parti n'avaient rien d'exceptionnel (McHale 2004).

41. En contrepoint de certains auteurs européens, sympathisants du régime de Pékin, qui s'enthousiasmèrent dès le début des années 1950 pour les progrès économiques et de justice sociale engendrés par l'application de la réforme agraire en Chine, H. Brenier s'est intéressé à la réalité des chiffres. À partir d'une série d'enquêtes de terrain menées à grande échelle entre 1932 et 1941 par un agronome américain, M. Lossing Buck, il met en doute l'existence d'une grande et d'une très grande propriété foncière « féodale » hégémonique qui se serait constituée en accaparant les terres du peuple et en exploitant les paysans pauvres et sans terre. 
À l'issue de cette étape préliminaire de réduction des fermages, lorsque le niveau d'informations collectées et la prise de conscience du peuple étaient jugés suffisants par l'équipe de réforme agraire, qui en référait alors à sa hiérarchie, la seconde phase était lancée. Elle consistait en la classification de la population suivant les cinq catégories précitées en insistant tout particulièrement sur l'identification des propriétaires fonciers. La classification était réalisée après délibération, par le Conseil des représentants des paysans, sous la supervision des cadres et devait être avalisée par le Comité provincial de la réforme agraire. La loi prévoyait même qu'en cas de différend, la question devait être soumise à l'examen et à la décision d'un tribunal populaire spécialement créé à cet effet dans chacune des régions où se déroulaient la mobilisation des masses et la réforme agraire (Pagniez 1955 : 51).

La commune de Ninh Dân fit partie des 210 communes concernées par la seconde vague de la réforme, qui se déroula du 23 janvier 1954 au 15 janvier 1955. D'après les souvenirs de M. Gấm, l'équipe composée d'une vingtaine de personnes arriva en fin d'année dans la commune, ce que confirme l'histoire du Parti :

À la fin de 1954, un groupe de cadres a été envoyé à Ninh Dân avec à sa tête M. Bổng [il s'agissait du même homme, écrivain de son état, qui avait participé un an plus tôt à l'équipe de réduction des fermages]. Le bureau du groupe siégeait chez M. Mệo à Đồng Xa et comprenait trois conseillers chinois. Le groupe s'est divisé en quatre brigades correspondant aux quatre thôn [villages] [...].

Sous la direction du Comité de la réforme agraire et de la cellule du Parti de la commune, les paysans ont mené une lutte contre les propriétaires terriens. La devise « celui qui laboure a des rizières » a été réalisée. [...] En plus des terres, les stocks de riz et de paddy, les maisons, les objets de culte, les outils agricoles des địa chủ ont été confisqués. (Ninh Dân 1996 : 39)

Le point d'orgue de cette lutte contre les « exploiteurs » était atteint lors de séances d'accusations publiques. Là, la population, au travers de récits des souffrances et brimades endurées, devait fustiger et dénoncer les propriétaires terriens cruels, les notables tyranniques. Le but était avant tout de provoquer un « choc émotionnel collectif », selon l'expression du propagandiste Nguyễn Khắc Viện (1974), par la mise en scène de l'abolition des hiérarchies sociopolitiques où les propriétaires fonciers se livraient à leur autocritique et reconnaissaient leurs crimes, réels ou fictifs (méthode du chỉnh huán). Dans ce dispositif, les cadres de la réforme agraire n'étaient théoriquement que les révélateurs et les catalyseurs du soulèvement prolétarien inscrit dans l'ordre des choses, l'étincelle qui devait mettre le feu aux poudres.

Mais un certain nombre de problèmes vinrent d'emblée gripper le mécanisme. En premier lieu, pour des motifs idéologiques mais aussi parce que leur nombre était limité, les cadres de la réforme reçurent l'ordre de recruter des paysans pauvres et des salariés agricoles n'appartenant à aucun lignage du village afin que la réforme agraire soit appliquée de façon impartiale. De fait, des personnages douteux ou ne jouissant d'aucun respect dans le village furent parfois recrutés dans les brigades de la réforme agraire, ce qui jeta le trouble au sein de la population qui ne comprenait pas que de tels individus soient devenus des piliers de la paysannerie (Boudarel 1991 : 179-180). Mais surtout, alors que la classification utilisée était celle établie en 1937 par Trường Chinh et Võ Nguyên Giáp, la situation avait considérablement évolué entre 1945 et 1953 : pour mémoire, les propriétaires terriens ne détenaient plus officiellement que $43,5 \%$ des terres 
qu'ils possédaient avant la Révolution d'août 1945. Dans ces conditions, il n'est pas étonnant que les cadres de la réforme aient éprouvé dès le départ des difficultés à opérer une stratification de classes, sachant que les critères discriminants étaient eux-mêmes on ne peut plus flous. Le malaise fut tel que lorsque la direction du Parti fut informée, à sa demande, des « doutes qui envahissent l'esprit » (thắc má̀ $)$ qui s'installaient chez les cadres, « elle les qualifi[a] de "droitisme" et décid[a] de noyer le poisson en imposant aux cadres de la réforme agraire l'utilisation de la "méthode du pourcentage" sans toutefois le déclarer publiquement, et pour cause » (Yvon-Trân 1994:23).

Un ratio de $5 \%$ de propriétaires terriens devait ainsi être identifié dans toutes les communes, ratio importé des expériences soviétiques et chinoises (de Hartingh 2003) et qui n'avait pas grand-chose à voir avec les réalités du monde rural nord-vietnamien ${ }^{42}$. En effet, d'après les résultats d'une série d'enquêtes menées entre 1953 et 1956, le pourcentage de propriétaires terriens avait chuté de $3,4 \%$ à $1,9 \%$ entre 1945 et 1949 , celui des paysans riches de $2,2 \%$ à $1,1 \%$ entre 1945 et 1953 (Hoàng Ước $1968: 156-160$ ). Pour atteindre le seuil fatidique des $5 \%{ }^{43}$ et en admettant que le ratio de propriétaires terrien n'évolua plus entre 1949 et 1953, il a donc fallu non seulement assimiler la classe des paysans riches à celle des propriétaires terriens, mais de surcroît y agréger une partie non négligeable des paysans moyens pour combler le déficit de 2 à $2,5 \%$ qui subsistait, ce qui représenta $10 \%$ des foyers de la totalité de cette dernière classe (Vickerman 1986 : 93). Pour réaliser un tel amalgame, les Comités de la réforme agraire durent entretenir un climat de haine au sein de la population et attiser les clivages internes lors des séances d'accusations publiques, où se télescopaient, pêle-mêle, la réalité d'un asservissement depuis trop longtemps contenue, des règlements de comptes personnels, la soif de terres des paysans les plus démunis que ne pouvait apaiser pleinement un déficit foncier chronique.

L'arbitraire et la terreur culminèrent dans les zones nouvellement libérées (les plaines littorales et le delta du fleuve Rouge) lors des $4^{\mathrm{e}}$ et $5^{\mathrm{e}}$ vagues de la réforme agraire, qui concernèrent à elles seules près de $80 \%$ du total de 3314 communes où la réforme fut appliquée. Face à l'ampleur de la tâche à accomplir et sous la houlette de Trường Chinh qui voyait en la mobilisation des masses « une excellente occasion pour renforcer la position politique des cadres et procéder à leur rééducation idéologique » afin de remédier à leur éloignement croissant des réalités du terrain et au " bureaucratisme » ambiant, des cadres appartenant aux organismes centraux et provinciaux furent envoyés dans les villages ${ }^{44}$. Si certains auteurs estiment que la formation superficielle de ces cadres et leur manque d'expérience dans les zones nouvellement libérées ont été à l'origine de bon nombre des erreurs commises, cette dérive semble avant tout être la conséquence logique de l'application radicale et mécanique des principales orientations définies par Trường Chinh en décembre 1953, le Parti disposant à la suite des accords de Genève (20 juillet 1954) de coudées franches pour considérablement durcir sa ligne en donnant à la réforme agraire une tournure avant tout politique ${ }^{45}$. De surcroît, le partage des terres

42. En Chine, dès le lancement effectif de la réforme agraire, les cadres avaient été confrontés à un problème similaire de détermination d'appartenance de classe. Face aux abus qui se révélèrent partout, le gouvernement chinois réagit rapidement en publiant le 4 août 1950, soit un peu plus d'un mois après la publication de la loi sur la réforme agraire (29 juin 1950), un texte très précis intitulé La différenciation du statut des classes dans les campagnes (Grosbois $1952: 46$ ).

43. Un document émanant de la direction du Parti évoque une norme plus prècise de 5,86\% de la population, norme « beaucoup plus élevée que dans la réalité » (Đặng Phong 2005 : 85).

44. Op. cit., Trường Chinh 1994 : 513-514.

45. En novembre 1954, un décret de la direction politique du Comité central du Parti, intitulé « Situation nouvelle, responsabilité nouvelle et politique nouvelle du Parti », souligne que la réforme agraire 
dans le delta du fleuve Rouge, caractérisé par une très forte densité de population et une atomisation extrême du foncier, posait des problèmes autrement plus complexes que la redistribution des terres effectuée dans les anciennes zones libérées, notamment dans la Moyenne région. Il fallut donc avoir recours à de nouveaux outils discursifs. À partir de quelques directives à diffusion interne, indiquant de se «méfier systématiquement des autorités locales et surtout des cellules du Parti » qui seraient toutes minées de l'intérieur par « les ennemis de classes » et par des agents impérialistes à la solde des États-Unis et de ses valets du régime sudiste de Ngô Đình Diệm, les cadres de la réforme agraire finirent effectivement par voir des ennemis partout. Cette paranoïa atteignit son paroxysme à la fin de l'année 1955 et au début de l'année 1956 : la situation semblait alors totalement échapper au contrôle de la direction du Parti.

Scènes d'un tribunal populaire (district de Thanh Ba, province de Phú Thọ) (Source : Faber 1955)

«Une ancienne servante accuse »

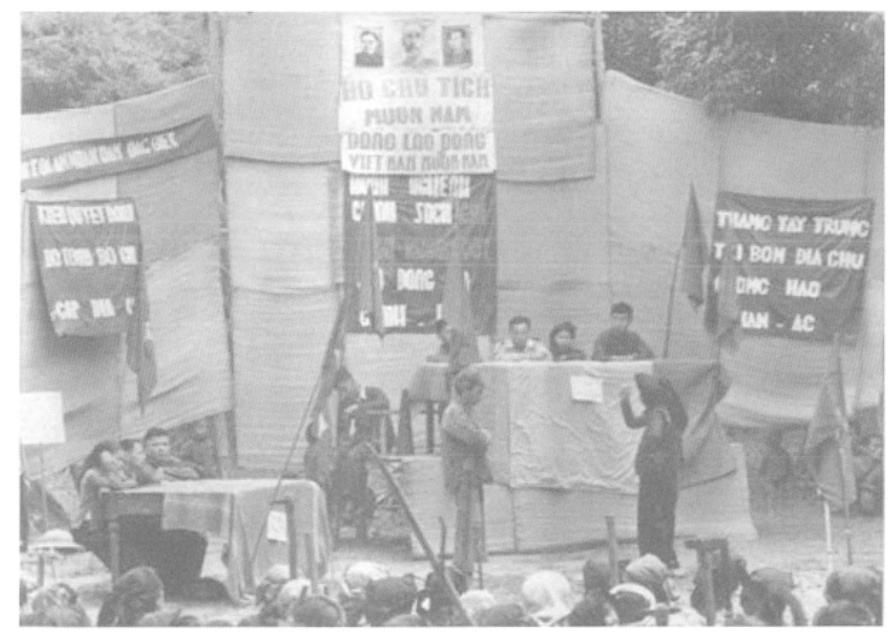

[Eine ehemalige Dienerin klagt an]
«Pourquoi as-tu assassiné ma fille?»

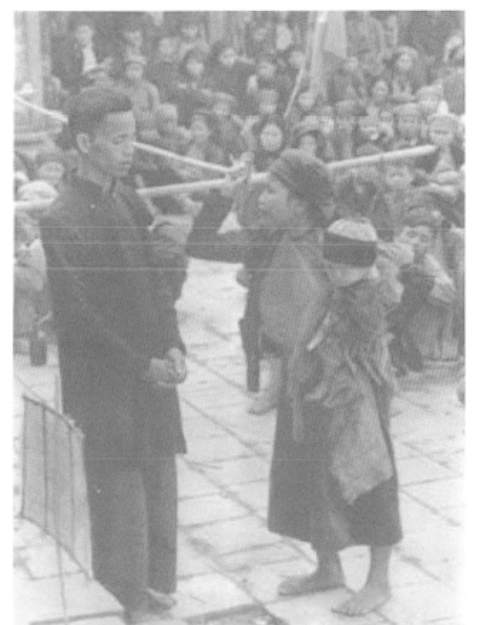

[ Warum hast du meine Tochter ermordet?]

La mise en place des tribunaux populaires, qui remplacèrent progressivement les assemblées paysannes et les séances d'accusations publiques, en fut la matérialisation la plus effrayante et permit d'intensifier et de généraliser la purge des cellules du Parti. Devant une audience de plusieurs centaines voire de milliers de paysans, les prétendus «propriétaires fonciers » et les notables féodaux devaient faire face à leurs accusateurs, des paysans pauvres ou sans terre manipulés par des cadres politiques ${ }^{46}$, et reconnaître

est la priorité du Parti, et qu'après avoir consolidé la paix il faut se concentrer sur la réforme, car elle représente la condition de base pour restaurer et développer l'économie.

46. Nguyễn Văn Ký rappelle les critiques acerbes que suscita la parution en 1993 du roman de Lê Lựu Chuyện Làng Cuội [Histoire du village des menteurs]. Lê Lựu y détaille l'omnipotence du Comité de la réforme agraire qui préside aux séances du tribunal, dont le déroulement est soigneusement préparé à l'avance : « Nous avons trente-six personnes qui sont prêtes à dénoncer, réparties en groupes de la façon suivante : trois dénonceront l'accaparement des terres; quatre, le métayage; six, les mauvais traitements; cinq, les intérêts versés en nature; une, le viol ; quatre, l'espionnage au profit d'ennemis; trois, la participation au Parti nationaliste VNQDD; six, l'exploitation des journaliers; deux, le complot d'assassinat visant Bat afin de faire taire le témoin; deux, le complot anti-réforme. Si l'une d'entre elles s'épuise pendant la dénonciation, le tribunal fera appel à quelqu'un d'un autre groupe pour respecter le temps qui nous est imparti. » (cité par Nguyễn Văn Ký 1997: 185) 
leurs crimes passés : ils étaient humiliés, insultés, battus, les plus cruels d'entre eux pouvant être exécutés sur-le-champ, et leurs terres immédiatement redistribuées. Mais au lieu de susciter un profond sentiment de solidarité entre des paysans enfin libérés de leur asservissement, ces tribunaux spéciaux distillèrent un climat de terreur et d'hystérie collective, car ils n'étaient en fin de compte qu'une mise en scène macabre de la méthode du «chỉnh huấn » (autocritique). L'historien Trầnh Huy I iệu (alias Hải Khách) a décrit en détail la séance d'un tribunal populaire à laquelle il a assisté le 18 mai 1953 dans la commune ( $x \tilde{a})$ de Dân Chủ ${ }^{47}$. Il y dénonce en bloc la bêtise, l'incompétence et l'absence de toute forme de moralité du chef du Comité de la réforme agraire et de ses assesseurs ${ }^{48}$, la violence et la fréquence des coups portés aux diạ chủ par la classe des paysans prolétaires - femmes comprises - érigée en accusateur public, et fustige une parodie de justice populaire dégradante qui dénia tout droit de défense aux accusés ${ }^{49}$ : « il ne semblait pas possible de trouver tortures aussi viles et méprisables que celles qui s'exprimaient sous ce pouvoir populaire démocratique-là » (Trầnh Huy Liệu 2007 : 26). À la litanie des rancœurs souvent légitimes et des frustrations accumulées par les paysans depuis de longues années, se mêlaient la convoitise pour les biens confisqués aux exploiteurs et des stratégies individuelles d'accession au sein de la sphère du pouvoir local. Au final, l'observateur brosse à grands traits un tableau d'ensemble chaotique et incohérent dont la seule finalité semblait être la recherche frénétique de l'humiliation des ennemis de classe afin que, sur les cendres d'un système féodal à jamais révolu, puisse naître « l'Homme nouveau ».

\section{La réforme agraire au village}

Concrètement, quelle forme prit cette lutte dans la commune de Ninh Dân, quelle fut sa réalité? D'un point de vue chiffré, l'histoire officielle du Parti n'a retenu que le nombre approximatif d'une dizaine de paysans riches et une liste nominative de vingt-huit dịa chủ. Parmi ces derniers, quatre furent déclarés « dịa chủ cương hào » (propriétaires fonciers notables tyranniques) et quatre autres furent condamnés à mort, dont trois par des Comités de la réforme agraire d'autres communes du district de Thanh $\mathrm{Ba}$, deux dans la commune de Sơn Cương et un dans la commune de Vũ Ẻn. Cette situation résulte de l'une des particularités de la commune de Ninh Dân, peuplée en grande partie d'immigrants « colonsplanteurs de thé » officiellement enregistrés dans leur village d'origine, dont ils dépendaient administrativement. Ainsi, le cas de certains membres du lignage Đào, rapporté par M. Nức :

47. Les notes inédites rédigées sur le vif par l'auteur ont été récemment (2007) publiées par la revue Xıra \& Nay dans un numéro spécial consacré à la réforme agraire.

48. Le général Bùi Tín insiste également sur la valeur souvent douteuse et très inégale des cadres recrutés, dont la plupart étaient des hommes sans culture et sans morale, avant tout préoccupés par la jouissance de leur pouvoir. «La promotion de ce genre d'individus a eu de graves conséquences à long terme. Un grand nombre d'entre eux sont en effet devenus des cadres du Công An, la force de sécurité publique. Avec l'armée, ce service a toujours été considéré comme le plus important du régime dont il assure la stabilité. » (Bùi Tín 1999: 51-52) Vision amère et désabusée, où l'auteur cite en exemple le cas de Muoi Van, cadre de la réforme agraire promu chef de la police ( $C \hat{n} n g A n)$ de la province de Hòa Binh, individu aux mœurs totalement dépravées et dépourvu de la moindre once de sens du devoir, qui fut condamné à mort en 1982 pour corruption et détournement de fonds.

49. L'cmpreinte de l'expérience chinoise est ici encore évidente, comme l'illustre cette description des tribunaux populaires qui pourrait s'appliquer au cas vietnamien : "Dans les campagnes, surtout pendant les périodes d'agitation nécessaires à la préparation des réformes agraires, les cadres ont usé et abusé du jugement populaire : 2 ou 3 cadres faisant fonction de juges, la foule soutenant l'accusation et formant le jury. Le prévenu était le plus souvent un de ces tyranneaux de village que son âpreté ou sa brutalité avait amené devant le peuple. La condamnation est acquise d'avance : le peuple se venge. » (Grosbois 1952:43) 
Le jeune frère de M. Kiêm, M. Lang, a été déclaré địa chü, mais dans la commune de Mạn Lạn. On lui a tout confisqué, jusqu'aux tables et aux bols. Il avait 6 ou 7 mấu de rizières à Mạn Lạn et environ 10 mâu de thé ici [au village de Hay] et donc devait employer des salariés. Il habitait à Mạn Lạn et c'est sa femme qui s'occupait de la plantation (trai) ici. Elle avait une maison tout près de celle de chez M. Hảo. [...] Alors que son frère [de M. Lang], M. Hiền, qui habitait à Hay et qui avait 4 mâu de rizières et seulement 2 ou $3 m \tilde{\hat{a} u}$ de thé, a été déclaré paysan riche ici ${ }^{50}$.

Sur les vingt-huit địa chủ, vingt-quatre furent déclarés résidents de la commune : neuf dans le village de Hay (incluant les quartiers xóm Lũng Bưởi et xóm Cầu Sắn), trois dans le village de Mánh, neuf dans le village de Đồng Xa et trois dans le village de Sen. Rapporté aux 310 foyers enregistrés en 1954, le pourcentage de propriétaires fonciers s'établit à $9 \%$ de la population, ce qui excède largement le ratio officieusement fixé à $5 \%$. Si, officiellement, une seule condamnation à mort fut prononcée pour acte de trahison, le Comité de la réforme agraire de la commune de Ninh Dân infligea de lourdes peines d'emprisonnement à dix d'entre eux (de 2 à 12 ans de prison). En revanche, aucune information ne précise la situation des autres classes, notamment celle des « paysans riches », ni les superficies et les biens confisqués à chacun des propriétaires terriens. Devant notre insistance, l'auteur de l'histoire du Parti de la commune de Ninh Dân a accepté de nous fournir les données officielles concernant le village de Hay, estimant que seul ce village intéressait notre recherche : 87 foyers furent recensés au moment de la réforme agraire ( 438 bouches à nourrir), pour un total de 146 mâu 5 sào de rizières et 216 mấu 4 sào de plantations de thé.

Tableau n 3 : Terres confisquées aux neuf dịa chü du village de Hay

\begin{tabular}{|c|c|c|c|c|c|c|}
\hline & Lieu & Emprisonnement & Rizières & Thé & Mares & Boufs \\
\hline M. Thư & Hay & 5 ans & $10 m \tilde{\hat{a} u}$ & 15 mâu & 2 sào & 2 \\
\hline M. Hoè & Hay & 11 ans & 20 mẫu & 35 mẫu & 2 sào & 4 \\
\hline M. Nông & xom Lũng Bưởi & 2 ans & 8 mẫu 2 sào & $10 m \tilde{\hat{a} u}$ & 3 sào & 2 \\
\hline M. Trình & xom Lũng Bưởi & & 2 mẫu 5 sào & 5 mẫu & & \\
\hline M. Lâm & xom Lũng Bưởi & & 2 mẫu 7 sào & 5 mẫu & & \\
\hline M. Xuyên & xom Lũng Bưởi & $?$ ans & 5 mẫu 4 sào & $5 m \tilde{a} u$ & 1 sào & 1 \\
\hline M. Chính & xom Cầu Sắn & & 5 mấu 5 sào & $5 m \tilde{a} u$ & 1 sào & 1 \\
\hline $\mathrm{M}^{\mathrm{me}}$ Nở & xom Cầu Sắn & & 4 mẫu 8 sào & $2 m \tilde{\hat{a} u}$ & & 1 \\
\hline M. Thơ & xom Cầu Sắn & & 4 mẫu 3 sào & 3 mẫu & & 1 \\
\hline Total & & & 63 mẫu 4 sào & $85 m \tilde{\hat{u}} u$ & 9 sào & 12 \\
\hline
\end{tabular}

Ces donnés chiffrées détaillées mettent en lumière l'importante variabilité des situations qu'embrassait le terme générique « địa chủ thường " (propriétaire foncier normal), seul le premier de la liste ayant été classé « địa chủ cuờng hào » (propriétaire foncier notable tyrannique). En première lecture, on constate que les terres confisquées, puis redistribuées, représentèrent $43 \%$ des rizières exploitées dans le village et $40 \%$ des plantations de thé. De plus, comme il ne s'agit que des surfaces confisquées, il est nécessaire d'y ajouter la

50. Entretien du 12/03/1997. 
superficie de rizières laissée aux familles pour subvenir à leurs besoins (théoriquement 3 sào $\times 6$ bouches à nourrir $\times 9$ địa chủ). On obtient ainsi, pour les seules rizières, un taux d'appropriation avoisinant les $55 \%$ et, partant de là, une forte légitimation de la redistribution équitable prônée par la réforme, puisque l'écrasante majorité des foyers ( 78 sur 87 ) ne possédait que $45 \%$ des terres. Mais une analyse au cas par cas permet de constater que les deux plus gros propriétaires du village détenaient près de la moitié des superficies confisquées, proportion qui atteint $60 \%$ des rizières et $70 \%$ des plantations de thé si l'on y ajoute le troisième propriétaire de la liste. Cette tendance à la concentration est encore plus nette lorsqu'on rapporte les terres saisies dans l'ensemble de la commune aux propriétés de M. Hiện, le «propriétaire foncier typique » de Ninh Dân, selon l'expression consignée dans l'histoire du Parti :

Après trois mois de lutte, les paysans ont confisqué aux địa chủ de la commune : 271 mấu 7 sào de rizières, 276 mâu 5 sào de thé, 30 mấu de palmierrônier, 6 mấu 4 sào de mares et 83 buffles et bœufs, qui ont été distribués aux paysans pauvres et moyens. Parmi les địa chủ, il y a eu un cas typique, M. Hiện à Đồng Xa. On lui a confisqué : $148 m \tilde{\hat{a} u}$ de thé, 97 mâu de rizières, $4 m \tilde{\hat{a} u}$ de mares, 50 buffles et bœufs. (Ninh Dân 1996 : 39)

À lui seul, il détenait donc $35 \%$ des rizières, $50 \%$ des plantations de thé et $60 \%$ des mares et du bétail confisqués dans l'ensemble de la commune de Ninh Dân pendant ces « trois mois de lutte ». La dimension politique de la réforme apparaît ici sans équivoque possible, dimension qui poussa les cadres dépêchés sur place à " fabriquer » des propriétaires fonciers pour atteindre les quotas fixés. En comparaison de la classification établie au début des années 1930 par P. Gourou fondée sur la propriété foncière (cf. supra), six des neuf địa chủ (propriétaires fonciers) identifiés dans le village de Hay étaient au mieux des « propriétaires moyens » et plus sûrement des «petits propriétaires ». On est par ailleurs surpris par le pourcentage élevé de địa chủ (propriétaires fonciers) dans le village de Hay, qui avoisine $10 \%$ du total des foyers, soit deux fois plus que le ratio généralement admis. A contrario, selon les villageois, seules trois personnes ont été classées « paysans riches », alors qu'elles possédaient des superficies comparables aux " propriétaires terriens » les plus modestes : la fluidité entre classes était de facto une réalité. Intervenait ici un second critère essentiel de classification : le comportement des propriétaires vis-à-vis du peuple. Il pouvait, selon les propres termes de M. An, « faire basculer un paysan moyen ou riche dans la classe des exploiteurs (dia chü) », sachant cependant que l'auteur de l'histoire du Parti s'est empressé de nuancer cette affirmation en soulignant que «le problème est que les cadres chinois nous ont fait appliquer des critères qui n'étaient pas adaptés : comme il fallait $5 \%$ de địa chủ, on en a déduit que tous ceux qui dépassaient un certain seuil de terres étaient des dịa chü ${ }^{51}$, redonnant ainsi la primauté au critère de surface. Certes, il est vrai qu'aux rizières venaient s'ajouter les plantations de thé et les salariés nécessaires à leur mise en valeur. Sur ce point, il convient également de revenir à la réalité des chiffres : en dessous de 5 mâu $(1,8$ ha), la mise en valeur des plantations de thé était principalement assumée par la famille du planteur, l'emploi de la main-d'œuvre salariée se limitant à des périodes ponctuelles, notamment lors de la pleine saison de récolte.

51. Entretien du 14/10/1996. 
Lors des entretiens avec d'anciens paysans et cadres de l'époque, l'évocation de la réforme agraire suscita un profond mutisme chez la plupart des interlocuteurs, hypothéquant du même coup toute possibilité d'en restituer un tableau d'ensemble à l'échelle de la commune, d'en établir une chronologie événementielle. Ce n'est pas tant l'oubli qui s'est opposé à cette tentative de reconstitution, bien qu'un demi-siècle se soit écoulé, mais le sentiment de malaise et de trouble que ravivaient nos questions, tant chacune des personnes rencontrées semblait s'être efforcée de mettre cette période entre parenthèses. Oblitération, voire falsification de la mémoire imposée par le fait que les ennemis à combattre n'étaient plus, comme hier, des étrangers au village et au pays, mais des acteurs de la vie quotidienne, des parents, des voisins, qu'ils aient été respectés ou haïs. De la puissante cohésion née de la lutte contre la force d'occupation face à laquelle ils se devaient de faire bloc, les paysans se trouvèrent brutalement entraînés dans une spirale de divisions internes et de désagrégation des réseaux sociaux. Au final, si la compilation de fragments d'histoires et de bribes de souvenirs ne forme pas une trame historique cohérente, elle s'avère être un témoignage précieux du processus de radicalisation des antagonismes sociaux et politiques locaux suscités et manipulés par le Parti. Au travers du récit de sa propre expérience, $M$. Thịnh, né en 1926, en donne un aperçu saisissant :

Mes parents étaient " tueurs de cochons ", ils ne possédaient pas de terres de colline ni de rizières : ils n'en reçurent qu'au moment de la réforme agraire. En 1954, j'ai été déclaré " paysan sans terre » (cố nông) et mon grand frère, boucher, a été déclaré petit commerçant (tiều thương). [...]

Avec ma femme, bien que nous soyons salariés des địa chủ et déclarés « cố nông ", nous n'avons reçu que 6 sào de terres de colline et 4 sào de rizières. C'était peu par rapport aux autres [du village], car nous n'avons pas voulu dénoncer les địa chủ. Comme nous n'étions pas membres du Parti et que nous n'avons pas participé aux réunions [séances d'accusation], les cadres nous ont distribué moins de terres. Et pourtant, les responsables de l'Association des paysans du village, $M$. Đức, son jeune frère et aussi $M$. Ngân, qui faisaient partie de la brigade de la réforme, étaient d'anciens salariés, comme nous. [...]

En revanche, si on dénonçait les địa chủ, on était déclaré «người tót » [littéralement «bonne personne »] et on recevait plus de terres : il suffisait de raconter ou d'inventer des fautes et des violences commises par les propriétaires fonciers. [...] C'est comme ça que le père de M. Bảo [le voisin immédiat de M. Thịnh] fut déclaré « paysan pauvre » (bần nông) alors qu'il avait presque 2 mâu de rizières pour 5 bouches à nourrir. C'est qu'en 1952, il avait acheté 1,3 mấu de rizières à $M$. Hoè [classé địa chủ] au moment où beaucoup de gens du village vendaient leurs terres du fait de l'augmentation importante des taxes qui fut appliquée cette année-là. Mais on n'en a pas tenu compte [au moment de la réforme], ce qui fait que le Comité [de la réforme agraire] lui a attribué de nouvelles rizières, car par rapport à sa situation d'avant 1952, il ne possédait pas la moyenne de 3 sào par bouche à nourrir que chacun devait recevoir. Il possédait également 2,5 mẫu de thé et 1,5 mẫu de terre en friche ${ }^{5 \hat{2}}$.

52. Entretien du 31/03/1997. 
Au-delà de l'imprécision des limites de classes, la nature des critères pris en compte favorisa non seulement une plus grande fluidité dans la classification, mais généra également des inégalités lors de la distribution des terres entre les foyers. La détermination de la taille de la propriété foncière tout d'abord, critère apparemment objectif puisque quantifiable, admit d'importantes variations, ne serait-ce qu'en fonction de la période de référence sur laquelle se basait l'évaluation. Ainsi, si les terres acquises après 1949 ne furent pas retenues dans le calcul des surfaces détenues par le père de $M$. Bảo, il semble que dans d'autres cas, c'est la situation foncière au moment de la réforme qui prévalut, comme l'indique M. Tài :

Mon père n'avait pas assez de terres ni de rizières pour être déclaré propriétaire terrien et il n'employait que rarement de la main-d'œuvre. Si on employait entre 200 et 500 công [un công: un jour de travail] par an, on était classé " phú nông " (paysan riche) et au-dessus de 500 công par an, địa chi (propriétaire foncier). [...] Quand j'étais petit [M. Tài est né en 1933], il avait 20 mấu de plantation de thé sur les collines, à peu près 5 mẫu de rizières et plusieurs buffles. Mais mon père a vendu beaucoup de terres au fur et à mesure après l'application de la réduction des taux de fermage. C'est pour ça que lors de la réforme, ma mère [le père de $M$. Tài est décédé peu de temps auparavant] a été déclarée "paysan moyen qui manque [de rizières] » (trung nông thiếu). [...] Même si des gens avaient vendu leurs terres, on tenait compte de leur comportement avec les salariés. C'est pour ça que certains avaient plus de terres que les dịa chü, mais ils respectaient les salariés et les autres paysans et ils avaient eu un comportement héroïque depuis la révolution, comme le père de $\mathrm{M}$. An qui n'avait que 7 ou 8 sào de rizières, mais presque 10 mâu de thé. [...] Le problème de $M$. Hoè et de $M$. Thư est que tous les paysans les ont dénoncés comme des propriétaires cruels ${ }^{53}$.

S'agissant du dernier critère évoqué, l'engagement révolutionnaire et politique, son appréciation était de fait confiée au seul jugement du Comité de la réforme agraire, ce qui ouvrait la porte aux arrangements locaux de toutes sortes, comme l'a laissé entendre M. Thịnh et le confirme M. Vóc :

Mon père a participé aux activités révolutionnaires. [...] En 1954, il faisait partie du groupe de la réforme agraire [du village de Hay]. Il aurait peut-être dû être déclaré địa chü, mais comme il était révolutionnaire et vice-président de la commune [1954-1958], il n'a même pas été classé « paysan riche », mais « paysan moyen ». Il avait 6 mẫu de rizières, 4 buffles et 4 mâu de thé et c'est d'ailleurs ce qu'il a donné à la coopérative en 1958. [...] Alors que d'autres qui possédaient 4 ou 5 mâu de rizières et 4 ou 5 mâu de thé ont été déclarés địa chü. Mais c'était différent, car ils avaient des salariés en permanence chez eux ${ }^{54}$.

La gestion discrétionnaire et le clientélisme local eurent parfois des conséquences dramatiques. Bien que la population de la commune de Ninh Dân eût échappé à la violence aveugle des tribunaux populaires, le climat de tension extrême dans lequel se déroula

53. Entreticn du 02/04/1996.

54. Entretien du 13/03/1997. 
la réforme agraire déboucha sur au moins deux actes désespérés symptomatiques d'un dérèglement profond des modalités d'autocontrôle et de régulation sociale du groupe : les suicides de M. Muồi du village de Mánh et de Mme Thị Tạ du village de Sen, classés propriétaires terriens (le premier était membre du Parti) et qui furent tous deux réhabilités trois ans plus tard ${ }^{55}$. La suspicion systématique des Comités de la réforme agraire, téléguidés par le Parti, quant à la sincérité de l'engagement des élites locales et des propriétaires fonciers dans la lutte anticoloniale et révolutionnaire permirent ainsi de légitimer l'épuration au sein des organisations du pouvoir villageois et communal par des opérations de manipulation et de falsification du passé.

\section{Erreurs, terreur et campagne de rectification}

Officiellement, c'est au cœur de la cinquième et ultime vague de la réforme agraire (été 1956) que le Parti prit conscience des graves erreurs commises et entreprit d'en réformer l'organisation (Trường Chinh 1956). Le signal de la rectification fut lancé le 18 août 1956 par Hồ Chí Minh dans une lettre ouverte à la population. Après avoir insisté sur la victoire que constituait la réforme agraire pour l'ensemble du peuple grâce à la juste politique du Parti et du gouvernement ${ }^{56}$, le président déclara : " Le statut de ceux qui furent injustement classés comme propriétaires terriens ou paysans riches doit être révisé. Les droits et l'honneur des membres du Parti, des cadres et des autres qui ont été injustement accusés doivent être restaurés. L'unité est notre force invincible. Dans le but de consolider le Nord pour en faire une base solide de lutte pour la réunification du pays, le peuple entier doit être profondément et étroitement uni sur la base de l'alliance ouvriers-paysans dans le Front de la Patrie du Việt Nam » (cité par Hy Van Luong 1992 : 194). Le message est on ne peut plus clair : seule l'unité retrouvée du peuple, la réconciliation et la confiance restaurée dans le Parti pourront permettre d'affronter l'épreuve à venir, la lutte pour l'unification du pays. Pour cela, il était indispensable au préalable de panser les plaies.

Emprisonnements, déportations, tortures et exécutions ont bel et bien existé dans toutes les communes où fut appliquée la réforme agraire. Dans une entrevue donnée à Ernst Utrecht en Indonésie, Hồ Chí Minh aurait admis 10000 morts (Houtard \& Lemercinier $1984: 18$ ), mais il reste actuellement impossible de vérifier cette allégation. Certaines sources occidentales évoquent 50000 à 100000 morts (Kleinen 1999 : 98), chiffres qui paraissent exagérés pour $\mathrm{P}$. Brocheux, qui retient un nombre de « 10000 à 15000 personnes exécutées à tort » (2000:169), sachant que cette comptabilité macabre spéculative passe sous silence les nombreux cas de suicides de paysans et de cadres locaux, actes ultimes de désespoir que seules les enquêtes de terrain sont à même de révéler (cf. supra). Quoi qu'il en soit, le traumatisme fut profond et le mécontentement vira çà et là à la dissidence, voire à la rébellion dans diverses localités catholiques du Nghệ An (Boudarel 1983 : 73).

55. Dans la commune de Sơn Dương (province de Phú Thọ), Hy Van Luong rapporte le cas de cette femme activement engagée auprès du Việt-minh et qui s'est suicidée après qu'elle fut classée « propriétaire terrien normal », effaçant ainsi d'un trait de plume son passé patriotique (1992: 190). Dans le village de Mộ Trạch (340 foyers en 1954), parallèlement à l'exécution d'un « propriétaire terrien " reclassé «paysan riche » lors de la campagne de rectification, A. Fiorucci a recensé les suicides de six villageois, dont trois étaient membres du Parti (2006 : 293).

56. L'intitulé de cette lettre est en soi révélateur de la stratégie adoptée par le Parti consistant à relativiser les erreurs commises au regard de la victoire acquise : Lettre aux compatriotes des campagnes et aux cadres à l'occasion du succès fondamental de la réforme agraire dans le Nord Vietnam (texte intégral reproduit en annexe de l'article de P. Brocheux, 1981 : 237-274). 
Si l'on ne pouvait ressusciter les disparus, on se devait de laver l'humiliation qui avait sali leur honneur et celui de leur famille, de réexaminer les classifications et de rétablir dans leurs droits (moraux et civiques) et leurs biens (indemnisation) ceux qui furent injustement spoliés et condamnés.

Dans le courant de l'automne 1956, le pouvoir dut prendre dans l'urgence un certain nombre de mesures. En septembre, les privilèges spéciaux accordés aux Comités de la réforme agraire furent abolis et les tribunaux spéciaux supprimés (Chaliand 1968:33-34); en novembre, après une longue et pénible élaboration débutée au mois de septembre, le $\mathrm{X}^{\mathrm{e}}$ plénum du Comité central du Parti publia une autocritique et présenta ses excuses à la population injustement maltraitée et accusée; conséquence immédiate, Trường Chinh quitta ses fonctions de secrétaire général du Parti et fut remplacé temporairement à ce poste par Hồ Chí Minh, puis par Lê Duẩn, les Comités de la réforme agraire étant supprimés à tous les échelons le mois suivant (Đặng Phong 2005 : 89-90). Deux membres éminents du Bureau politique furent également exclus, Hoàng Quốc Việt et Lê Văn Lương, ainsi qu'un membre du bureau exécutif du Comité central, Hồ Viết Thắng.

Alors que la colère grandissait et que des familles indûment accusées se rassemblaient devant le bâtiment du Comité central du Parti en face du Palais présidentiel, les protestataires furent conviés le 29 octobre 1956 à se rendre au grand stade de Hà Nội, où le général Võ Nguyên Giáp, le héros de Điện Biên Phủ au prestige toujours intact, donna une conférence d'information au cours de laquelle il résuma l'autocritique du Parti. Après avoir rappelé les succès de la réforme agraire ${ }^{57}$, le général Giáp admit que de graves erreurs avaient été commises, ce qui avait limité le succès de la lutte antiféodale et suscité de nombreuses difficultés. S'il n'y a pas lieu de rendre compte ici de la liste des erreurs identifiées par le Comité central du Parti, certaines d'entre elles méritent d'être brièvement énoncées : graves atteintes à la liberté religieuse dans les régions catholiques ${ }^{58}$; manque de crédibilité de chiffres artificiellement gonflés, notamment au point de vue des facteurs de production possédés par les « ennemis de classe »; instauration d'un climat de défiance vis-à-vis des " paysans moyens »et de franche hostilité vis-à-vis des « paysans riches »; accusation sans discernement des " propriétaires fonciers » alors que certains d'entre eux étaient d'authentiques patriotes; négation systématique des mérites acquis par les organisations anciennes et les cellules du Parti pendant la période de résistance ${ }^{59}$.

57. «Maintenant, au Nord, la classe des propriétaires fonciers est renversée. La terre est désormais la propriété des paysans. Plus de 10 millions de paysans ont leurs propres terres et sont devenus les maîtres de la campagne; plusieurs milliers de cadres ont été formés; le régime de la propriété féodale est à jamais aboli. C'est là un changement très important d'un point de vue économique, politique et social. [...] Si ce changement a été possible, c'est que la ligne politique du Parti est fondamentalement juste » (Võ Nguyên Giáp cité par Hoàng Ước 1968 : 109-110).

58. Cet ostracisme avéré envers les catholiques fut à l'origine de mouvements de rébellion dans les provinces du Nghệ An et de Thanh Hoá : « Car dans ces zones, aux excès "ordinaires” s'ajoutaient des restrictions importantes à la liberté de culte, que dénoncera violemment le Comité national de Liaison Catholique lors d'une conférence organisée d'urgence par le gouvernement à Hà Nội du 14 au 16 novembre 1956. [...] Des erreurs commises pendant la réforme agraire ont violé la politique de liberté religieuse du Parti Lao Động et du gouvernement et ont empiété sur les droits sacrés des fidèles » (Fall 1960 : 119). Il faut rappeler que la liberté de croyance et de culte a été inscrite dans la constitution de 1946 et qu'elle fut réaffirmée par plusieurs décrets $(04 / 01 / 1953 ; 14 / 06 / 1956)$.

59. «Cependant, n'ayant pas confiance dans les "anciennes organisations" dans lesquelles il y avait pourtant de bons paysans pauvres et des ouvriers agricoles, voyant l'ennemi partout et frappant sans discernement, surévaluant parfois de façon notable les superficies cultivées et les capacités productives des terres, il leur est arrivé de léser ou même de frapper certains paysans pauvres et ouvriers agricoles " (Võ Nguyên Giáp, 1956, cité par Lê Thành Khôi 1978 : 60). Pour Moise (1980) cité par Vickerman 
Mais une telle introspection critique avait évidemment sa propre limite, puisqu'elle se devait de respecter l'orthodoxie de la ligne marxiste-léniniste. La rhétorique du Comité central du Parti consista à imputer la responsabilité des dérives aux cadres de la réforme agraire et à son organisation défectueuse sur le terrain ${ }^{60}$ ainsi qu'à son application mécanique sur le modèle chinois qui ne tint pas suffisamment compte des spécificités vietnamiennes, seule attaque à l'encontre de la direction de la réforme qui valut à Trường Chinh d'être remercié ${ }^{61}$.

Ce dernier publia en novembre 1956 un texte autocritique où cette référence au modèle chinois est notablement absente, texte dans lequel l'échec du mouvement de mobilisationconscientisation des masses et de son encadrement par les brigades de la réforme agraire ${ }^{62}$ est présenté comme la cause principale des erreurs commises, tout en reconnaissant une part de responsabilité de la direction centrale ${ }^{63}$. En revanche, le principe et la nature des stratifications de classes, dont les limites n'avaient cessé de s'estomper depuis 1945, ne furent nullement remis en cause, pas plus que ne fut relevé le déficit chronique de terres disponibles, sans même évoquer l'ambiguïté intrinsèque d'une réforme dont les objectifs politiques et sociaux portaient en eux les germes des excès à venir ${ }^{64}$.

(1986: 103) : «Il n’est pas sûr que les injustices commises contre les membres du Parti, les propriétaires fonciers et les paysans riches aient à elles seules justifié une campagne de rectification. Mais le nombre de paysans moyens et de paysans pauvres injustement attaqués fut suffisamment large pour rendre une campagne de rectification obligatoire ».

60. Cette analyse partielle est toujours la thèse défendue par l'historiographie officielle, à l'image de l'historien et député Dương Trung Quốc qui, dans un article paru en 2007, met en avant la conjonction d'erreurs concrètes d'organisation et d'une orientation déviationniste « gauchiste » $(2007: 7)$.

61. Ironie de l'histoire, dans sa critique de la politique agraire conduite depuis la Révolution, Trường Chinh avait dénoncé dès 1953 le même déviationnisme : « d'autre part, nous avons appliqué mécaniquement l'expérience de la révolution chinoise pendant la guerre anti-japonaise. » Op. cit., Trường Chinh $1994: 456$.

62. «L'erreur ne se situe pas dans le mouvement de mobilisation des masses, mais principalement parce qu'au fil du temps, les cadres des brigades n'ont pas sincèrement cru à la mobilisation des masses et au pouvoir des masses; [ils ont cru] à la contrainte, à la torture et les arrestations ont progressivement remplacé la mobilisation des masses; ils n'ont pas suffisamment utilisé les mesures [prônées] par le gouvernement » (Trường Chinh $1956: 12$ ).

63. Si Trường Chinh insiste à de nombreuses reprises sur le caractère fondamentalement juste et équitable de la ligne politique du Parti, il admet en ces termes un manque de préparation et d'encadrement de la direction centrale : «C'est pourquoi le Parti a des imperfections : une partie des organes dirigeants (le Comité Central et le Bureau politique) n'a pas assez enquêté, ses recherches ne se sont pas suffisamment appuyées sur la réalité de la situation vietnamienne, les vérifications n'ont pas été suffisamment poussées, le travail a manqué de coordination; et une partie des organes centraux en charge de l'exécution des opérations (précisément le Comité central permanent de la réforme agraire et le Comité central de l'organisation du Parti) n'a pas fait un exposé exact et à temps [de la situation], n'a pas découvert à temps les erreurs et proposé des solutions politiques et des mesures adéquates pour $\mathrm{y}$ remédier » (Trường Chinh $1956: 17$ ).

64. L'instauration d'un climat de haine était programmée depuis au moins 1953, comme le montre le paragraphe du rapport de Trường Chinh intitulé Provoquer des clivages parmi la classe des propriétaires fonciers, rassembler toutes les forces antiféodales dans la mobilisation des masses, à tel point qu'il prit soin de préciser, conscient de ce que cette politique avait toutes les chances de provoquer : " Il faut réprimer à temps leurs agissements [ceux des propriétaires fonciers traîtres, réactionnaires et des notables cruels] et les traduire devant des tribunaux populaires d'exception pour les juger et les punir comme ils le méritent. Mais il est formellement interdit de procéder à des arrestations et à des mises à mort illégales, de recourir aux sévices et à la torture ou à tout autre mauvais traitement corporel »op. cit., Trường Chinh 1994: 494. 
Il est par ailleurs improbable que la direction du Parti et le Comité central de la réforme agraire n'aient pris conscience de la gravité des dérives que dans le courant de l'été 1956. Dans un courrier adressé le 19 juin 1953 au camarade Trường Chinh, le député Đặng Thai Mai (Interzone IV, Nghẹ Tĩnh) enjoignit les autorités centrales de prêter attention aux graves dysfonctionnements dont il était témoin : " mais si, parallèlement, le Parti et le gouvernement pouvaient dépêcher des missions de contrôle dans les villages pour examiner les raisons de la colère de la population et des troubles [thắc mắc] provenant de l'exécution de la politique générale [de la réforme agraire] et, sur cette base, mettre de l'ordre face à toutes les erreurs relevées sur le terrain, alors je suis sûr que cela aurait un impact très positif sur la prise de conscience et la confiance du peuple $»(2007: 27)^{65}$. Au-delà de cet exemple particulier, les directives données par le Bulletin interne de la réforme agraire destiné aux cadres chargés de sa mise en œuvre montrent en creux que les autorités centrales étaient parfaitement informées des pratiques violentes qui avaient cours dans les villages. Dans le bulletin du 19 février 1956, il est précisé que « pour éviter d'avoir recours à la torture, il faut connaître à fond la politique de différenciation de classes. Ce n'est pas nécessaire d'atteindre le seuil de $5 \%$ de địa chủ ». Face à la généralisation de la torture, le même périodique, en date du 25 février 1956, publia l'intégralité d'un rappel à l'ordre du président Hồ Chí Minh dénonçant son usage : « La torture est une méthode barbare, c'est une pratique impérialiste, capitaliste et féodale utilisée contre les masses et contre la révolution. [...] C'est pourquoi il ne faut absolument pas utiliser la torture, son usage est contraire à la politique du Parti, du gouvernement et aux manières révolutionnaires » (Đặng Phong 2005 : 86). Les plus hauts dignitaires du régime étaient donc informés. Mais disposaient-ils des relais suffisants et des moyens adéquats pour réagir? Autrement dit, faut-il donner foi à la version officielle de la perte de contrôle mise en avant par les autorités centrales pour expliquer les dérapages du processus sur le terrain? En référence aux travaux menés par Shawn McHale sur la période 1945-1958 et qui concluent que « l'État Việt-minh était faible » (McHale 2004 : 98), on serait enclin à accorder un certain crédit à cette version.

Pour sa part, dans la biographie qu'il consacre à Hồ Chí Minh, P. Brocheux souligne que le président avait pleinement conscience des dérives engendrées par l'application de la réforme et, partant de là, il attribue son attitude complaisante, ou tout au moins sa passivité, à la prégnance du modèle chinois, matérialisée par la présence de milliers de conseillers sur le terrain, et à sa crainte d'être accusé par le puissant voisin du Nord de ne pas faire preuve de fermeté politique (2000:173-174). En d'autres termes, malgré ses appels au respect de la dignité humaine et à l'arrêt de l'usage de la torture, sûrement sincères bien que tardifs, le bouleversement total de l'ordre social et politique qu'incarnait la réforme agraire devait être mené jusqu'à son terme sans être entravé par les inévitables

65. Dans ce même courrier, l'auteur portait à la connaissance de Trường Chinh un cas emblématique des dérives en cours, en des termes policés qui ne dissimulaient cependant pas son indignation et sa profonde tristesse. Il s'agissait du traitement réservé à l'un des descendants de Phan Bội Chau (1867-1940), lettré patriote et figure nationale de la résistance anticoloniale (fondateur du mouvement nationaliste Việt Nam Duy Tân Hội [Ligue pour la rénovation du Việt Nam]), premier héros collectif de l'ère révolutionnaire, qui fut intégré au panthéon national et pour ainsi dire « nationalisé » par le régime de Hà Nội (de Tréglodé 2001 : 64). L'épouse de l'un des deux petits-fils du grand homme venait d'être classée địa chi parce qu'elle possédait un mấu de rizières $(0,36$ ha) affermé. Et d'expliquer en substance que, dans la mesure oủ le petit-fils en question se trouvait actuellement (1953) en mission dans le Nord (chef d'une brigade, sans autre précision), son épouse, responsable depuis longtemps de l'Union des femmes de la commune et mère de trois enfants scolarisés, n'avait eu d'autre choix que de placer sa terre en fermage, ce qui lui permettait à peine de subvenir aux besoins vitaux de sa famille. 
drames humains qu'il ne manquait pas d'engendrer. C'est pourquoi Vũ Đình Dinh Huỳnh, l'ancien secrétaire particulier de Hồ Chí Minh, considère ce dernier comme « le principal responsable [de la tragédie qui accompagna la réforme agraire], [et] que Trường Chinh ne fut que le bouc émissaire " (cité par Brocheux 2000 : 174; Nguyễn Minh Cần 2002). C'est également la thèse que défendent deux auteurs, Nguyễn Minh Cần (ancien haut dirigeant du Parti) et Nguyễn Quang Duy, à partir du cas emblématique de Mme Nguyễn Thị Năm (alias Cát Thành Long), qui fut la première personne déclarée « địa chú ác ghê » (propriétaire tyrannique) à être exécutée à la fin de l'année 1953. Emblématique à plusieurs titres : d'une part, cette première exécution fixa dès le lancement de la vague expérimentale (25/12/1953-30/03/1954) le caractère violent que devait prendre la réforme agraire et constitua l'acte originel légitimant l'éradication physique de la classe des exploiteurs; d'autre part, en éliminant une femme, le Parti démontrait avec force l'inflexibilité de la ligne de la justice prolétarienne quelle que soit la condition humaine et sociale de l'accusé ; enfin, et peut-être surtout, la personnalité exceptionnelle de Mme Nguyễn Thị Năm, qui avait hébergé et nourri les plus hauts dirigeants du Parti pendant leur exil forcé dans la province de Thái Nguyên ${ }^{66}$, marqua le coup d'envoi de la traque acharnée aux propriétaires fonciers « faux résistants » et «patriotes de circonstance ». Une véritable cabale contre Mme Nguyễn Thị Năm fut orchestrée dès juillet 1953 par le Parti via le journal Nhân Dân, l'organe de presse officiel du Parti ${ }^{67}$ : Hồ Chí Minh était donc parfaitement au courant de la situation et, malgré ses affirmations, il ne fit rien pour la sauver pas plus qu'il n'intervint en faveur des milliers d'innocents qui furent exécutés durant la réforme (Nguyễn Minh Cần 2002).

En fin de compte, « le tournant de 1956 s'opère donc bien plus dans la forme que sur le fond » (Boudarel 1983: 74) et ce ne fut qu'une parenthèse rapidement refermée, comme fut écrasé en 1958 le mouvement contestataire Nhân văn Giai phẩm ${ }^{68}$, du nom de la principale revue qui s'en fit l'écho, rassemblement d'intellectuels et d'artistes qui avaient cru que la démarche courageuse d'autocritique menée par le Parti ouvrait un réel espace de liberté d'expression dont la revue fut le principal relais. Car si entreprise critique il y eut, le Parti entendait garder le monopole de son énoncé et de sa portée afin de prévenir tout risque de débordement idéologique susceptible de remettre en cause l'esprit du maoïsme qui guidait ses orientations politiques. La condamnation infamante qui fut infligée à l'universitaire et avocat Nguyễn Mạnh Tường vint rappeler à tous, et au milieu intellectuel en particulier, le principe inébranlable selon lequel « si le Parti peut se tromper, seul le Parti peut reconnaître et corriger ses erreurs ». À la demande du secrétaire général du Front de la Patrie, Nguyễn Mạnh Tường avait rédigé un rapport sur la réforme agraire qui fut présenté le 30 octobre 1956 lors du congrès du Front. La liberté de ton et la virulence d'un texte qui interpellait ouvertement la légitimité du régime et les pratiques du Parti ${ }^{69}$ valurent à son auteur d'être déclaré coupable, même

66. Nguyễn Minh Cần (2002) cite : Trường Chinh, Hoàng Quốc Việt, Phăm Văn Đồng, Lê Đức Thọ, Lê Thanh Nghị, Lê Giàn...

67. Dans un réquisitoire implacable daté du 21 juillet 1953, le Nhân Dân accusa Mme Nguyễn Thị Năm et ses deux garçons (tous deux engagés dans le Việt-minh avant 1945) d'avoir provoqué directement et indirectement la mort de 260 paysans, d'avoir torturé et maltraité des dizaines d'enfants et d'orphelins, etc. (texte intégral reproduit par Nguyền Quang Duy 2007).

68. Également dénommé mouvement des «Cent Fleurs », par analogie à la campagne lancée en Chine par Mao Zedong en 1956 (voir Boudarel 1991).

69. Extraits choisis par nous : «Quand on lance le slogan "Même si dix innocents doivent périr, cela vaut mieux que de laisser échapper un seul ennemi", ce slogan n'est pas seulement gauchiste et absurde 
s'il n'y eut pas de procès au sens juridique du terme. Il fut destitué de toutes ses fonctions politiques et professionnelles et condamné à une forme d'indignité sociale et nationale, à une « mort lente » (Nguyễn Văn Ký 2004). Et si l'élimination physique des dissidents n'a jamais été appliquée à grande échelle comme en URSS, en Chine ou au Cambodge, les pires méthodes d'anéantissement moral et social ont été employées à l'encontre des intellectuels et des artistes ayant pris part au mouvement contestataire des "Cent Fleurs » (Brocheux 2000 : 172).

La campagne de rectification des erreurs proprement dite, c'est-à-dire celle qui toucha directement la population, démarra en début d'année 1957 sous la conduite de « Comités de rectification des erreurs ». Hồ Chí Minh envoya le général Giáp faire campagne à travers tout le pays; c'est donc ce dernier qui dut affronter la fureur et les reproches du peuple et la colère des cadres rescapés de la réforme. On essaya tant bien que mal de réparer les erreurs et d'indemniser les personnes lésées. Or la tâche s'avéra des plus complexes, car pour redonner la terre aux paysans injustement spoliés, il fallait la reprendre à ceux à qui on venait de la distribuer, source inévitable de nouvelles récriminations et d'inégalités foncières.

Quant aux indemnisations, elles ne couvrirent qu'une infime partie des préjudices subis, puisqu'aucune ligne budgétaire spéciale n'avait était ouverte à cet effet dans le budget national. Interpellé par un député sur l'existence d'une telle ligne budgétaire, Nguyễn Duy Trinh répondit au nom du gouvernement par la négative et ajouta que « les paysans auront à se faire des concessions les uns aux autres, à négocier et à résoudre le problème entre eux » (cité par Fall 1960 : 284), signe supplémentaire du cynisme de l'État-Parti qui s'affranchissait ainsi de toute implication concrète dans l'entreprise de réparation des graves dérèglements dont il était pourtant à l'origine. Mais c'est surtout le réexamen de la classification et la réhabilitation de familles injustement calomniées et condamnées qui permirent d'apaiser quelque peu les profondes rancœurs et l'hostilité vis-à-vis du Parti.

La situation sociale et économique dramatique des " propriétaires fonciers » dont la classification fut déclarée erronée appelait les solutions les plus urgentes. Les chiffres officiels du Comité central de rectification des erreurs sont éloquents : 72263 dị chủ furent réhabilités sur un total de 109816 cas étudiés, soit les deux tiers de cette classe, sans que l'on sache combien d'entre eux avaient été exécutés, jetés en prison, ou s'étaient suicidés ${ }^{70}$; pour la classe des « paysans riches », la proportion des réhabilitations s'éleva à $82 \%$, soit 51003 des 62192 cas étudiés (Đặng Phong $2005: 85$ ). À la lecture de tels chiffres, la qualification d' " erreurs commises " s'apparente à un doux euphémisme et l'emploi des termes « victoire, succès » dans la lettre ouverte adressée par le président

mais il est encore contre-révolutionnaire. La mise en application de ce slogan a discrédité la révolution et nombre de révolutionnaires. [...] Quand on amène un blessé grave à l'hôpital, ce qu'on cherche à savoir en premier, c'est à quelle classe il appartient. Soigner un propriétaire signifie qu'on n'a pas de ligne politique. Le laisser mourir prouve qu'on en a une. Pourquoi ces choses monstrueuses ont-elles pu se produire? Parce que la politique a envahi tous les domaines de notre conscience, et nous a fait perdre jusqu'au sens de l'humanité; elle nous détourne des vérités. [...] Si notre vie intérieure est agitée par l'inquiétude de voir les tenants du pouvoir commettre des abus, c'est parce qu'il nous manque un régime de droit bien clair, que les devoirs et les responsabilités de chacun ne sont pas mentionnés, que le citoyen n'a pas de droit, ni les moyens d'exprimer ce qu'il pense. Ainsi la rectification des erreurs doit s'orienter vers un véritable régime de droit, un véritable régime démocratique. » (cité par Nguyễn Văn Ký 2004 : 222-223)

70. Interrogation qui concerne au premier chef le sort des 20493 « propriétaires fonciers notables tyranniques " (địa chủ curòng hào gian ác) qui furent réhabilités sur un total de 26453 cas étudiés, soit une proportion d'erreur de $77,4 \%$. 
Hồ Chí Minh à la population (cf. supra) paraît quelque peu indécent pour les victimes : il aurait été plus approprié de parler d'une faillite complète du processus de classification et d'une falsification à grande échelle des réalités socio-économiques et politiques du pays, alors même que la réforme agraire dans sa dimension politique devait être un acte fondateur de la RDVN mettant fin à la « crise sociale et économique de l'époque colonialiste et féodale » (Đào Thế Tuấn \& Lê Đức Thịnh, cités par Fiorucci 2006 : 295).

Dans un article polémique paru dans la revue Văn Sü Địa en février 1957, soit trois mois seulement après l'autocritique du Comité central du Parti, Hải Khách (pseudonyme adopté par l'historien Trần Huy Liệu) livra une analyse au vitriol stigmatisant l'aveuglement idéologique des responsables nationaux et locaux de la réforme agraire qui les avait amenés à faire un amalgame systématique entre la taille de la propriété foncière et l'attitude politique de leurs propriétaires vis-à-vis de la révolution et de la population, attitude invariablement dénoncée comme d'essence « féodale, impérialiste et cruelle ». Après avoir rappelé que le Việt Nam était un pays essentiellement agricole et rural dont les structures sociopolitiques et économiques villageoises avaient été profondément affectées par un siècle de colonisation française à peine achevé, il souligna avec force que la classe des propriétaires fonciers ne pouvait être assimilée à celles d'autres pays (Chine et URSS), ce qui fut pourtant le cas pendant la réforme. Cet appel au discernement peut paraître tardif et pour ainsi dire «confortable », puisque coïncidant avec le déclenchement de la campagne de rectification, mais l'auteur l'avait déjà lancé une première fois en mars 1954 sous la forme d'un courrier adressé à Hoàng Quốc Việt, l'un des cadres du Comité central de la réforme agraire. Son opinion, à l'époque, était que, parallèlement à une frange minoritaire de " grands propriétaires fonciers féodaux valets de l'impérialisme », la classe des địa chú était principalement composée de petits propriétaires patriotes qui aimaient leur pays, ce qui impliquait en retour modération et retenue dans le traitement qui leur serait réservé (Trần Huy Liệu 1954 : 16). Il n'a manifestement pas été entendu.

Indéniablement, comme partout ailleurs dans le pays, cette campagne fut accueillie avec un profond soulagement par la population de la commune de Ninh Dân. En avril 1957, une équipe de cadres du district de Thanh Ba fut envoyée dans la commune afin de procéder au réexamen de la classification et des jugements prononcés trois ans plus tôt par le Comité de la réforme agraire. En recoupant les rares informations fournies par 1'histoire du Parti, qui se montre fort discrète sur le sujet et pour cause, et celles collectées lors des entretiens, il est possible de procéder à une évaluation chiffrée : parmi les vingt-cinq ressortissants de la commune originellement déclarés địa chủ, au moins quinze furent réhabilités et reclassés comme paysans moyens (neuf) ou riches (six) ${ }^{71}$. Quelquesuns purent recouvrer une partie de leurs biens confisqués : ainsi M. Quý Hậu, du village de Đồng Xa, put-il récupérer sa maison ainsi qu'un mẫu de rizières. D'autres se virent attribuer une nouvelle habitation, la leur ayant été vendue entre-temps, comme ce fut le cas pour M. Noãn du village de Mánh. Mais la plupart n'a bénéficié que d'une réparation morale : faute de mieux, on leur restitua "leur nom et leur honneur». M. Oanh (né en 1911, village de Sen), qui contribua matériellement à la résistance (d'après l'histoire du Parti, il fit don d'un bœuf, de 200 kilos de paddy, de plusieurs centaines de đồng) et qui

71. Dans le village de Sơn Dương, sur les trente-six chefs de foyer originellement classés « propriétaires terriens ", seuls sept furent confirmés après la rectification, alors que cinq étaient reclassés paysans riches et quatorze paysans moyens (Hy Van Luong 1992 : 194-195). Autre exemple, dans les quatre villages qui composent actuellement la commune de Tân Hồng et qui comptaient à l'époque officiellement 280 foyers inscrits, vingt-huit ont été déclarés « propriétaires terriens », soit exactement $10 \%$, et dix-huit ont été reclassés à l’issue de la campagne de rectification (Fiorucci 2006 : 290). 
hébergea à partir de 1949 une escouade de l'APV, ne cacha pas lors d'un entretien son ressentiment tenace malgré les années écoulées :

Entre 1946 et 1947, j'ai été chef de la police du premier Comité administratif et de résistance de la commune de Nguyễn Trãi [fusion éphémère des communes de Ninh Dân et de Yên Nội] et j'ai occupé ce poste jusqu'en 1951 pour la commune de Ninh Dân [scission des deux communes en 1948]. J'ai participé au Việt-minh et je me suis battu dans des opérations contre les Français à Phú Thọ. J'ai adhéré au Parti dès 1950. [...] Eh bien j'ai été déclaré địa chủ (propriétaire foncier) par le Comité de la réforme agraire et exclu du Parti. On m'a tout pris : 12 mấu de thé, 1 mấu de rizières, ma maison, mes objets de culte. Il ne me restait rien! [...] J'ai été accusé par les villageois [du village de Sen] d'être brutal et d'avoir battu des salariés. C'était faux, mais c'est parce qu'ils ne m'aimaient pas. [...] Plus tard, on a réhabilité mon nom, mais on ne m'a rendu que mon honneur, pour le reste je n'ai eu droit qu'à quelques sào de rizières ${ }^{72}$.

Aux problèmes concrets et souvent insolubles que posait la rétrocession à leurs propriétaires de biens et de terres depuis redistribués et exploités par d'autres familles du village, s'ajoutaient des considérations d'ordre politique, comme l'analysa a posteriori $\mathrm{M}$. Chí :

Ma famille a été déclarée famille de «paysans riches », mais mon père ne possédait que peu de terres, car auparavant il avait un atelier de séchage de thé et il était commerçant : il était riche en argent. On ne lui a supprimé que ses papiers et nous avons pu rester dans notre maison. Dans d'autres cas, le gouvernement rachetait la maison des paysans riches et on leur attribuait une nouvelle parcelle d'habitation ainsi que suffisamment de rizières pour vivre. [...] En 1957, lors de la politique de rectification, on a remis les papiers de ses biens à mon père. Pour les autres paysans riches et les propriétaires terriens réhabilités, on devait théoriquement leur rendre leurs maisons et leurs rizières. Mais ici [au village de Hay], ça ne s'est presque jamais passé comme ça, car le gouvernement avait déjà planifié la création des coopératives, ce qui arriva en $1958^{73}$.

Effectivement, la campagne de rectification intervint tardivement dans les villages, alors que la décision de procéder à la collectivisation graduelle de l'agriculture était déjà prise. Cette politique agraire s'était concrètement traduite, depuis 1956, par des mesures dirigistes d'incitation à la création de groupes d'entraide institutionnalisée, étape préliminaire à l'établissement des coopératives agricoles socialistes qui devaient mutualiser les moyens de production des 2300000 petites exploitations paysannes générées par la réforme agraire, dont la majorité n'était économiquement pas viable sur le moyen terme (cf. infra). En ce sens, la campagne de rectification s'apparenta plus à une mesure d'apaisement et de réconciliation dans une société rurale profondément divisée et traumatisée par le « grand bouleversement » (long trời lở đất) que fut la réforme agraire qu'à une réelle volonté de réparation matérielle des erreurs commises et des préjudices subis. Face aux deux grands défis à venir, la collectivisation de l'agriculture et la réunification du pays, le Parti se devait impérativement de regagner la confiance d'une paysannerie incrédule et méfiante à son égard.

72. Entretien du $15 / 10 / 1997$.

73. Entretien du 03/05/1997. 


\section{Bilan et impact de la réforme agraire : quelques points de repère}

Tous les auteurs qui se sont intéressés de près ou de loin à la question de la réforme agraire donnent des chiffres qui se déclinent sur le mode « avant-après ». Leur comparaison fait apparaître d'importantes variations en fonction des sources mobilisées, du niveau de sympathie des auteurs vis-à-vis du régime de Hà Nội, et des bornes historiques prises en compte : selon que l'on retient 1945 ou 1953 comme point de départ, la proportion des terres redistribuées varie quasiment du simple au double et permet donc d'affirmer avec plus ou moins de force la légitimité et la nécessité de la réforme agraire. Le tableau ci-dessous en donne trois exemples :

Tableau $\mathrm{n}^{\circ} 4$ : Dotation moyenne de terre par bouche à nourrir avant et après la réforme agraire

\begin{tabular}{|c|c|c|c|c|c|c|}
\hline & \multicolumn{2}{|c|}{$\begin{array}{l}\text { d'après Chaliand } 1968 \text { : } \\
\text { 33* }\end{array}$} & \multicolumn{2}{|c|}{$\begin{array}{l}\text { d'après Vo Nhân Tri } \\
1960: 361\end{array}$} & \multicolumn{2}{|c|}{$\begin{array}{l}\text { d'après Lê Thành Khôi } \\
(1978: 56 \text { et } 68)^{* *}\end{array}$} \\
\hline & $\begin{array}{c}\text { avant } \\
\left(\text { en } m^{2}\right)\end{array}$ & $\begin{array}{l}\text { après } \\
\left(\mathrm{en} \mathrm{m}^{2}\right)\end{array}$ & $\begin{array}{c}\text { avant } \\
\left(\text { en } \mathrm{m}^{2}\right)\end{array}$ & $\begin{array}{c}\text { après } \\
\left(\text { en } \mathrm{m}^{2}\right)\end{array}$ & $\begin{array}{c}\text { avant } \\
\left(\text { en } \mathrm{m}^{2}\right)\end{array}$ & $\begin{array}{c}\text { après } \\
\left(\text { en m }^{2}\right)\end{array}$ \\
\hline $\begin{array}{l}\text { Propriétaires } \\
\text { fonciers }\end{array}$ & 6779 & $\begin{array}{l}825 \\
(-88 \%)\end{array}$ & 6499 & $\begin{array}{l}1010 \\
(-84 \%)\end{array}$ & 10093 & $\begin{array}{l}738 \\
(-92 \%)\end{array}$ \\
\hline Paysans riches & 2116 & $\begin{array}{l}2159(\approx \\
0 \%)\end{array}$ & 2141 & $\begin{array}{l}2135(\approx \\
0 \%)\end{array}$ & 6393 & $\begin{array}{l}1547 \\
(-76 \%)\end{array}$ \\
\hline $\begin{array}{l}\text { Paysans } \\
\text { moyens }\end{array}$ & 999 & $\begin{array}{l}1565 \\
(+57 \%)\end{array}$ & 1151 & $\begin{array}{l}1665 \\
(+45 \%)\end{array}$ & 1372 & $\begin{array}{l}1610 \\
(+17 \%)\end{array}$ \\
\hline $\begin{array}{l}\text { Paysans } \\
\text { pauvres }\end{array}$ & 343 & $\begin{array}{l}1372 \\
(+400 \%)\end{array}$ & 455 & $\begin{array}{l}1431 \\
(+314 \%)\end{array}$ & 431 & $\begin{array}{l}1437 \\
(+333 \%)\end{array}$ \\
\hline $\begin{array}{l}\text { Paysans } \\
\text { prolétaires }\end{array}$ & - & 1421 & 199 & $\begin{array}{l}1528 \\
(+768 \%)\end{array}$ & 124 & $\begin{array}{l}1413 \\
(+1100 \%)\end{array}$ \\
\hline
\end{tabular}

* Source : statistiques du Comité de la réforme agraire de la RDVN.

** Source : situation dans 3653 communes en 1945, sur un total de 5673 (Kinh tế Việt Nam 1945-1960, p. 49).

Par rapport à la situation d'avant 1945 (chiffres de Lê Thành Khôi), c'est donc un bouleversement radical de la structure de la propriété foncière qui a été opéré. Les effets sur la production agricole furent immédiats. La réforme, dans sa composante économique, c'est-à-dire une redistribution plus ou moins égalitaire des moyens de production aux paysans, revitalisa pour un temps l'agriculture de la RDVN et marqua une pause dans le processus de détérioration du ratio grain/population et une nette amélioration des conditions de vie de la frange la plus pauvre de la population (Nguyễn Đức Truyên 1993 : 22), comme le montre la courbe ci-dessous.

Pendant la période 1955-1960, la production rizicole connut une nette amélioration et l'accroissement dépassa celui de la population (Beresford $1988: 130$ ).

Cette embellie est d'autant plus remarquable qu'elle se fit par un accroissement continu des rendements moyens, de 13,7 quintaux/ha en 1954 à 22,9 quintaux/ha en 1959 , sans que les systèmes culturaux et techniques ne subissent de transformation ou d'amélioration notable (Barbier et al. 1997 : 83). Apparait ici une des caractéristiques récurrentes de la période contemporaine postrévolutionnaire : l'indéniable impact de la volonté de la paysannerie sur l'évolution de la production agricole, notamment par le biais d'une intensification du travail et d'une optimisation des pratiques culturales. La période collectiviste allait, a contrario, en donner la preuve. 
Reconstitution de l'évolution de la production de paddy par tête au Việt Nam (source : Đào Thế Tuấn $1998:$ 14)

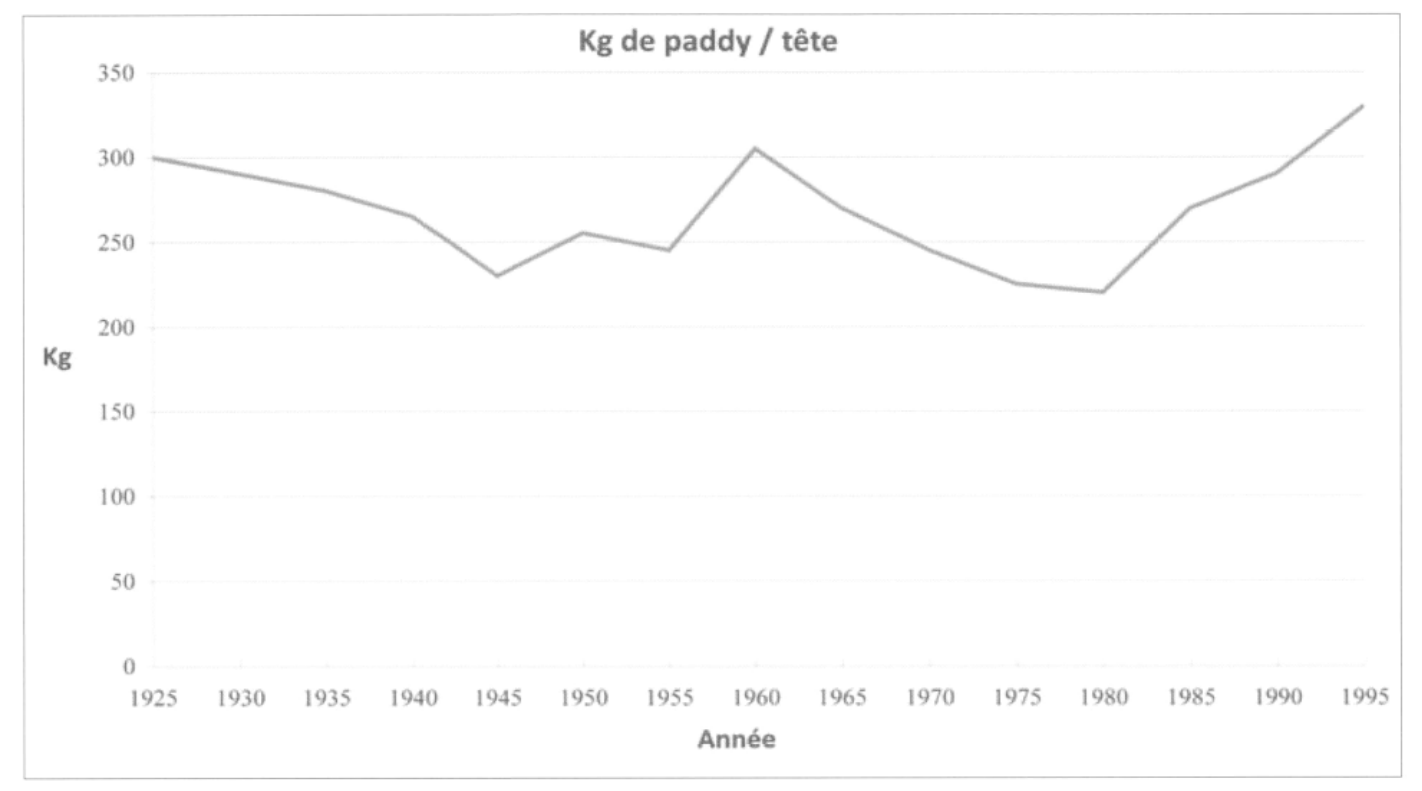

Bien que les chiffres avancés par les services statistiques de l'État doivent être considérés avec circonspection, la production rizicole nationale passa officiellement de 2,55 millions de tonnes de paddy en 1954 à 5,19 millions de tonnes en 1959, accroissement pour partie conséquence de l'augmentation de près de $20 \%$ des superficies cultivables effectivement mises en valeur : 1,89 million d'hectares en 1954 pour 2,27 millions d'hectares en 1959 (Vickerman 1986 : 111). L'inversion des flux d'échange de produits agricoles fut symptomatique de cette embellie : alors que la RDVN était importatrice nette de paddy en 1955 (près de 200000 tonnes), elle exporta annuellement, à partir de 1957, 70000 tonnes en moyenne. Ce redressement se répercuta logiquement sur les caisses de l'État, qui put accroître ses prélèvements en paddy de $68 \%$, par le biais des livraisons obligatoires, le volume de la taxe agricole restant stable, aux alentours de $10 \%$ de la production (Yvon-Trân 1994 : 42). La réforme agraire eut donc un impact positif sur la production et le niveau de vie de la population, ce qui était un de ses objectifs affichés. Mais, en quelques mois, elle fit voler en éclats l'unité qui s'était forgée et cristallisée autour du Việt-minh et bouleversa durablement le paysage social et politique des villages, à l'image des transformations engendrées dans la commune de Ninh Dân.

\section{Le « grand bouleversement » ou la volonté de refonte des sociétés villageoises}

\section{Le nouveau visage du pouvoir communal}

Si la réforme agraire avait indéniablement une portée idéologique, qui explique l'acharnement du Parti à la voir conduite jusqu'à son terme, reste à savoir comment cette dimension politique s'est traduite dans les faits au niveau local. Pour cela, nous avons reconstitué les trajectoires des ressortissants de la commune de Ninh Dân qui furent détenteurs du pouvoir de la veille de la Révolution d'août 1945 au lendemain de la campagne de rectification. Les résultats sont présentés sous forme d'un tableau synoptique qui fait la synthèse de différentes sources : le «huoong ước » de la commune (coutumier villageois 
" rénové » rédigé au début des années 1940), l'histoire du Parti et la série d'entretiens menée entre 1996 et 1998 . Le découpage chronologique en colonnes restitue la succession des postes occupés dans les trois institutions majeures du pouvoir local : le Comité révolutionnaire provisoire qui prit en fin d'année 1945 le nom de Comité administratif et de résistance (décret $n^{\circ} 63,22 / 11 / 1945$ ) pour s'appeler, avec la paix recouvrée, Comité populaire $^{74}$; la cellule du Parti (fondée en 1948); la section communale du Việt-minh puis du Liên Việt.(Voir le tableau n ${ }^{\circ} 5$ de la structure du pouvoir en annexe)

La première colonne fait état de la situation à la veille de la Révolution (1941-1942) complétée, lorsque nous disposions d'informations, des éventuelles anciennes fonctions de lý trương et de phó ly $\dot{y}^{75}$ occupées par les futurs cadres locaux du nouveau régime. Les trois dernières colonnes dressent un bilan synthétique : $1^{\circ}$ de la classification et des exclusions du Parti prononcées par le Comité de la réforme agraire (1953-1954); $2^{\circ}$ des éventuelles révisions apportées lors de la campagne de rectification des erreurs (1957); $3^{\circ}$ de l'évolution de la situation des élites locales après 1957 (post-réforme). Bien que persistent un certain nombre d'incertitudes et de lacunes que les entretiens n'ont pas permis de combler, cette synthèse met en lumière des tendances significatives.

En première analyse, on est frappé par la fluidité qui apparaît entre les structures du pouvoir pré- et postrévolutionnaire (1945-1953) : il n'y a pas eu rupture dans le recrutement des élites locales, mais continuité. Cette situation s'explique tout autant par la volonté d'union nationale prônée à l'époque par le Parti dans le bras de fer que le Việt-minh était en train d'engager avec la France coloniale que par l'impossibilité de renouveler d'un seul trait l'ensemble de la classe dirigeante locale puisque, de facto, rares étaient les paysans pauvres ou prolétaires ayant reçu le minimum d'éducation requis. Il s'agissait donc de composer avec l'ancien régime, ce qui n'était pas en soi une hérésie pour peu qu'on abandonnât la vision par trop manichéenne d'une classe de notables inféodée en bloc au pouvoir colonial. Ainsi, M. Thư, le dernier lý trương de la commune, a-t-il été nommé à la tête du premier Comité révolutionnaire provisoire de la commune de Ninh Dân, quelques jours après avoir été symboliquement destitué de ses anciennes fonctions; parcours surprenant, que suivit également $\mathrm{M}$. Cóc, ancien phó lý du village de Đồng Xa devenu le premier président de l'éphémère commune de Đồng Tâm avant d'être nommé président de la commune de Ninh Dân (1947-1949). Et si, dès le lendemain de la Révolution, le Parti prônait l'abolition " des superstitions et des coutumes rétrogrades », cela n'empêcha pas « le maître de cérémonie » (chıoơng bạ) du temple du village de Mánh, M. Hanh, ancien lý trương, d'être nommé vice-président. Pragmatisme et continuité donc, qui furent également de mise dans les sphères politiques et militaires locales. L'un des trois fondateurs de la cellule du Parti, qui en fut le secrétaire de 1950 à 1954, était un ancien phó lý devenu caissier du Comité administratif et de résistance de 1945 à 1947, tout comme deux chefs de la section communale du Việt-minh étaient d'anciens lý trương.

Les cadres de la réforme agraire portèrent un coup d'arrêt définitif à ce continuum politique qu'ils jugèrent être de la compromission réactionnaire avec le régime féodal ${ }^{76}$.

74. Les domaines de compétence de ces organes d'administration locale, leur autonomie relative ainsi que les modalités de recrutement de leurs dirigeants ont fluctué en fonction de l'évolution des rapports de force entre le gouvernement révolutionnaire et le pouvoir colonial. G. Ginsburgs en proposa en 1962 une analyse détaillée.

75. En l'absence d'une correspondance sémantique satisfaisante, le terme lý trương peut être traduit par « maire » de la commune et phó lý par « adjoint au maire».

76. La trajectoire du « propriétaire foncier notable tyrannique » (địa chủ curờng hào), Nguyễn Văn Bính (alias B.), au cœur de la séance d'accusation du tribunal populaire de la commune de Dân Chủ 
Seul le prolétariat était apte à diriger le peuple vers le socialisme. Selon M. An, le Comité de la réforme agraire de la commune exhorta chacune des quatre brigades en charge de l'un des quatre villages à se pencher avec attention sur le cas des anciens lý trướng, sujets desquels « il fallait se méfier » : et, de fait, quatre des neuf địa chủ identifiés dans la zone du village de Hay avaient exercé cette fonction par le passé. En substance, M. An précisa :

Comme mon père avait été lý trưởng, le Comité de la réforme a interrogé des paysans à Ninh Dân ainsi que des paysans de la commune de Vũ Ẻn [planteur originaire de cette commune]. Mais comme les paysans ont dit qu'il était bon et qu'il ne maltraitait pas les salariés, il a été déclaré paysan moyen (trung nông) alors qu'il possédait $8 m \tilde{\hat{a}} u$ de thé et $1 m \tilde{\hat{a}} u$ de rizières ici [au village de Hay] et d'autres rizières à Vũ Ẻn ${ }^{77}$.

En cela, le parcours des élites locales de la commune de Ninh Dân destituées lors de la réforme agraire présente de fortes similitudes avec celui des autorités et agents communaux du village de Mộ Trạch : $76 \%$ des villageois classés propriétaires terriens ou paysans riches y avaient exercé ou exerçaient toujours en 1955 une fonction dans l'administration communale ou cantonale (Fiorucci $2006: 471$ ).

Mais ce n'est là qu'un des aspects que prit la rupture de 1953-1954. La plus grande fracture fut sans nul doute la purge de la cellule du Parti de la commune. Ses trois fondateurs, qui tous exerçaient ou avaient exercé des responsabilités dans le Comité administratif et de résistance, en furent exclus : l'un fut accusé de corruption, les deux autres furent soupçonnés "d'avoir entretenu des relations avec la classe des exploiteurs ». Au total, dix membres sur les seize que comptait la cellule en 1953, soit les deux tiers, subirent le même sort, épuration qui fut associée à une nouvelle vague d'adhésions où sept membres, classés paysans prolétaires ou pauvres, furent admis ${ }^{78}$.

L'épuration affecta non seulement les anciens dirigeants et les địa chü, dont on ne sait trop en définitive si c'est leur classification qui entraîna leur exclusion ou l'inverse,

méticuleusement décrite par Trần Huy Liệu (cf. supra), présente des caractéristiques similaires (continuité de l'exercice du pouvoir brutalement interrompue par la réforme agraire) : «B. a été lý trirơng, puis chef de canton adjoint pendant la période coloniale. À la suite de la Révolution d'août 1945, il fut nommé président du Comité administratif et de résistance de la commune puis du district. Il était également membre de la première cellule du Parti créée ici. » (2007 : 23-24)

77. Entretien du 14/10/1996.

78. À l'échelle nationale, un rapport du Bureau politique du mois de novembre 1956 estime que la réorganisation complète du Parti pendant les $4^{\circ}$ et $5^{c}$ vagues de la réforme a affecté $85 \%$ des cellules, dont le nombre est passé de 2876 à 3777 , et celui des membres de 150000 à 178000 . Dans le même temps, 84000 membres furent exclus, soit $47,1 \%$ des effectifs. Le bilan des nouvelles adhésions s'est donc élevé à 112000 , soit un taux de renouvellement de $63 \%$. En substance, le rapport conclut que cette réorganisation a eu des effets contraires à ceux attendus : désorganisation du Parti, perte de cohésion au sein du Parti et avec l'administration, et défiance de la population (Đặng Phong 2005 : 87 ).

Le même rapport du Bureau politique dénonce « une des composantes de la pensée idéologique de la réforme agraire fondée sur l'esprit de propriété des paysans, [qui] a conduit à placer les paysans prolétaires (Scố nông) au-dessus de tout, à établir les paysans prolétaires au sein du Parti et même au-dessus du Parti. [...] Augmenter la part des paysans prolétaires dans les cellules du Parti à hauteur de $97 \%$ [des effectifs] démontre l'aberration de cette composante idéologique. » (Đặng Phong 2005 : 87). À titre de comparaison, une enquête réalisée en 1953 dans 22 villages montra que les cellules villageoises du Parti ne comptaient que 3,7\% de paysans pauvres; $13,5 \%$ des membres étaient des propriétaires, $15 \%$ des paysans riches, $61,4 \%$ des paysans moyens et $3,5 \%$ des «petits bourgeois » (de Hartingh 2003 : 32). Mais une fois encore, cette critique virulente des autorités centrales leur permit de se désolidariser de la mise en œuvre sur le terrain de la ligne politique qu'elles avaient pourtant elles-mêmes tracée. 
mais aussi les nouvelles élites en cours d'ascension qui, à peine entrées dans le sérail, s'en voyaient éjectées ${ }^{79}$. Ainsi, M. Nguyện, nommé simultanément président du Comité populaire de la commune et membre du Parti en 1954, fut exclu du Parti la même année, «car après vérification on le soupçonnait d'être réactionnaire ». Le cas de $M$. Gấm est symptomatique de cette période d'instabilité. Adhérent au Parti depuis le début des années 1950 et président de la commune depuis novembre 1952, il se présentait comme une figure emblématique de la nouvelle élite montante : ancien salarié agricole et à ce titre représentant de la classe des prolétaires exploités qui avait su prendre le pouvoir en renversant l'ordre féodal, il fut membre du Comité de la réforme agraire avant d'être révoqué de son poste de président de la commune et exclu du Parti « pour avoir participé à un repas avec les exploiteurs ", et remplacé à ce poste par M. Nguyện, à son tour exclu. Procédure expéditive et quelque peu chaotique dont il est difficile a posteriori de saisir les finalités : s'agissait-il, dans une cellule encore embryonnaire, d'admettre de nouveaux membres pour mieux pouvoir les exclure afin d'envoyer des signes d'allégeances à la hiérarchie du Parti montrant que le Comité de la réforme agraire était intraitable avec la déviance « droitiste " et à l'unisson des directives? Quoi qu'il en soit, la campagne de rectification des erreurs se solda par la réintégration de la quasi-totalité des seize membres « injustement (bi quan oan) exclus du Parti »-seul un cas resta en suspens -, réintégration qui s'accompagna pour quatre địa chủ d'une réhabilitation et d'une nouvelle classification. Pour l'un d'entre eux, M. Hỷ, cette réhabilitation dut être octroyée à titre posthume : classé « propriétaire terrien traître », il fut fusillé en 1955 alors qu'il avait été président de la commune puis chef adjoint de la section communale du Việt-minh jusqu'en 1951.

Mais malgré ses accents de repentance, la campagne de rectification ne transforma pas significativement le nouveau visage du pouvoir local forgé pendant la réforme agraire. Entre 1953 et 1954, l'ensemble des cadres ayant été discrédité et évincé, c'est une nouvelle équipe qui s'empara de la direction des affaires de la commune, équipe issue de la classe des paysans moyens et de la masse des « exploités " ${ }^{80}$, à l'image de M. Ngân, salarié agricole, adhérent au Parti en 1953 et désigné responsable de la brigade de la réforme agraire du village de Hay. En d'autres termes, la réintégration des anciens cadres au sein du Parti et la réhabilitation de certains propriétaires fonciers ne changèrent pas fondamentalement la nouvelle donne, dans la mesure où ce mouvement de réconciliation ne s'accompagna pas d'une réinsertion dans l'organigramme du pouvoir local. La rupture était consommée et les nouveaux dirigeants allaient se maintenir en place pendant les deux décennies à venir. Signalons toutefois quelques exceptions notables, dont la plus remarquable est celle de $\mathrm{M}$. Giảng, planteur de thé du village de Hay originaire de la

79. Dans la commune de Sơn Dương, la purge porta sur 42 membres, soit $46 \%$ de l'effectif de la cellule, alors que la proportion de propriétaires terriens et de paysans riches n'atteignait que $13 \%$ de la population (Hy Van Luong 1992 : 192-193).

80. L'économiste Vo Nhân Tri, longtemps l'un des conseillers les plus influents du sérail communiste dirigeant, expliqua en 1960 que cette prise de contrôle des structures du pouvoir local par les paysans pauvres et prolétaires répondait à une volonté du Parti afin de lancer rapidement la phase de collectivisation. Les membres du Comité central du Parti estimaient en effet que les exploités d'hier seraient les plus motivés par l'instauration d'un système coopératif, car ils étaient ceux qui avaient le plus souffert de l'accaparement des moyens de production par les propriétaires fonciers et les paysans riches. Quant à la classe des paysans moyens, il en souligna la «nature dualiste » : « il [le paysan moyen] est à la fois un travailleur (côté positif) et un petit producteur qui a une tendance spontanée au capitalisme (côté négatif) » (1960:367). Cette analyse s'inscrit donc en faux contre le rapport du Bureau politique précédemment cité (cf. note 81 ), qui imputait cette prise de contrôle des cellules du Parti à une dérive " gauchiste » de sa base. 
commune de Mạn Lạn. Personnage unanimement respecté par les villageois, il est le seul cadre à avoir traversé les trois périodes (coloniale, postrévolutionnaire et post-réforme agraire). Après avoir été mis à l'index pendant plusieurs années, il fut nommé président du Comité populaire de la commune de 1961 à 1963 et retrouva en 1964, dix ans après en avoir été chassé, son poste de secrétaire de la cellule du Parti qu'il conserva jusqu'à sa retraite en 1976. Citons également le cas de M. Cụ, vice-président du Comité administratif et de résistance pendant la période de transition 1950-1952, et qui fut président du Comité populaire de 1964 à 1967, puis de 1973 à 1977.

\section{Redistribution et recomposition de l'espace habité}

Au lendemain de la proclamation de l'indépendance, les dirigeants de la jeune RDVN ont affirmé leur volonté de remodeler l'espace rural, symbole de l'ancien régime " féodal », en imposant une redéfinition progressive, mais en profondeur, des unités territoriales locales dans les zones libres contrôlées par le Việt-minh, à l'instar de celle entreprise dans le district de Thanh $\mathrm{Ba}$. À la veille de la réforme agraire, la quasi-totalité des communes $(x \tilde{a})$ avait été remaniée, au minimum, par un changement de nom ou, plus profondément, au fil d'un processus de concentration/fusion en des unités de plus grande taille qui les apparentait parfois à celle des anciens cantons. Cette entreprise de refonte des découpages territoriaux fut menée dans l'ensemble du delta du fleuve Rouge, ce qui a conduit l'ethnologue Nguyễn Tùng à proposer une titulature distinguant explicitement les « anciennes communes » (prérévolutionnaires) des « nouvelles communes », fruits de remaniements successifs (1999: 53). Considérée sous cet angle, la réforme paracheva l'entreprise de transformation débutée dix années auparavant en s'immisçant au cœur même des villages. Pour rendre compte de cette dynamique de restructuration interne, nous avons comparé l'organisation de l'espace habité du village de Hay tel qu'il apparaissait avant et après la réforme agraire. L'évolution des lieux de résidence des villageois (attribution éventuelle d'une nouvelle parcelle d'habitation et/ou d'une maison, confiscation) en fonction de leur classification lors de la réforme agraire est matérialisée sous forme de deux cartes diachroniques (voir carte 2). Leur comparaison met en évidence l'importance des bouleversements réalisés alors qu'en principe, seules les habitations des «propriétaires fonciers notables tyranniques » (địa chủ cương hào) devaient être confisquées puis redistribuées, les possessions immobilières des propriétaires fonciers normaux et résistants ne devant pas être aliénées (article 3, loi sur la Réforme agraire). Un faisceau de facteurs explique cette situation (voir carte $n^{\circ} 2$ ).

En premier lieu, les mesures de confiscation furent appliquées indistinctement aux propriétaires fonciers quel que soit leur statut. Bien que pour le village de Hay stricto sensu (hors quartiers xóm Lũng Bưởi et xóm Cầu Sắn) ces mesures n'affectèrent que deux propriétaires fonciers, ces derniers possédaient chacun plusieurs habitations, comme l'explique $\mathrm{M}^{\text {me }}$ Thang, fille de l'un d'entre eux :

Avant la réforme, mon père avait 6 maisons. Il avait 2 maisons sur le terrain actuel de $M$. Ngân, où il vivait avec ses deux femmes, une maison sur le terrain de $\mathrm{M}$. Cương, où habitait mon frère Đạt, une maison sur le terrain de M. Giao, où habitait mon autre frère Phấn, et 2 maisons en bambous, une sur le terrain de $M$. Thuy et celle où j'habite actuellement. [...] Les 2 dernières maisons ont été construites après l'attaque française, quand la fabrique de thé et quelques 
maisons ont été brûlées. [...] Mon terrain actuel a été redistribué lors de la réforme à deux paysans pauvres, $\mathrm{M}$. Ba Dục et $\mathrm{M}$. Huy. Avec mon mari qui était militaire, on nous a attribué un terrain dans le jardin actuel de M. Hảo, puis deux ou trois années plus tard, on a racheté à $\mathrm{M}$. Ba Dục et $\mathrm{M}$. Huy l'ancien terrain de mon père ${ }^{81}$.

L'autre propriétaire foncier, M. Hoè, possédait au centre du village deux maisons où il vivait avec ses deux épouses, ainsi que deux autres habitations où résidaient ses deux fils. Aussi, lorsque l'histoire du Parti déclare que " les deux địa chủ du village [de Hay] ont été chassés par l'Association des paysans dans le thôn Mánh, puis [qu'] ils ont été emprisonnés ", laissant ainsi penser que l'impact de la réforme sur l'espace villageois fut minime, c'est en réalité une dizaine de maisons et de terrains d'habitation qui furent confisqués et redistribués, sur le total de soixante-cinq toits que comptait alors le village.

Intervint alors le second facteur : l'attribution d'habitations aux exploités (salariés et paysans pauvres) ainsi qu'aux patriotes méritants. Dans le village de Hay comme dans les autres communes alentour, les modes d'exploitation et les rapports de production induits par le développement de la culture du thé, notamment les exigences de cette dernière en termes de main-d'œuvre, ont amplifié la proportion des villageois susceptibles de bénéficier de ces mesures de redistribution. Le tableau ci-dessous présente la synthèse des mouvements d'attribution d'habitations et/ou de terrains provoqués par la réforme.

Tableau n" 6 : Changement de résidence lors de la réforme agraire, village de Hay

\begin{tabular}{|l|c|c|c|c|c|}
\cline { 2 - 5 } \multicolumn{1}{c|}{} & Salariés & $\begin{array}{c}\text { Paysans } \\
\text { pauvres }\end{array}$ & $\begin{array}{c}\text { Réfugiés de } \\
\text { Vũ Ėn }\end{array}$ & $\begin{array}{l}\text { Militaires } \\
\text { Cadres }\end{array}$ & Total \\
\hline Attribution d'une habitation & 12 & 2 & 1 & 2 & 17 \\
\hline Attribution d'un terrain d'habitation & 5 & 2 & 3 & 1 & 11 \\
\hline Résidence inchangée & 2 & 7 & 1 & 1 & 11 \\
\hline
\end{tabular}

Les principaux bénéficiaires de ces mesures furent logiquement les anciens salariés agricoles. Antérieurement à la réforme agraire, seuls neuf d'entre eux possédaient une habitation dans le village, chiffre qui fut porté à dix-neuf après la redistribution. Parmi ces bénéficiaires, sept étaient d'anciens journaliers itinérants qui se déplaçaient de plantation en plantation au gré des opportunités de travail : ce chiffre est cependant loin de refléter l'ensemble de la main-d'œuvre flottante nécessaire à la mise en valeur des plantations de thé du village, car les anciens salariés rejoignirent pour la plupart leur village d'origine à partir de 1953, échappant de fait à toute comptabilité. Ce rapport d'attribution s'inverse pour la catégorie des "paysans pauvres », la majorité d'entre eux ayant conservé leur lieu de résidence.

Enfin, troisième facteur, la redistribution de l'habitat ne se solda pas systématiquement par l'allocation d'une habitation individuelle à chaque foyer paysan, loin s'en faut. La carte de l'espace habité post-réforme agraire fait apparaître sept cas de cohabitation de deux ou trois foyers, cohabitation décidée administrativement, comme l'explique M. Bảo :

81. Entretien du 07/01/1998. 
Cette maison [la sienne] était celle de M. Hoè. Avant, elle comptait sept travées $^{82}$. Lors de la réforme agraire, trois travées ont été distribuées à $\mathrm{M}$. Khương, qui était un salarié de Hà Tây, deux au père de Mme Thị Lâm [réfugié de Vũ Én] et les deux dernières à $M$. Nức. [...] M. Nức était célibataire et habitait chez son oncle $\mathrm{M}$. Hiền avec ses trois frères et sœurs : ils ont été tous les quatre considérés comme formant un foyer et c'est pour ça qu'on leur a attribué deux travées. [...] Je me suis marié en 1955 et en 1957 mon père a racheté pour moi les trois travées de $M$. Khương et les deux travées du père de Mme Thị Lâm. J'ai ensuite cohabité pendant dix ans avec M. Nức et en 1967 je lui ai racheté ses deux travées. [...] C'est pareil pour la maison voisine, qui appartenait à M. Thư. Au départ elle a été distribuée à M. Ngân et à Mme Thị Thể. En 1968, Mme Thị Thể a démonté ses deux travées et les a remontées sur le terrain actuel de Mme Thị Cúc. [...] Après le départ de Mme Thể, M. Ngân a remplacé les deux travées manquantes pour refaire une maison de cinq travées ${ }^{83}$.

Cette modalité dirigiste de regroupement s'explique en premier lieu par l'indéniable déséquilibre qui existait entre le nombre d'habitations à allouer et le nombre de bénéficiaires potentiels. Dans cette région, le facteur limitant n'était pas la quantité de terre constructible, mais bien le bâti existant. À quoi bon recevoir un terrain si l'on ne disposait pas de moyens suffisants pour y construire une maison, fût-elle modeste? S'est ainsi imposée la nécessité de « découper» les habitations en lots de deux à trois travées, chaque lot étant attribué individuellement à un foyer. On devenait donc propriétaire d'une fraction d'habitation qui pouvait être physiquement détachée du reste du bâti et reconstruite ailleurs, mobilité permise par la nature même de la construction en compartiments démontables en bois. Mais cette forme de cohabitation imposée ne résulta pas uniquement d'une pénurie de logement : elle fut dictée par des besoins de cohérence idéologique, une seule famille, fût-elle des plus pauvres et au passé révolutionnaire irréprochable, ne pouvait occuper seule l'habitation d'un ancien propriétaire terrien. Le Comité de la réforme agraire poussa cette logique de cohérence jusqu'à son terme en prenant soin de ne pas faire cohabiter sous un même toit des familles issues d'un même lignage ou d'un même village d'origine, la parenté et le voisinage représentant les deux pôles de sociabilité qu'il fallait bannir pour parachever le renversement de l'ordre féodal.

L'artificialité des situations ainsi créées (la cohabitation n'est socialement admise que dans certains cas au sein de la parentèle) généra des tensions, conséquences du niveau élevé de promiscuité parfois atteint. Ainsi, dans le premier cas décrit par M. Bảo, ce ne sont pas moins de huit adultes et quatre enfants, relevant de trois foyers distincts sans aucun lien de parenté, qui résidèrent quotidiennement pendant plusieurs années sous le même toit. Ces tensions furent apaisées et résolues au fil du temps par la vente ou la séparation des corésidents, ce qui contribua à redessiner la configuration générale de l'espace habité. À la fin des années 1960 , il ne restait plus de trace concrète de cette tentative de collectivisation de l'espace domestique.

82. Le décompte du nombre de travées et de colonnes est une façon courante de décrire et d'estimer la taille d'une maison. La travée est l'unité de base, sorte de compartiment délimité par deux colonnes (dans le sens de la longueur de la maison); la travée centrale est réservée à l'autel des ancêtres. I a largeur d'une travée fluctue d'une région à l'autre et parfois même d'un village à l'autre. Dans le cas du village de Hay, la largeur des travées varie de $2 \mathrm{~m} 40$ à $2 \mathrm{~m} 70$ suivant les habitations.

83. Entretien du 02/09/1997. 
La réforme agraire n'a pas cherché à remettre en cause les unités supérieures de parenté (lignage, branche de lignage) ${ }^{84}$ en procédant par amalgame entre « propriétaires terriens » et membres du groupe lignager présents au village, à la différence de son application en Chine où la réforme (1950-1952) visa explicitement ces unités de parenté par assimilation du rang statutaire de chef de lignage ou de segment de lignage à celui, infamant, d'exploiteur (voir notamment Thireau \& Kong Mak 1992). Ce discernement souffrit cependant d'une limite majeure : celle du groupe de filiation directe. Les trois fils de M. Thư et les deux fils de M. Hoè furent associés à la classe des địa chủ et furent, à ce titre, également « chassés du village », comme s'en souvint M. Sang :

Tous les địa chủ et leurs familles ont été regroupés dans le village voisin de Mánh, dans un même quartier près de l'hôpital actuel. Cela faisait au moins 20 địa chủ au même endroit! [...] Les autorités les avaient rassemblés pour pouvoir mieux les gérer et les surveiller plus facilement ${ }^{85}$.

Véritable processus d'exclusion du groupe villageois qui toucha des foyers entiers; en cela, parler d' " héritage » statutaire n'est pas un vain mot, comme en témoignent les propos amers, malgré les décennies écoulées, de $M$. Đạt, fils de $M$. Thư :

Je n'ai pu rentrer au village qu'en 1959. [...] Mon père est mort à Mánh comme M. Hoè. [À la question : «êtes-vous à la retraite? »] Comment pourraisje être à la retraite? Je ne pouvais pas être employé, ni cadre, ni même ouvrier : je suis fils de địa chủ. Après la réforme, j'ai dû tout recommencer à zéro, mais mes enfants s'en sont bien sortis, comme mon fils aîné qui travaille à la Pourquoi radio nationale à Hà Nội. [...] Mon frère aîné, Phấn, qui est maintenant le chef de la branche du lignage installée ici, habite à xã Quảng Nạp [commune limitrophe de celle de Ninh Dân]. Il aurait pu revenir ici comme moi, mais il ne l'a pas voulu, trop de mauvais souvenirs ${ }^{86}$.

Malgré la campagne de rectification, les familles de địa chủ durent ainsi assumer pendant de nombreuses années le poids social et politique de leur statut ${ }^{87}$, à l'image

84. La structure de la parenté au Việt Nam se présente comme un découpage en unités de taille croissante dont la plus petite serait englobée par celle de niveau supérieur et ainsi de suite : le lignage (dòng $h o, h o, t o ̂ c$ en sino-vietnamien) se ramifie en branches de lignage (chi, phái, ngành) qui englobent à leur tour les unités de niveaux inférieurs que sont la famille élargie (đại gia đình) et la cellule familiale élémentaire (gia đinh). Le principe de cet ordonnancement repose sur le culte rendu aux défunts (ascendants directs, aïeux et ancêtres plus lointains, jusqu'au fondateur), puisque la « famille au sens large » (dòng ho, ho, tộc) désigne des personnes qui descendent du même ancêtre commun éponyme. Dans ce système de parenté patrilinéaire, qui admet cependant une certaine dose de mixité, la cellule familiale élémentaire peut être qualifiée d'unité domestique, car c'est en son sein que se réalisent la plupart des activités de production et de consommation.

85. Entretien du 02/09/1997.

86. Entretien du 03/10/1997.

87. Cette discrimination fondée sur la filiation était d'ailleurs un élément consubstantiel de la politique gouvernementale après la réforme agraire. À propos de la procédure de création des coopératives, l'économiste Vo Nhân Tri expliqua ainsi en 1960 : "signalons enfin que "les enfants des paysans riches et des propriétaires terriens qui n'ont pas encore participé à l'exploitation" et qui vivent avec leur parents, ne sont pas assimilés à ceux-ci politiquement mais ne peuvent entrer dans une coopérative » (1960:367). 
des pratiques discriminatoires décrites par M. Bát, fils de M. Đốc, déclaré « propriétaire foncier » à Đồng $X a$ avant d'être réhabilité :

Lors de la réforme agraire, le Comité [de la réforme agraire] devait en théorie distribuer des terres d'une superficie égale pour tous, 3 sào par bouche à nourrir. Mais aux familles de dịa chủ et à leurs descendants, on a donné les terres les plus mauvaises et les plus éloignées du village : les parcelles les plus hautes qui ne retiennent pas l'eau et où il était impossible de cultiver du riz ou les parcelles basses, toujours inondées pendant la saison d'été. [...] Quand on a réquisitionné la maison de mon père, les cadres ont dit que le gouvernement la rachetait, mais ils n'ont rien donné, pas de papier ni d'argent, alors comment se plaindre ensuite? [...] Jusqu'à la création des coopératives [1959], c'était très dur pour nous; il y avait toujours des conflits avec les autres [du village] et on était tenus à l'écart de tout. Après, ça s'est s'arrangé, et aujourd'hui, en apparence, il n'y a plus de problèmes. Mais quand un arbre reçoit un coup de couteau, même si l'écorce se referme, il reste toujours la blessure à l'intérieur ${ }^{88}$.

Et ce n'est là qu'un des aspects du processus de reformulation de l'espace social local initié par la réforme. Dans le village de Hay, à défaut de s'attaquer directement aux unités supérieures de parenté, le Comité de la réforme agraire s'efforça de modifier l'organisation interne villageoise, qui en était la matérialisation concrète, en vidant de son sens historique l'opposition " giũa làng [le centre du village]/ngoài làng [l'extérieur du village] ». Cette opposition affirmait en effet l'antériorité d'installation des trois lignages fondateurs reconnus (Trịnh, Trần et Lương) par rapport à la population plus nombreuse des colons-planteurs établis ultérieurement à partir du début du $x^{\mathrm{e}}$ siècle. La centralité $s$ 'imposait ici avant tout comme un moyen pour les descendants des fondateurs de revendiquer la primauté de leur statut d'autochtone (voir Tessier 2003). La confiscation des biens mobiliers et immobiliers des familles de «propriétaires terriens » affiliées à deux des trois lignages fondateurs et leur redistribution exclusive dans les deux quartiers du centre à des membres de la " classe des exploités » ainsi qu'à des cadres ou à des militaires ont inversé et dénaturé le rapport "fondateurs/population allochtone », fondement de l'opposition " centre du village/extérieur » et principal critère de différenciation sociale. Cette inversion de polarité sociohistorique s'est traduite par une dilution de l'emprise des descendants des fondateurs sur le centre du village. Concrètement, de treize foyers sur vingt établis au centre du village à la veille de la réforme agraire, les descendants de fondateurs ne représentaient plus que sept foyers sur vingt-deux au lendemain de la réforme, la nouvelle force dominante se composant d'allochtones (anciens salariés : 7 foyers; paysans pauvres : 5 foyers; cadres ou militaires : 3 foyers). S'est ainsi inscrite dans l'espace villageois la volonté politique de rejet de la hiérarchisation sociale de "l'ancienne vie» fondée sur l'autochtonie, ce que F. Paul-Lévy et M. Sigaud qualifient de " reformulations endogènes volontaristes de l'espace [...] liées généralement à des finalités étatiques. Changer l'espace c'est manifester concrètement l'apparition d'un nouvel ordre qui peut laisser présager l'avènement d'un nouveau pouvoir » (1983:248). Et quoi de plus symbolique que d'inverser l'inscription spatiale de l'ancien ordre social en établissant physiquement les « exploités » en lieu et place des « exploiteurs». 


\section{Mise au pas des croyances populaires et des communautés religieuses}

Le renversement de l'ordre social ancien ne pouvait se satisfaire du seul bouleversement de son inscription territoriale. Restait un dernier bastion à ébranler : le domaine de la religion et des croyances populaires. Au lendemain de la Révolution fut lancée la campagne «Construire une nouvelle vie » (Xây dụng đời sống mói $i)$, dont l'histoire du Parti de la commune se fait l'écho en des termes triomphants :

Ce mouvement a été déclenché pour protester contre les superstitions, les coutumes arriérées, améliorer l'hygiène [...]. Les activités culturelles et artistiques se sont alors développées et de nombreux spectacles furent organisés au đình (maison communale) du village de Hay. À partir de 1949, le mouvement «Construire une nouvelle vie » a été généralisé, les vices sociaux ont diminué. La cellule du Parti a organisé une campagne de propagande auprès du peuple pour la «Liberté de croyance » et la «Suppression des superstitions » : on abandonna alors de plus en plus le culte aux đình, chùa et đền [respectivement : maison communale, pagode et temple] (Ninh Dân 1996 : 17).

Au travers de cette brève évocation, on comprend sans détour que la volonté du Parti était de s'immiscer et de s'imposer dans tous les domaines de la culture populaire comme promoteur et maître d'œuvre des transformations radicales nécessaires à l'émergence de "l'Homme nouveau ». Il était donc logique d'investir le champ religieux, et puisque les cultes aux đình, chùra et đèn étaient explicitement assimilés à des « superstitions » obscurantistes et rétrogrades, il devenait légitime de les abolir. Ainsi, la cérémonie collective de cultes et de prières qui se déroulait chaque année du $12^{\mathrm{e}}$ au $15^{\mathrm{e}}$ jour du onzième mois lunaire dans les maisons communales (đình) de trois villages de la commune fut abrogée dès 1946 et remplacée par du théâtre populaire. Cette opération de substitution marqua le premier acte concret de la mise au pas des cultes locaux, véritable coup de force contre l'institution la plus symbolique de l'identité du groupe villageois : le đinh.

L'interventionnisme dogmatique du Parti culmina avec la destruction, entre 1956 et 1959, de tous les édifices cultuels de la commune dans des conditions qui restent troubles et controversées. Cette matérialisation extrême de la volonté de " faire table rase du passé » est encore aujourd'hui source d'un profond malaise au sein de la population, qui se traduit par une forme d'amnésie collective dont semblent être frappés ceux qui l'ont vécue. Les rares allusions des anciens villageois évoquent un processus lent de dégradation des édifices cultuels plutôt qu'une destruction brutale, tant de tels actes paraissent, avec le recul, d'une gravité inconcevable. Ainsi, M. Cương d'expliquer :

Au début du nouveau régime, on a confondu croyance, superstition et religion. Pour respecter les principes de la révolution, les cultes, les processions et les fêtes au đinh ont été abandonnés. [...] Personne n'entretenait plus le đình du village, qui s'est dégradé petit à petit à cause des intempéries. [...] Les habitants ont pris au fur et à mesure les planches des murs et les colonnes de bois pour faire des tables et des chaises; les feuilles de latanier du toit pour couvrir les maisons; les dalles de l'intérieur et de l'extérieur pour paver les cours. Et puis on a brûlé l'autel et les objets de cultes. Cela s'est également passé comme ça pour les dinh des villages de Mánh et de Sen. Heureusement, pour le «miéu » [temple] de Mánh, le père de M. Phương [le dernier «chủ tế » : maître de cérémonie] a caché chez lui la boîte en bois qui contenait le «ngộc phả» [récit de 
fondation] et les «sắc phong » [décrets royaux], sans quoi on n'aurait pas pu reconstruire le temple. [...] Plus tard on a reconnu qu'il ne fallait pas confondre les superstitions et les religions et donc on a réhabilité le culte. Mais ce n'est pas partout que l'on a tout détruit; ç'a été particulièrement violent ici dans la province de Phú Thọ ${ }^{89}$.

M. Hiếu, adolescent à l'époque, décrit un processus similaire :

Le đinh se situait sur l'emplacement actuel de la maison de M. Kim et c'est pour ça que cette famille connaît autant de difficultés et de malheurs. [...] Son entrée était bordée d'un grand "cây si » [figuier de Benjamin] et d'un " cây đa » [figuier banian] de plus de cent ans qui était superbe. Puis, dans la période « abolir les superstitions » (phá mê tín), plus personne ne prêta attention au dinh. Chacun venait prendre ce qu'il voulait, une planche, une colonne, et c'est comme ça que le dinh a disparu progressivement, en faisant du feu ! [...] Et puis on a coupé les deux grands arbres. C'est à partir de là que la situation du village s'est dégradée ${ }^{90}$; avant la révolution il était prospère ${ }^{91}$.

La disparition est ainsi décrite comme progressive et presque accidentelle, puisque résultant de la combinaison des assauts du temps et de prélèvements collectifs, sans véritable responsable (nommément désigné), les villageois n'étant " coupables ", en fin de compte, que d'un désintérêt pour des pratiques et des lieux fustigés par la ligne politique de l'époque. Processus entendu d'autodisculpation qui nécessita cependant dans certains cas, quand la destruction violente est avérée, d'identifier ses auteurs, comme le montre le récit de M. Hải au sujet de la commune voisine de Mạn Lạn :

Auparavant il y avait à Mạn Lạn une grande maison communale, une pagode et deux temples. Une procession se déroulait chaque année le $14 \mathrm{e}$ jour du onzième mois lunaire. [...] Après la réforme agraire, la procession n'a plus été organisée. Les deux temples, la maison communale et la pagode ont été détruits sous la direction de la cellule du Parti de la commune et du Comité populaire. Le responsable du Bureau de la culture et un groupe qui prend en charge les activités sociales de la commune ont réalisé la destruction. Avant de le faire, ils ont rendu un culte en disant : « on ne veut pas faire ça mais on nous a ordonné de le faire ». Les đình, « đền » et " chùa » ont été rasés. Les « gia phả » [livres généalogiques] ont été brûlés, des objets de culte jetés dans le fleuve Rouge et les colonnes de bois ont été découpées pour construire le nouveau "tru sở " [siège du pouvoir local]. [...] Mais ensuite, les responsables de la destruction ont tous été ruinés ou sont morts prématurément ${ }^{92}$.

Entreprise de désacralisation totale où les matériaux récupérés lors du démantèlement des édifices cultuels servent à bâtir le siège de la nouvelle puissance locale, le Parti, qui

89. Entretien du 01/12/1997.

90. Le banian est un arbre doté d'une forte puissance symbolique présent dans tous les villages vietnamiens, généralement à proximité des lieux de culte.

91. Entretien du 03/12/1996.

92. Entretien du $18 / 09 / 1996$. 
se substitue ainsi à celle, ancestrale, des divinités tutélaires. Entreprise à haut risque toutefois, puisque malgré leurs prières expiatoires (les « vrais responsables » sont ailleurs), les blasphémateurs furent frappés par la colère des divinités offensées. Cette démarche est, au fond, comparable au processus d'autodisculpation précédemment évoqué à propos du village de Hay : bien qu'en identifiant des coupables, le groupe villageois soit devenu comptable de sa passivité, voire de sa complicité, la déresponsabilisation prit la forme d'un transfert de la faute sur les structures de pouvoir et non sur des individus.

Quelle fut l'ampleur réelle de ce mouvement d'éradication des bâtiments de culte que $\mathrm{M}$. Cương décrit comme particulièrement intense dans la province de Phú Thọ? Nous avons tenté d'en faire une évaluation à l'échelle du district de Thanh $\mathrm{Ba}$, mais cette tentative de recensement a été prématurément interrompue sous la pression insistante des autorités locales. Il est malgré tout possible de dresser un bilan partiel : dans les dixhuit communes visitées ${ }^{93}$ (sur les vingt-six nouvelles communes que comptait alors le district de Thanh $\mathrm{Ba}$ ), un seul et unique bâtiment datant de la période prérévolutionnaire est encore debout. Il s'agit du đền (temple) de la commune de Chí Tiên (anciennement xã Trí Chủ) dédié, selon les habitants, au héros Nguyễn Thị Hạnh, femme générale qui s'est illustrée par ses faits d'armes lors de l'insurrection des deux sœurs Trung. Endommagés à plusieurs reprises pendant les deux guerres d'Indochine et du Việt Nam, les quatre đinh et la pagode que comptait la commune auraient, quant à eux, été détruits lors de bombardements; quant au temple, il fut restauré au début des années 1990 grâce aux dons des villageois et classé monument historique. Partout ailleurs, le même constat : la destruction des đinh, "đè̀n » et « chìa » est imputée à la guerre et, plus rarement, au mouvement «abolir les superstitions». Ainsi l'unique đình de la commune de Vũ Lao aurait été brûlé lors d'une attaque française en 1952 ; les cinq đình de la commune de Đồ Sơn et sa pagode auraient disparu après la réforme agraire, etc.

Qu'une fraction des édifices cultuels ait été effectivement détruite lors des deux guerres contemporaines est tout à fait vraisemblable, mais il est en revanche hautement improbable que ce soit là l'unique explication ni même la principale cause de leur disparition eu égard au nombre de bâtiments que comptait à l'époque le district, chaque commune possédant sur son territoire plusieurs maisons communales (đình), un ou plusieurs temple(s) (đì̀n, miếu) et pagode(s) (chìa). La quasi-absence d'édifices cultuels prérévolutionnaires est avant tout la conséquence de la volonté politique d'éradication de croyances populaires jugées réactionnaires. S'impose alors une contradiction fondamentale entre la finalité politique " éliminer les superstitions locales » et la nature des destructions opérées, la majorité des lieux de culte que comptait la province de Phú Thọ étant dédiée à des divinités du panthéon national, bâtisseuses puis garantes de l'unité du pays : les vingt souverains (Kinh Dương Vương, Lạc Long Quân et la succession de 18 rois Hùng Vương) de la mythique dynastie Hồng Bàng fondatrice du premier État việt (le royaume Văn Lang) ${ }^{94}$,

93. Il s'agit de : Thanh Vân, Hanh Cù, Yên Khê, Thanh Xá, Chí Tiên, Sơn Cương, Mạn Lạn, Phương Lĩnh, Vũ Ẽn, Ninh Dân, Quảng Nạp, Thái Ninh, Yên Nội, Thanh Hà, Đông Thành, Vũ Lao, Đại An, Khải Xuân.

94. L'historiographie officielle consacre la Moyenne région comme berceau de la civilisation việt : « d'après le Nam Sir, cette région, occupée actuellement par la province de Phú Thọ, était autrefois le pays de la famille des Hồng Bàng [ho Hồng Bàng] - une famille avec vingt générations de rois qui régnèrent de 2879 à 258 avant l'ère chrétienne » (Phạm Xuân Độ 1939 : 9). Lès auteurs en veulent pour preuve la multiplicité des vestiges et monuments évoquant plus ou moins directement un des monarques de la dynastie, vestiges dont la province de Phú Thọ compte la plus grande concentration. Ainsi Nguyễn Ngọc Chương a-t-il recensé dans huit districts (huyện) de la province de Phú Thọ pas moins de 40 lieux de culte dédiés à l'un des rois Hùng, 77 à l'une de leurs épouses, 228 vénérant Cao Sơn, Tản Viên ou 
leurs épouses et généraux aux comportements hérö̈ques dans les luttes contre les envahisseurs. En d'autres termes, on a mis à terre ce que l'on cherchait justement à ériger en valeurs morales transcendant les particularismes locaux, notamment le désintéressement et le sacrifice ultime pour l'édification de la patrie, contradiction symptomatique de l'aveuglement idéologique du moment qui ne prit malheureusement pas fin, loin s'en faut, avec la campagne de rectification ${ }^{95}$.

Sous l'angle de la liberté de croyance, le bouddhisme fut délibérément assimilé à une pratique superstitieuse, ce qui valut aux pagodes et au clergé de subir un traitement comparable à celui réservé aux temples et maisons communales. L'attitude adoptée par les autorités de la commune de Ninh Dân vis-à-vis de la religion catholique fut en revanche plus équivoque : pas de destruction des lieux de culte ${ }^{96}$, mais une tentative de récupération et de mise au pas d'une communauté fortement structurée autour de la mission catholique et qui représentait plus de la moitié de la population communale. Un exemple de cette logique de récupération, où le pouvoir s'immisce directement dans les activités de l'Église en se substituant à sa hiérarchie, est mentionné dans l'histoire du Parti : «Le 19 mai 1949, la cellule du Parti a organisé une procession pour les catholiques de Đồng Xa à laquelle 500 personnes ont participé » (Ninh Dân 1996 : 30). Cette logique d'encadrement fut complétée par des mesures de restriction des pratiques religieuses, comme l'expliqua $\mathrm{M}$. « X », un leader catholique du village de Đồng Xa :

Tu connais l'histoire du Việt Nam. Les Français ont utilisé la religion catholique pour contrer la révolution, ce qui a été fait également au Sud par les Américains, qui ont utilisé les catholiques et les caodaïstes. Les autorités ont toujours dans la tête le préjugé selon lequel les catholiques sont antirévolutionnaires. [...] Après la campagne de Điện Biên Phủ, beaucoup de catholiques de Đồng

un autre général illustre, et enfin 88 autres lieux de culte ayant un lien direct avec l'histoire de cette dynastie (1973 : 72). La commune de Ninh Dân n'échappe pas à cette emprise, puisqu'en plus du đền dédié à Quang Trĩ Đại Vương, les trois dinh (maison communale) qu'elle comptait jusqu'à la fin des années 1950 - un đinh par village - étaient dédiés à la même divinité tutélaire, Cao Sơn, dont le culte est le plus répandu de la province. L'épopée de la dynastie des rois Hùng Vương ne manque pas de susciter de sérieux doutes lorsqu'elle est envisagée dans le cadre de l'histoire événementielle, comme le souligne cette remarque de bon sens de R. Deloustal : " en effet, la famille des Hồng Bàng ayant fourni d'après les annales vingt souverains, s'ils avaient régné 2622 ans, cela ferait une moyenne de 131 années de règne par souverain, ce qui est un peu exagéré même pour ces temps reculés » (1915:5).

95. Confronté à une telle entreprise de destruction, on ne peut que s'interroger sur le niveau d'implication des autorités politiques à l'origine de cette initiative. À l'échelon central, le ministère de la Culture devait veiller à " guider la saine vie culturelle de la nation », à protéger « les belles et bonnes mœurs » et à « éliminer ou corriger la culture décadente laissée par l'impérialisme et le féodalisme » (de Hartingh 2003 : 274). Si cet exercice d'introspection culturelle consistant à séparer le bon grain de l'ivraie devait être pour le moins délicat à mener sur le terrain, les autorités centrales affichèrent leur détermination à protéger « une longue et hérö̈que histoire, une ancienne et riche culture et un très beau pays " (intervention à l'Assemblée nationale du député Nguyễn Đình Thi le 18/01/1957, citée par de Hartingh 2003 : 274), et créèrent en conséquence une structure ad hoc, le Comité de recherche des vestiges historiques (mission d'inventaire et de restauration). Dans ce contexte, doit-on en déduire que l'initiative de destruction systématique fut prise par des autorités de la province et/ou du district qui auraient ainsi surinterprété ou mésinterprété la ligne politique gouvernementale? S'il est en l'état impossible de trancher, se pose à nouveau la question de la capacité du centre à maîtriser et à contrôler ses représentants locaux et donc celle de l'efficience du centralisme démocratique de la RDVN.

96. Ce constat ne peut cependant être généralisé. Un des premiers objectifs des milices locales fut la destruction, en 1947, de l'église de Phú Thọ, symbole de la présence française et des valeurs spirituelles importées par le régime colonial (Ninh Dân 1996 : 20). 
Xa sont partis vers le Sud suivant « l'appel » de la statue de la Sainte Vierge, dont le geste de la main semblait indiquer le rassemblement ${ }^{97}$. Les activités de l'Église ont été interdites seulement quelques années pendant la guerre contre les Français. Après cela, elles ont théoriquement repris, mais comme il n'y avait plus de nomination de prêtre, il n'y avait plus de messe! On a quand même continué à lire une fois par semaine la Bible à l'église. [...] Pour les sept églises du district, il n'y avait qu'un prêtre à Sơn Cương. Les activités étaient donc très ralenties et cela ne s'est pas amélioré par la suite, car après la réforme agraire, le séminaire de Hà Trạch [ville de Phú Thọ] a été fermé. Cela ne fait que trois ans qu'un prêtre donne à nouveau la messe à Ninh Dân ${ }^{98}$.

Ce contrôle et cette restriction des conditions de la pratique s'accompagnèrent d'une réduction drastique des moyens humains et matériels dont disposait la mission catholique de Ninh Dân. Interrogé sur le sujet, le prêtre de la commune nous a clairement signifié qu'il refusait d'aborder cette question comme tout autre aspect ayant trait à son ministère. Le mutisme de la population sur le sujet fut général. Seul M. Cao (né en 1936), actuel exploitant des terres de l'église, fit une brève allusion au cours d'une conversation portant sur le réseau d'irrigation villageois :

Les 7 sào de rizières qui furent attribuées au prêtre en 1992 sont des terres hautes qui ne peuvent pas être irriguées. [...] Avant la réforme agraire, la mission avait plus de 30 mẫu [de rizières], mais ils ont été confisqués ${ }^{99}$. On a juste conservé l'église; les autres maisons de la mission ont été redistribuées. Maintenant, avec cette surface [7 sào], on ne peut même pas avoir un prêtre pour Ninh Dân ${ }^{100}$.

À cette tentative de dissolution de la communauté catholique par la confiscation d'un élément fondamental de son unité, à savoir la pratique cultuelle collective, fut associée, comme partout ailleurs en RDVN, une politique de discrimination lors de la réforme agraire. Les catholiques étaient, par leur confession même, suspects, à tel point que la raison de la création tardive de la cellule du Parti de la commune fut imputée à leur seule présence : « cette création tardive par rapport aux autres communes du district de Thanh $\mathrm{Ba}$ est due au fait que dans la commune les catholiques sont nombreux et donc qu'il manquait de cadres [pour former la cellule du Parti] » (Ninh Dân 1996 : 23). M. Hảo, en donne une nouvelle illustration :

Mon père était secrétaire de l'Union des jeunes de la commune et secrétaire adjoint au niveau du district. Au moment de la réforme, le Comité a déclaré que ce n'était pas possible d'être catholique et membre du Parti. Comme il ne

97. En 1954 , la communauté catholique représentait $10 \%$ de la population de la RDVN, proportion qui n'était plus que de 6,5\% en 1956, $40 \%$ de cette minorité confessionnelle ayant préféré migrer au Sud.

98. Entretien du 16/08/1996.

99. La confiscation des terres des communautés religieuses, prévue par la loi sur la réforme agraire, ne s'opposait pas à la liberté de croyance ni à l'attribution de rizières aux paysans catholiques, même si « le système d'appropriation des terres de l'Église relève du système d'appropriation féodaliste » (décret $n^{\circ} 315$ TTg du 4 octobre 1953, cité par de Hartingh $2003: 53$ ).

100. Entretien du 29/10/1996. 
voulait pas renier sa religion, il a été exclu du Parti. [...] Le fait d'être catholique n'a pas eu vraiment de conséquences pour ma famille, si ce n'est que, bien que mes frères aient fait de brillantes études, ils n'ont pas pu partir à l'étranger pour continuer à étudier. ${ }^{101}$

Dans le village de Đồng Xa, cette mise au pas de la communauté catholique se matérialisa dans l'espace villageois. À la fin des années 1950 , la vingtaine de foyers paysans, descendants des six familles fondatrices catholiques originaires de la commune de Chiểu Úng, qui habitaient dans le quartier originel xóm Đồng $\mathrm{Xa}$, fut expulsée et relogée en périphérie de la plaine. En lieu et place de leurs maisons, furent implantés les sièges du Comité populaire et de la cellule du Parti de la commune, l'école, ainsi que, ultérieurement, les bâtiments de la coopérative et les hangars de stockage. Comme dans le village de Hay, cette reformulation endogène volontariste de l'espace traduisit l'avènement du nouveau pouvoir.

La réforme agraire, dans sa composante économique, c'est-à-dire l'octroi d'un lopin de terre aux paysans les plus démunis, revitalisa pour un temps l'agriculture du Nord du Việt Nam et marqua une pause dans le processus de détérioration du ratio grain/ population. Cette réalité est indéniable, tout comme le sont les graves excès et dérives idéologiques, souvent violents, qui furent commis en son nom. Au-delà de ces errements qualifiés pudiquement "d'erreurs " par le régime, l'étude menée dans la commune de Ninh Dân et le village de Hay montre que le dessein des dirigeants de la RDVN était de bouleverser non seulement les rapports de production, mais également la société dans son ensemble pour bâtir sur les ruines du régime " féodal et impérialiste " une société nouvelle. À ce titre, la réforme agraire devait être une réforme de la pensée, comme elle l'avait été en Chine.

Dans le cadre de ce projet politique global, commun à tous les partis communistes de l'époque, les institutions villageoises traditionnelles représentaient autant d'obstacles politiques et culturels qu'il fallait mettre à terre. Trois dimensions emblématiques de cette volonté d'éradication ont été décrites et analysées à l'échelle villageoise et communale. En premier lieu, la refonte des organisations locales et la purge sévère des cellules du Parti ont brutalement mis fin au compromis tacite à l'œuvre depuis la Révolution qui reposait sur une logique pragmatique de continuité dans le recrutement des élites locales. Autrement dit, si de 1945 à 1953 les institutions du pouvoir local avaient bel et bien été entièrement remaniées, les détenteurs du pouvoir n'avaient, eux, pas changé. En second lieu, la réforme agraire a provoqué une redistribution de l'espace habité au bénéfice de paysans sans terre et de salariés agricoles, redistribution associée à l'exclusion de certains groupes de parenté et dont le corollaire fut un affaiblissement du principe d'organisation spatial fondé sur le partage d'une origine commune, lignagère et/ou villageoise, entre les résidents d'un même quartier. Cette reformulation autoritaire de l'espace villageois, qui visait explicitement un renversement de l'inscription géographique de l'ancien ordre social, est une constante dans l'histoire vietnamienne depuis l'indépendance ${ }^{102}$. Enfin, la

101. Entretien du 08/02/1996.

102. Ainsi, Lê Duẩn, secrétaire du Parti communiste vietnamien, déclara en 1976 que la coopérative socialiste, même de type supérieur, à l'échelle de la commune, " est encore un échelon trop restreint, 
destruction des lieux de culte, point d'orgue de la stratégie de désacralisation et de mise au pas des croyances populaires, paracheva l'entreprise de déstabilisation et de remodelage de collectivités paysannes jugées arriérées et féodales afin de donner naissance à «l'Homme nouveau ».

Mais plus encore que les faits eux-mêmes, l'une des caractéristiques essentielles de la réforme agraire est qu'elle ne fut qu'un leurre, qu'une respiration calculée avant le " grand bond en avant » qui devait mener le pays sur la voie de la « grande agriculture socialiste ». On allait bientôt reprendre ce que l'on venait de donner. Et c'est sûrement la gratuité de l'entreprise, l'inutilité des souffrances endurées et des compromissions de circonstance, qui sont aujourd'hui encore à l'origine de la profonde aversion des paysans pour la réforme agraire et de la survivance de rancœurs tenaces vis-à-vis des acteurs locaux qui l'ont mise en œuvre. Tout comme la campagne de rectification des erreurs ne fut qu'une mise en scène, malgré ses airs de repentance, qu'un geste d'apaisement sans conséquence effective sur le déroulement du processus de collectivisation de l'agriculture, dont le principe avait été arrêté dès le lendemain de l'indépendance (Nguyễn Đức Truyên 1993 : 23). En effet, avant même le lancement de cette campagne, le régime avait imposé un recours accru à l'entraide institutionnalisée et standardisée au travers de " groupes d'échange de travail " (tồ đổi công) puis de "groupes réguliers d'échange de travail " (tổ đổi công thường xuyên) et enfin de " groupes d'échange de travail permanents fondés sur des points de travail » (tổ đổi công bình công chấm điểm), étape ultime qui précéda l'intégration forcée des foyers paysans dans les coopératives de production agricole, finalisée en 1960 (Kerkvliet $1998: 440)^{103}$.

Et, à nouveau, les mêmes travers, les mêmes pratiques de falsification des données chiffrées dans un système en trompe-l'œil qui permit rapidement aux autorités centrales d'annoncer le succès de cette phase intermédiaire de mutualisation « volontaire » de la force de travail : au milieu de l'année 1956, 58,7 \% des foyers avaient ainsi officiellement adhéré spontanément aux équipes d'entraide. Toutefois, toujours selon des sources officielles, cette proportion n'était plus que de $21,9 \%$ à la fin de l'année 1957. L'explication avancée par le Parti pour expliquer cette chute brutale fut la « découverte des erreurs commises pendant la réforme agraire » (Vo Nhân Tri $1960: 364$ ), comme si les victimes de ladite réforme avaient dû attendre les révélations et l'autocritique du Bureau politique pour prendre conscience de leur état. Plus prosaïquement, la méfiance et la réticence des paysans vis-à-vis de formes d'entraide institutionnalisées fondées sur des principes de

favorable à l'esprit de clocher. Chacune d'elle est une organisation presque indépendante, peu liée aux autres coopératives et à l'économie nationale. " (cité par Nguyễn Đức Nhuận 1992 : 346) Aussi, pour faire de chaque coopérative une grande manufacture agricole, il faut détacher la coopérative du cadre du village (làng) où le paysan se trouve englué dans les troubles attaches familiales du lignage (ho hàng) (Nguyễn Đức Nhuận $1992: 347$ ).

103. Extrait du rapport sur le projet de constitution révisée présenté par le président Hồ Chí Minh le 18/12/1959 : « L'expérience prouve que chez nous la coopération agricole doit passer par les groupes d'entraide et les coopératives de production agricole. C'est là une nécessité. Le développement à pas sûrs des groupes d'entraide et des coopératives mènera immanquablement la coopération agricole au succès » (1994:223). Malgré cette tentative de légitimation faisant référence aux spécificités de la société rurale vietnamienne ( L'expérience prouve que chez nous... »), la fidélité au modèle chinois était sans faille : en février 1953, les paysans avaient été invités à s'organiser en équipes d'entraide mutuelle et la même année, le Comité central du Parti communiste chinois décidait le développement généralisé des coopératives de production agricole (Troillet $1962: 232$ ). Avec quelques années de décalage, la RDVN marchait dans les pas de son puissant voisin du Nord : « ici comme en Chine populaire, le mouvement coopératif agricole progresse graduellement et passe par 3 étapes : groupes d'entraide, coopératives de type semi-socialiste et coopératives entièrement socialisées " (Vo Nhân Tri 1960:363). 
fonctionnement diamétralement opposés à ceux qui présidaient aux formes traditionnelles de coopération dans le travail (Tessier 1999) expliquent qu'elles furent délaissées par les paysans, leur existence étant plus virtuelle que réelle (Vickerman $1986: 128$ ). Mais qu'importe, la ligne doctrinale du Parti étant fondamentalement juste, le problème provenait une fois encore de sa mise en œuvre sur le terrain par des cadres insuffisamment formés. La preuve en est que l'établissement par le Comité central du Parti (05/1957 et 07/1958) d'un plan de «consolidation et de développement des groupes d'entraide », diffusé dans les provinces, districts et communes par le biais de cours dispensés aux cadres, permit miraculeusement au mouvement de prendre un nouvel essor : " en 1958, $41 \%$ de l'ensemble des familles paysannes ont adhéré aux groupes d'entraide, puis $70 \%$ en avril $1959^{104} »$.

L'histoire semblait ainsi devoir se répéter.

104. La coopération agricole au Nord-Việt Nam, discours prononcé par Trường Chinh lors de la $10^{\mathrm{e}}$ session de l'Assemblée nationale, le 20/05/1959. Les chiffres avancés par B. Fall sont légèrement différents, car ils proviennent d'informations collectées dans la presse de l'époque et notamment dans l'organe officiel du Parti, le journal Nhân Dân (« Le peuple »); mais ils dessinent une évolution tendancielle similaire : de $60 \%$ de familles intégrées à des groupcs d'ćchange de travail en décembre 1956 , la proportion chute à $29 \%$ en novembre 1957 et à $31,6 \%$ en juillet 1958 , pour enregistrer en quelques mois un redressement spectaculaire et atteindre $51,1 \%$ en octobre 1958 et $65 \%$ en décembre de la même année $(1960: 286)$. 


\section{Bibliographie}

BARBier, Jean-Marc, Tung Hung Bach, Le QuÉrÉ, Éric \& NgOc Han Tran

1997 «La riziculture irriguée du delta du Fleuve Rouge (Viêt-nam) : analyse des transformations de quelques pratiques culturales ", dans Spécial Vietnam, Montpellier, numéro commun Cahiers Agricultures 6iAgriculture et développement 15, p. 81-91.

BERESFORD, Melanie

1988 Vietnam: Politics, Economics and Society, London, Pinter.

BOUDAREL, Georges

1983 "L'idéocratie importée au Viêt-nam avec le maoïsme ", dans Georges Boudarel (éd.), La Bureaucratie au Vietnam, Paris, L'Harmattan (VietnamAsie-Débat 1), p. 31-106.

1991 Cent Fleurs écloses dans la nuit du Viêt Nam : communisme et dissidence, 1954-1956, Paris, Jacques Bertoin.

BRENIER, Henri

1951 «La réforme agraire en Chine », Politique étrangère 16/2, p. 167-175.

1954 «La prolétarisation du paysannat chinois et ses conséquences », Politique étrangère 19/2, p. 195-210.

Brocheux, Pierre

1981 «Communistes et paysans au Vietnam », dans Pierre Brocheux (éd.), Histoire de l'Asie du Sud-Est. Révoltes, Réformes, Révolutions, Lille, Presses universitaires de Lille, p. 247-275.

2000 Ho Chi Minh, Paris, Presses de Sciences Po.

BrocheuX, Pierre \& Daniel HÉmERY

1995 La colonisation ambiguë 1858-1954, Paris, La Découverte.

Bùı Tín

1999 1945-1999 Vietnam, la face cachée du régime, Paris, Kergour.

Chaliand, Gérard

1968 Les paysans du Nord Viêt-nam et la guerre, Paris, Maspero (Cahiers libres 130-131).

\section{CHen Chi-Yi}

1962 «La révolution agraire chinoise et les pays sous-développés », Revue Tiers Monde 3/9, p. 217-227.

Đạng Phong (éd.)

2005 Lịch sủ kinh tế Việt Nam 1945-2000, tập II : 1955-1975 [Histoire de l'économie du Việt Nam, 1945-2000, tome II : 1955-1975], Hà Nội, nhà xuất bản Khoa Học Xã Hội.

Đạng Thai Mai

2007 «Thư gửi đồng chí Trường Chinh » [Lettre au camarade Trường Chinh], Tap chí Xura \& Nay: Hơn Nỉa Thế Kỷ "Dân cày có ruộng " [Après plus d'un demi-siècle que « les paysans ont des rizières »], $\mathrm{n}^{\circ} 297$, p. 27-28. 
Đìo Thế Tuấn

1998 « La transition agraire au Vietnam comme changement d'institutions », Développement et changement vers l'économie de marché, Actualité scientifique, universités francophones, Montréal, AUPELF-UREF, p. 457-471.

Deloustal, Raymond

1915 Calendrier annamite-français de 1802 à 1922 avec une liste chronologique des rois d'Annam, Hanoi/Haiphong, IDEO.

DUMONT, René

1995 (1935) La culture du riz dans le delta du Tonkin, Patani, Grand Sud, Prince of Songkia University \& CNRS.

Dương Trung Quốc

2007 «Hơn Nửa Thế Kỷ Dân cày có ruộng » [Après plus d'un demi-siècle que les paysans ont des rizières], Tạp chí Xúa \& Nay: Hơn Nứa Thế Kỷ «Dân cày có ruông » [Après plus d'un demi-siècle que « les paysans ont des rizières »], $\mathrm{n}^{\circ} 297$, p. 4-9.

FABER, Franz

1955 Rot Leuchtet des Song Cai, Berlin, Kongress-Verlag Berlin.

FALL, Bernard

1960 Le Viet Minh. La République démocratique du Viet-Nam, 1945-1960, Paris, Armand Colin.

FIorucci, Alain

2006 «Parenté, propriété agricole et autorité locale : forme et relations de pouvoir dans un village littéraire du delta du Nord Vietnam - làng tiến sí Mộ Trạch ", thèse de doctorat, Académie d'Aix-Marseille, université de Provence (AixMarseille I), département de sociologie, secteur Lettres \& sciences humaines.

GinsBuRgs, George

1962 « Local Government and Administration in North Vietnam, 1945-1954 », The China Quarterly 10 (avril-juin 1962), p. 174-204.

Gosch^, Christopher E. \& Benoît de TrÉGlodÉ (éd.)

2004 Naissance d'un État-Parti : le Viêt Nam depuis 1945 / The Birth of a PartyState: Vietnam since 1945, Paris, Les Indes savantes.

Gourou, Pierre

1940 L'utilisation du sol en Indochine française, Paris, Centre d'étude de politique étrangère, publication $n^{\circ} 16$, P. Hartmann.

Grosbors, Charles

1952 « La Chine en nouvelle démocratie », Politique étrangère 17/2, p. 29-48.

GuILLEMot, François

2004 «Au cœur de la fracture vietnamienne : l'élimination de l'opposition nationaliste et anticolonialiste dans le Nord du Viêt Nam (1945-1946) », dans Goscha \& de TrÉGlodí (éd.) 2004, p. 175-216.

HÄl Khách

1957 « Xét lại "hồ sơ" của giai cấp phong kiến địa chủ » [Réexaminer « le dossier » de la classe des propriétaires féodaux], Tập san Nghiên Cúu Văn Sủ Địa 25 (février 1957), p. 16-21. 
HaRTINGH, Bertrand (de)

2003 Entre le peuple et la nation. La République démocratique du Việt Nam de 1953 à 1957, Paris, EFEO (Monographies nº 189).

HI:NRI, Yves

1932 Économie agricole de l'Indochine, publié à l'occasion de l'Exposition coloniale internationale de Paris de 1931, Hà Nội/Hải Phòng, Imprimerie d'Extrême-Orient.

Hò Chí Minh

1994 Écrits (1920-1969), Hà Nội, nhà xuất bản Thế Giới.

HOÀNG Ước

1968 Cách mạng ruộng đất ỏ Việt Nam [La révolution agraire au Việt Nam], Hà Nội, nhà xuất bản Khoa Học Xã Hội.

HOUTART, François \& Geneviève LEMERCINIER

1984 Hai Van, Life in a Vietnamese commune, London, Zed Book Ltd.

Hừu Ngộc (éd.)

1997 Dictionnaire de la culture traditionnelle du Vietnam, Hà Nội, nhà xuât bản Thế Giới.

Hy Van Luong

1992 Revolution in the Village, Honolulu, University of Hawai'i Press.

KerkvLiet, Benedict J. Tria

1998 « Xây dụng các hợp tác xã ở Việt Nam, giai đoạn 1955-1961 : tại sao nông dân lại lien kết với nhau ? » [Building co-operatives in rural Vietnam, 19551961: why did peasants join?], dans Việt Nam Học kỷ yếu hội thảo quốc tế [International Conference on Vietnamese Studies], Hà Nội, 15-17 tháng 7, nhà xuất bản Thế Giới, tập III, p. 440-449.

KLEINEN, John

1999 Facing the future, reviving the past. A study of social change in a Northern Vietnamese village, Singapore, Institute of Southeast Asian Studies.

L̂̂. Thành Khôi (éd.)

1978 Socialisme et développement au Viêt-nam, Paris, PUF.

LEwIN, Moshé

1982 «Aux prises avec le stalinisme. Quelques réflexions historiques », Actes de la recherche en sciences sociales 43/1, p. 71-82.

MCHALE, Shawn

2004 "Freedom, Violence, and the Struggle Over the Public Arena in the Democratic Republic of Vietnam, 1945-1958 », dans GosCHA \& de TRÉGLODÉ (éd.) 2004, p. 81-99.

NGÔ Văn

1995 Viêt-nam, 1920-1945, révolution et contre-révolution sous la domination coloniale, Paris, L'Insomniaque.

NGUYĖN Đức Nhuận

1992 «Le district rural vietnamien ou l'État en campagne », dans Jacqueline Matras-Guin \& Christian Talllard (éd.), Habitations et habitat d'Asie du Sud-Est continentale : pratique et représentation de l'espace, Paris, L'Harmattan, p. 345-376. 
NGUYĖN Đức Truyên

1993 «Les effets de la politique économique vietnamienne sur les modes de vie paysans dans la région du delta du fleuve Rouge ", mémoire de DEA, Paris, EHESS.

NGUYĖN Khắc Viện

1974 « Le développement agricole en République démocratique du Vietnam ", Études rurales 53-56 (janv.-déc. 1974), p. 505-512.

NGUYẺN Minh Cần

2002 «Xin đừng quên! Nửa thế kỷ trước: Vấy Máu Cải Cách Ruộng Đất » [N'oublions pas ! Un demi-siècle plus tôt : la réforme agraire entachée de sang], lien internet : http://giaithcongsan.wordpress.com (consulté le 7 déc. 2010).

NGUYĖN Ngọc Chương

1973 «Về tình hình phân bố các di tích lích sử thuộc thời các vua Hùng 》 [Au sujet de la répartition des vestiges historiques appartenant à la période des rois Hùng], dans Lê Văn Hảo, Hùng Vương dựng nước [Les rois Hùng construisent le pays], tome III, Hà Nội, nhà xuất bản Khoa Học Xã Hội, p. 72-89.

NGUYĖN Quang Duy

2007 "Vai trò của Hồ Chí Minh trong Cải cách ruộng đất " [La position de Hồ Chí Minh vis-à-vis de la Réforme agraire] ; lien internet : http:/iwww.talawas.org/ talaDB/ (consulté le 7 déc. 2010).

NGUYĖN Thế Anh

1985 «La famine de 1945 au Nord Viêt-nam », Approche Asie 8, p. 103-116.

NGUYĚN Tùng

1999 « Du canton à la commune : territoire et identité », dans NGUYẺN Tùng (éd.), Mông Phu, un village du delta du fleuve Rouge (Viêt-nam), Paris, L'Harmattan, p. $21-59$.

NGUYÈN Văn Ký

1997 «Aujourd'hui, le temps du renouveau », dans Georges BOUdAREL \& NGUYẼN Văn Ký (éd.), Hanoi 1936-1996, du drapeau rouge au billet vert, Paris, Autrement (Mémoires), p. 170-186.

2004 «Contestataires et contestation au Vietnam : à la recherche d'un mode d'expression », dans Goscha \& de TRÉGLODÉ (éd.) 2004, p. 217-251.

NiNH Dân

1996 Lịch Sủ Đảng Bộ xã Ninh Dân [Histoire de la cellule du Parti communiste de la commune de Ninh Dân], manuscrit non publié.

Pagniez, Yves

1955 Le Viet Minh et la guerre psychologique, Paris, éditions du Vieux Colombier.

Paul-LÉvy, Françoise \& Marion Sigaud

1983 Anthropologie de l'espace, Paris, éd. du Centre Georges Pompidou, Centre de création industrielle.

PHẠM Xuân Độ

1939 Phú Tho tỉnh địa chi [Géographie de la province de Phú Thọ], Hà Nội, nhà xuất bản Tổng Phát Hành. 
STOWE, Judy

2004 «Money and Mobilisation: The Difficulties of Building an Economy in Time of War », dans GosChA \& de TRÉGLODÉ (éd.) 2004, p. 61-70.

TESSIER, Olivier

1999 «Aide et entraide agricole dans un village du Nord Vietnam : modalités pratiques et motivations », Aséanie 4, p. 125-159.

2002 «Fondateurs, ancêtres et migrants : mobilité et reformulation des espaces d'appartenance dans un village du Nord du Việt Nam », Moussons 6, p. 99-132.

TESsier, Olivier \& Jean-Philippe Fontenelle

2000 «Pression démographique et contraintes politiques : la paysannerie nord vietnamienne dans la tourmente du $x^{\mathrm{e}}$ siècle $»$, dans P. Gubry (éd.), Population et développement au Việt Nam, Paris, Karthala-CEPED, p. 495-527.

Tessier, Olivier \& Philippe Papin

2002 《Le village en questions " [Làng ở vùng châu thổ sông Hồng : vấn đề còn bỏ ngỏ], dans Philippe PAPIN \& Olivier Tessier (éd.), Le village en questions [Làng ở vùng châu thổ sông Hồng : vấn đề còn bỏ ngỏ], Hà Nội, nhà xuất bản Lao Động - Xã Hội (Bibliothèque vietnamienne EFEO), p. 41-57.

THIREAU, Isabelle \& Kong MaK

1992 «Parenté et territorialité dans les villages du Sud de la Chine : 1911 - 1990 », dans De village en village. Espace communautaire et développement, Paris, Presses universitaires de France, Cahiers de l'Institut universitaire d'études du développement, Genève, p. 47-73.

TrẢnH Huy Liệu

1954 «Vân đề ruộng đất trong Cách Mạng Việt Nam » [La question de la terre dans la révolution vietnamienne], Tập san Nghiên Cưu Văn Sủ Địa, no 2, p. 9-31.

2007 «Ghi chép trong Cải cách ruộng đất » [Notes prises pendant la Réforme agraire], Tạp chi Xưa \& Nay: Hơn Nưa Thé Kỷ «Dân cày có ruộng » [Après plus d'un demi-siècle que « les paysans ont des rizières »], $\mathrm{n}^{\circ} 297$, décembre 2007, p. 22-27.

Tràn Thị Liên

2004 «Les catholiques et la République démocratique du Việt Nam (1945-1954) : une approche biographique », dans GosCHA \& de TRÉGLODÉ (éd.) 2004, p. 253-276.

TrÉGLODÉ, Benoît (de)

2001 Héros et Révolution au Viêt Nam, Paris, L'Harmattan.

TRỊNH Văn Thảo

1987 «Vie théorique, l'Homme nouveau introuvable », dans NGUYẺN, Đúc Nhuán, Le Viêt-nam post-révolutionnaire : population, économie, société 1975-1985, Paris, L'Harmattan (Asie-Débat 4), p. 173-184.

Trolliet, Pierre

1962 «Les communes populaires rurales chinoises », Revue Tiers Monde 3/9, p. 229-269.

TRƯờng Chinh

1956 «Sửa sai và tiến lên » [Réparer et aller de l'avant], Hoc Tập - Tạp chí lý luận và chính trị của Đảng Lao động Việt Nam 11 (nov.-déc. 1956), p. 9-23.

1994 Écrits (1946-1975), Hà Nội, nhà xuất bản Thế Giới. 
Trường Chinh \& Võ Nguyên Giáp

1937 Vấn Đề Dân Cày [La Question paysanne], Hà Nội (rééd. 1959), traduit en anglais par Christine Pelzer White, The Peasant Question (1937-1938), New York, Cornell University Press, 1974.

VÃN Tạo \& Furuta Moto

1995 Nạn đối năm 1945 ở Việt Nam [La famine de 1945 au Việt Nam], Hà Nội, nhà xuất bản Viện Sử học Việt Nam.

Vesin, Dominique

1992 «Histoire du fleuve Rouge. Gestion et aménagement d'un système hydraulique au Tonkin des années 1890 jusqu'à la Seconde Guerre mondiale », mémoire de maîtrise, Paris, université de Paris VII, UER de Géographie, histoire, sciences de la société.

Vickerman, Andrew

1986 The fate of the peasantry, New Haven \& London, Yale University Press.

Võ Nguyên Giáp

2005 Điện Biên Phủ, Rendez-vous avec l'histoire, Hà Nội, nhà xuất bản Thế Giới.

Vo Nhân Tri

1960 «I a politique agraire au Nord Việt Nam », Revue Tiers Monde 1/3, p. 353-372.

WoOdside, Alexander B.

1970 « Decolonization and Agricultural Reform in North Vietnam », Asian Survey 10/3, p. 705-723.

YVON-TRÂN, Florence

1994 "Une résistible collectivisation 1959-1988 ", thèse de doctorat, Paris, université de Paris VII, UFR Géographie, histoire, science de la société. 


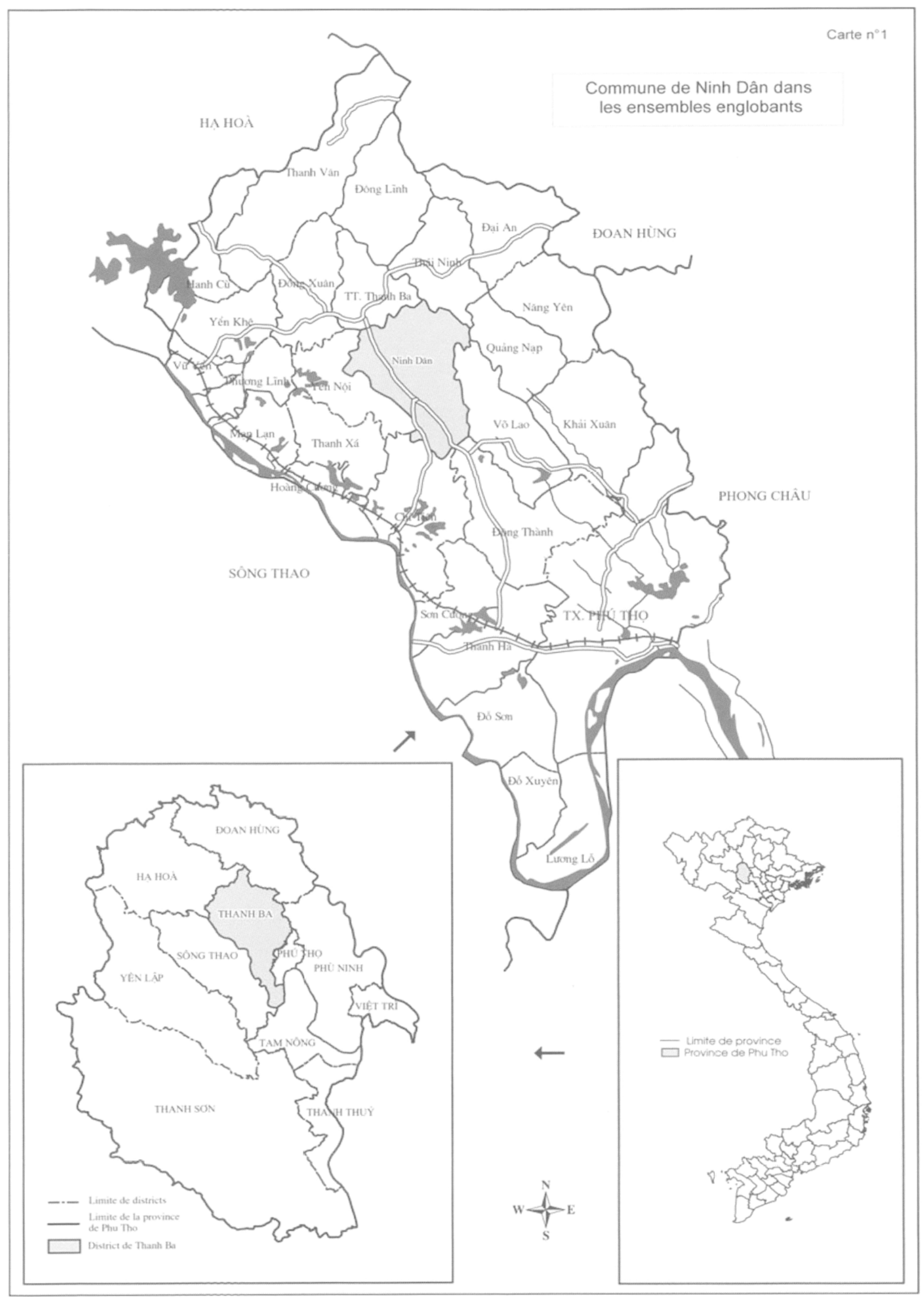


Espace habité du village de Hay : répartition des habitants par appartenance de classe

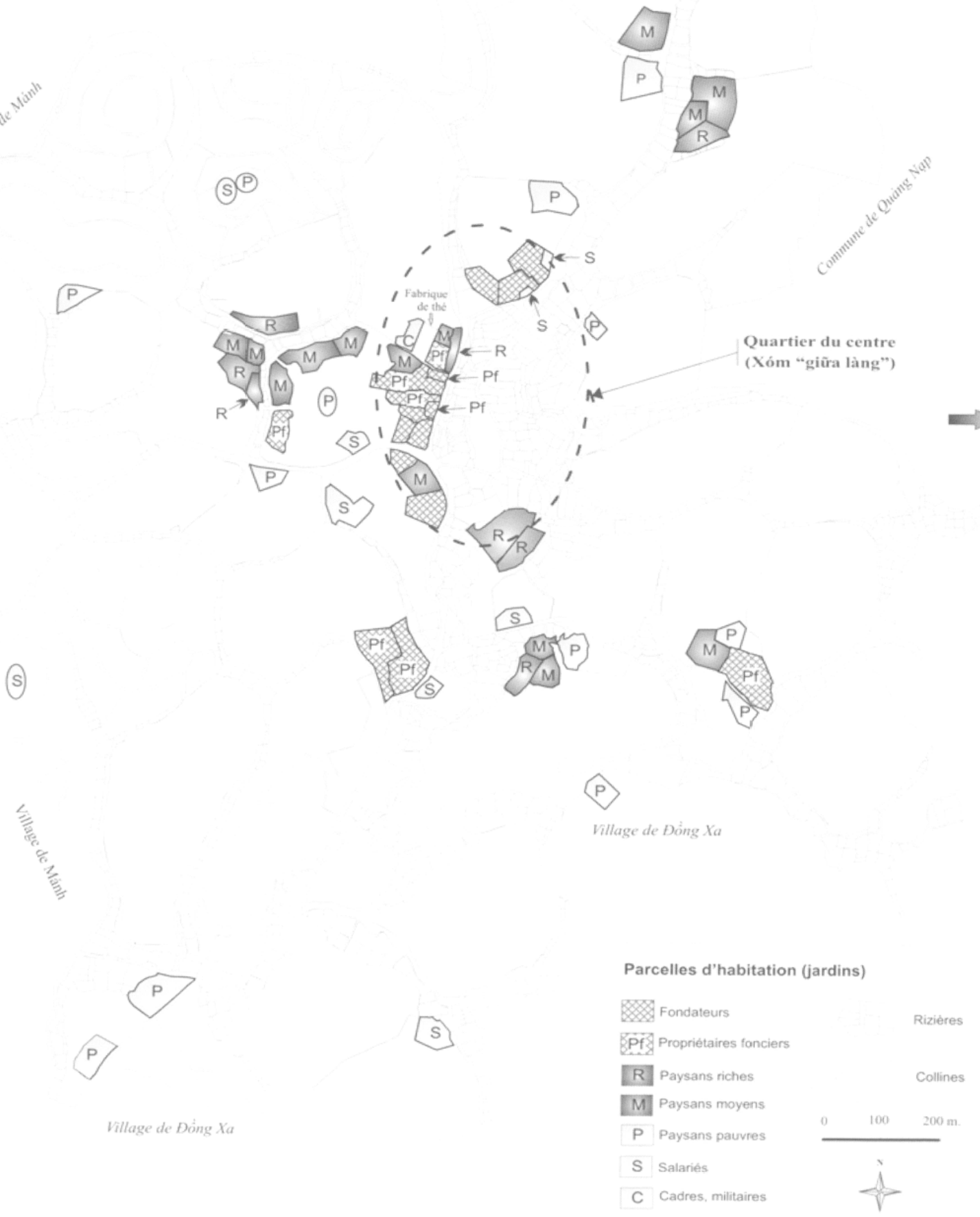




\section{Après la réforme agraire}

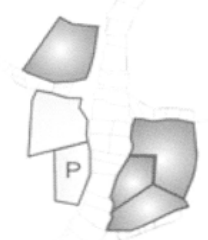

(s)
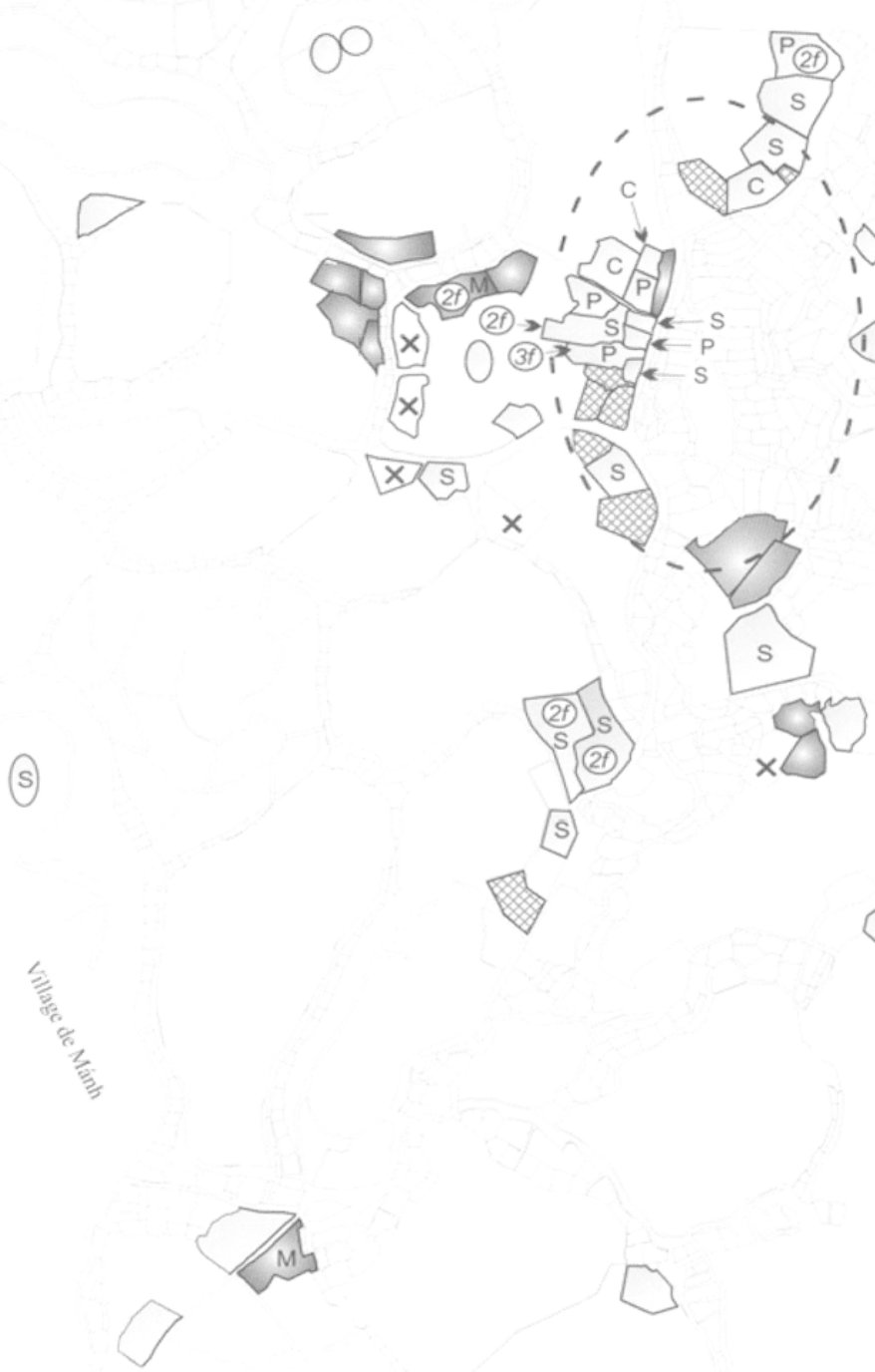

is

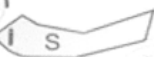

I
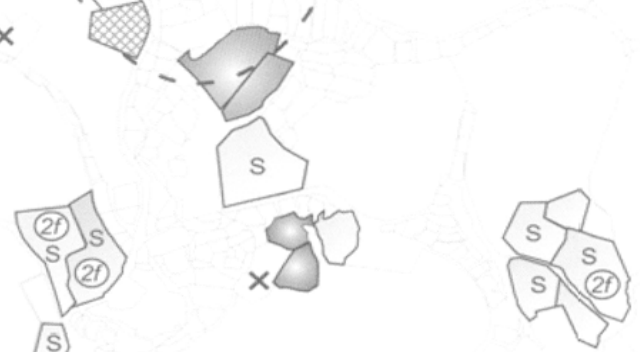

S)

$$
\text { \% }
$$

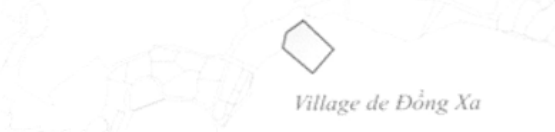

Village de Đông Xa

M Seuls les changements sont indiqués

$\times$ Habitation abandonnée

(2f) Cohabitation imposée de 2 ou 3 foyers 
Tableau n 5 : Évolution du pouvoir local, de la Révolution d'août 1945 à la réforme agraire

\begin{tabular}{|c|c|c|c|c|c|c|c|c|c|c|c|}
\hline & 1940 & $\begin{array}{l}1945^{\star} \\
\text { Ninh Dân }\end{array}$ & \begin{tabular}{|l} 
Fin 1945 \\
Ninh Dân
\end{tabular} & \begin{tabular}{|l|}
1946 \\
Ninh Dân
\end{tabular} & $\begin{array}{l}\text { 1946-47 } \\
\text { Nguyển Trài }\end{array}$ & \begin{tabular}{|l|}
$1947-49$ \\
Ninh Dân
\end{tabular} & \begin{tabular}{|l} 
1950-52 \\
Ninh Dân
\end{tabular} & \begin{tabular}{|l} 
1953-54 \\
Ninh Dân
\end{tabular} & $\begin{array}{l}\text { Réforme } \\
\text { agraire }\end{array}$ & \begin{tabular}{|l|}
$\begin{array}{l}\text { Rectification } \\
1957\end{array}$ \\
\end{tabular} & Post-réforme \\
\hline M. Hoè & Caissier & & & & & & & & dia chu & confirmé & \\
\hline M. Thur & by truaring & Président & Président & & & & & & dia chi & confirmé & \\
\hline M. Hào & phóly & & & & & & & & paysan riche & & \\
\hline M. Nhân & Ancien pho by & Vice-président & Vice-président & Vice-président & & & & & ? & & \\
\hline M. Đinh & & Secrétaire & Secrétaire & & & \begin{tabular}{|l|} 
Fondateur, \\
secrétaire de \\
la cellule \\
\end{tabular} & Président & & $\begin{array}{l}? \\
\text { exclu du Parti }\end{array}$ & $\begin{array}{l}\text { réintégration } \\
\text { controversée }\end{array}$ & \\
\hline M. Giäng & Ancien phó $\hat{l}^{2}$ & Caissier & Caissier & Caissier & Caissier & Fondateur & Secrétaire & Secrétaire & $\begin{array}{l}\text { paysan riche } \\
\text { exclu du Parti }\end{array}$ & réintégré & \begin{tabular}{|l|} 
Président 1961-63 \\
Secrétaire 1964-76 \\
\end{tabular} \\
\hline M. Doãn & & $\begin{array}{l}\text { Vice-président } \\
\text { (DT) }\end{array}$ & & & & & & & dia chu & réhabilité & \\
\hline M. Cóc & phỏ lý (Đổng Xa) & Président (DT) & & & & Président & & & \begin{tabular}{|l|}
$\begin{array}{l}\text { dia chui } \\
\text { exclu du Parti }\end{array}$ \\
\end{tabular} & $\begin{array}{l}\text { rćhabilité } \\
\text { réintégré }\end{array}$ & \\
\hline M. Hỳ & & Secrétaire (DT) & Secrétaire & Président & & $\begin{array}{l}\text { Sous-chef } \\
\text { VM }\end{array}$ & $\begin{array}{l}\text { Sous-chef VM } \\
\rightarrow 1951\end{array}$ & & \begin{tabular}{|l} 
traitre \\
dia chu
\end{tabular} & $\begin{array}{l}\text { fusillé } 1955 \\
\text { réhabilité }\end{array}$ & \\
\hline M. Hanh & $\begin{array}{l}\text { Ancien lý trwờng } \\
\text { Chroung ba }\end{array}$ & & Vice-président & & & Chef VM & $\begin{array}{l}\text { Chef VM } \\
\rightarrow 1951\end{array}$ & & dia chu & $\begin{array}{l}\text { confirmation } \\
\text { controversée }\end{array}$ & \\
\hline M. Trung & & & $\begin{array}{l}\text { Chef du } \\
\text { cadastre }\end{array}$ & & & Fondateur & & & $\begin{array}{l}\text { ? } \\
\text { exclu du Parti }\end{array}$ & réintégré & \\
\hline M. Hiền & & & Sous-chef VM & Sous-chef VM & Chef VM & & & & paysan riche & & \\
\hline M. Đức & Ancien ly trowng & & Chef VM & Chef VM & Sous-chef VM & $3005=$ & 3051 & & ? & & \\
\hline M. Sáng & & & & Secrétaire & & & & & paysan moyen & & \\
\hline M. Cừu & & & & Caissier & & & Chef de la police & & $?$ & & \\
\hline M. Chi & & & & & Caissier & Secrétaire & & & paysan moyen & & \\
\hline M. Oanh & & & & & $\begin{array}{l}\text { Chef de la } \\
\text { police }\end{array}$ & $\begin{array}{l}\text { Chef de fa } \\
\text { police }\end{array}$ & & & $\begin{array}{l}\text { dia chu } \\
\text { exclu du Parti }\end{array}$ & $\begin{array}{l}\text { réhabilité } \\
\text { réintégré }\end{array}$ & \\
\hline M. La & & & & & Militaire & Militaire & & & paysan riche & & \\
\hline M. Cự & & & & & & & Vice-president & & $\begin{array}{l}\text { paysan riche } \\
\text { exclu du Parti }\end{array}$ & réintégré & $\begin{array}{l}\text { Président1964-67 } \\
\text { Président 1973-77 } \\
\end{array}$ \\
\hline M. Gấm & & & & & & & & Président 1953 & \begin{tabular}{|l|} 
paysan prolétaire \\
exclu du Parti
\end{tabular} & réintégré & \\
\hline M. Thành & & & & & & & & Vice-président & paysan pauvre & & \\
\hline M. Hat & & & & & & & & Chef de la police & paysan prolétaire & & \\
\hline M. Nguyện & & & & & & & & Président 1954 & $\begin{array}{l}\text { ? } \\
\text { exclu du Parti }\end{array}$ & réintégré & Président 1958-60 \\
\hline M. Diền & & & & & & & & Vice-président & paysan moyen & & \\
\hline $\mathrm{M}^{\mathrm{me}} \mathrm{Nớ}$ & & & & & & & & Vice-présidente & dia chi & réhabilitée & \\
\hline M. Phẩm & & & & & & & & Secrétaire & paysan prolétaire & & \\
\hline
\end{tabular}

*En 1945, la commune de Ninh Dân fut scindée pendant 6 mois en deux communes distinctes : Ninh Dân (villages de Hay, Mảnh et Sen) et Đồng Tâm (DT : village de Đồng Xa).

"Entre nov. 1946 et déc. 1947, les communes de Ninh Dân et de Yên Nội fusionnèrent en une seule entité : Nguyễn Trài. Le président et le vice-président furent deux ressortissants de Yên Nội

Comité révolutionnaire provisoire, puis Comité administratif et de résistance et. $\square$ Cellule communale du Parti $\square$ Section communale du Việt-minh (VM) enfin. Comité populaire 